CORPORATE SOCIAL RESPONSIBILITY IN THE APPAREL INDUSTRY:

A MULTIPLE CASE STUDY ANALYSIS

By

Anika Kozlowski

Bachelor of Science Honors, University of Manitoba, 2003

Bachelor of Communication \& Design, Ryerson University, 2008

\author{
A Thesis \\ Presented To Ryerson University \\ In partial fulfillment of the \\ requirements for the degree of \\ Master of Applied Science \\ in the program of \\ Environmental Applied Science and Management
}

TORONTO, ONTARIO, CANADA, 2012

CANIKA KOZLOWSKI 2012 


\section{AUTHOR'S DECLARATION}

I hereby declare I am the sole author of this thesis or dissertation. This is a true copy of the thesis, including any required final revisions, as accepted by my examiners.

I authorize Ryerson University to lend this thesis or dissertation to other institutions or individuals for the purpose of scholarly research.

I further authorize Ryerson University to reproduce this thesis or dissertation by photocopying or by other means, in total or in part, at the request of other institutions or individuals for the purpose of scholarly research.

I understand that my thesis may be made electronically available to the public 


\author{
ABSTRACT \\ Corporate Social Responsibility in the Apparel Industry: A Multiple Case Study Analysis \\ Anika Kozlowski \\ Environmental Applied Science and Management, 2012 \\ Master of Applied Science, Ryerson University
}

There has been a growing concern over apparel brands in improving their environmental impact and the social responsibility throughout their supply chains. Corporate Social Responsibility (CSR) reporting has increased within the apparel industry as a response. This thesis presents a review of the CSR reporting on the websites of the 14 apparel brands belonging to the Sustainable Apparel Coalition. Qualitative and quantitative data are collected on all reported CSR initiatives, actions and indicators. The data are organized into the five elements that represent important aspects in developing a sustainable apparel system: product sustainability, design practice, sustainable supply-chain management, consumer engagement, and business innovation. A cross-case analysis of the apparel brands is conducted. The key findings of the study include a lack of comparability among reported CSR indicators. In addition, a similar distribution pattern of CSR indicators across the five elements was observed. The results highlight that CSR reporting currently is not effective in providing a true reflection of an apparel brands CSR actions and initiatives. This study shows that the means for evaluating effectiveness in CSR reporting has not yet been put in place. 


\section{ACKNOWLEDGEMENTS}

I would like to endlessly thank Dr. Michal Bardecki and Dr. Cory Searcy for their patience in dealing with a fashion student, their continuous advice, guidance, insightful conversations and academic support during the past couple of years.

I would like to thank my mom and especially my dear dad who typed all my notes when my arm was

broken, Dr. Lynda McCarthy whose positive spirit is infectiously inspirational, friends, academic colleagues, and professional associates who have supported and assisted me throughout my graduate education.

This thesis would not have been possible without all of your support.

Thank You! 


\section{TABLE OF CONTENTS}

AUTHOR'S DECLARATION

ABSTRACT

ACKNOWLEDGEMENTS iv

TABLE OF CONTENTS V V

LIST OF TABLES viii

LIST OF FIGURES $\quad$ ix

LIST OF APPENDICES $\quad \mathrm{X}$

LIST OF ABBREVIATIONS $\quad$ xi

1 - Introduction 1

1.1 - Problem statement 1

1.2 - Organization of the thesis 2

2 - Literature Review 3

2.1 - History of apparel and fashion 3

2.2 - Democratization of fashion and apparel production 4

2.2.1 - Early industrialization of apparel production 4

2.2.2 - Industrialization 5

$\begin{array}{ll}2.3 \text { - Fast fashion } & 7\end{array}$

2.3.1 - Rising level of consumption $\quad 8$

2.3.2 - Apparel consumption behaviours and environmentally friendly apparel $\quad 9$

2.4 - Environmental and social impacts 11

2.4.1 - Fibres 12

2.4.1.1 - Natural fibres 12

2.4.1.2 - Synthetic fibres $\quad 14$

$\begin{array}{ll}2.4 .2 \text { - Textile wet processing } & 15\end{array}$

$\begin{array}{ll}2.4 .3 \text { - Consumer use - laundering } & 16\end{array}$

$\begin{array}{ll}2.4 .4 \text { - Textile and apparel waste } & 17\end{array}$

$\begin{array}{ll}2.4 .5 \text { - Social impacts } & 18\end{array}$

2.5 - Corporate Social Responsibility 19

2.5.1 - CSR and the apparel industry 19

2.5.2 - CSR reporting 21

2.5.2.1- Criticisms of CSR reporting 23

2.5.3 - The use of indicators $\quad 24$

2.5.4 - Codes of conduct 25

2.5.5 - Sustainable Apparel Coalition (SAC) 28 
2.5.6 - SAC apparel brands $\quad 29$

2.6 - Motivation for research $\quad 30$

3 - Research questions 31

3.1 - Central question 31

3.2 - Sub-questions 31

4 - Methods $\quad 32$

4.1 - Scope 32

4.2 - Multiple case studies 33

4.3 - Data collection and model development 34

4.4 - Data analysis $\quad 41$

5 - Elements of the apparel system model $\quad 42$

5.1 - Product sustainability 43

5.2 - Design practice 45

5.3 - Sustainable supply-chain management 46

5.4 - Consumer engagement 49

5.4.1 - Extended producer responsibility 51

5.5 - Business innovation 51

6 - Results 53

6.1 - Background CSR information 53

6.2 - Indicators per element $\quad 54$

6.2.1 - Product sustainability $\quad 54$

6.2.2 - Design practice $\quad 55$

6.2.3 - Sustainable supply-chain management 56

6.2.3.1 - Environment 56

6.2.3.2 - Social 56

6.2.4 - Consumer engagement 58

6.2.5 - Business innovation $\quad 58$

6.3 - Distribution of indicators $\quad 59$

6.4 - Summary of total reported indicators 59

7 - Discussion $\quad 63$

7.1 - Type of indicators reported 63

7.1.1 - Product sustainability 63

7.1.2 - Design practice $\quad 64$

$\begin{array}{ll}\text { 7.1.3 - Sustainable supply-chain management } & 68\end{array}$

7.1.4 - Consumer engagement and business innovation 71

7.2 - Distribution of indicators 74 
7.3 - Comparability of indicators

7.4 - Total number of indicators

7.5 - Progress towards sustainability

8 - Conclusion

79

8.1 - Contributions

80

8.2 - Limitations

81

8.3 - Foundations for future research

81

APPENDIX A: Database of collected CSR information

83

REFERENCES

91 


\section{LIST OF TABLES}

Table 1: List of apparel brands belonging to the SAC

Table 2: Categories resulting from the observed similarities

Table 3: Excerpt from Puma Annual Report 2010, training and certification of Puma's suppliers

Table 4: Complete list of final 87 indicators and their categorization

Table 5: CSR descriptives

Table 6: Summary of reported indicators within product sustainability

Table 7: Summary of reported indicators within design practice

Table 8: Summary of reported indicators within sustainable supply-chain management

Table 9: Summary of reported indicators within consumer engagement

Table 10: Summary of reported indicators within business innovation

Table 11: Breakdown of reported indicators per apparel brand

Table 12: Average number of indicators reported per element 


\section{LIST OF FIGURES}

Figure 1: Fibre production and demand

Figure 2: Synopsis of research method

Figure 3: Illustration of the elements of the apparel system

Figure 4: The Product Life Cycle as developed by the United Nations Environmental Program

Figure 5: The apparel supply-chain

Figure 6: Number of reported indicators per element

Figure 7: Breakdown of reported indicators per apparel brand and element

Figure 8: Breakdown of total reported indicators per apparel brand 


\section{LIST OF ABBREVIATIONS}

AFSS: Apparel and Footwear Sector Supplement

AP: Alkylphenols

BSR: Business for Social Responsibility

C2C: Cradle-to-Cradle

CSR: Corporate Social Responsibility

EJF: Environmental Justice Foundation

EPA: Environmental Protection Agency

EPI: Environmental Performance Indicator

EPR: Extended Producer Responsibility

FLA: Fair Labor Association

GAAP: Generally Accepted Accounting Principles

GHG: Greenhouse Gas

GRI: Global Reporting Initiative

GRI AFSS: Global Reporting Initiative Apparel and Footwear Sector Supplement

GRS: Global Recycling Standard

ILO: International Labor Organisation

IPEA: Institute of Public Environmental Affairs

KPI: Key Performance Indicators

LCA: Life Cycle Assessment

M\&S: Marks \& Spencer

MEC: Mountain Equipment Co-op

NGO: Nongovernmental Organisation

NPE: Nonylphenol ethoxylate

OIA: Outdoor Industry Association

OTA: Organic Trade Association

PET: Polyethylene terephthalate

PLA: Poly lactic acid

PVC: Polyvinyl chloride

RSL: Restricted Substance List

SAC: Sustainable Apparel Coalition

UNGC: The United Nations Global Compact

VOC: Volatile organic compound

WWF: World Wildlife Foundation 


\section{1 - Introduction}

\section{1 - Problem Statement}

Apparel is one is of the oldest commodities and the apparel industry has only continued to grow into what is now one of the largest industries globally. Apparel is clothing that may not be fashionable (Stephens Frings, 2002), while fashion is defined as "style or styles of clothing and accessories worn at a particular time by a particular group of people" (Stone, 2012:6). Fashion is a temporary cyclical phenomena adopted by consumers that involves change (Sproles, 1981: Easey, 1995). The concept of fashion has been an accepted aspect of society and the relationship between fashion and apparel has only strengthened with the continued growth of the industry. Apparel and fashion play a significant role within society from a basic need to the conspicuous consumption by those concerned with displays of status and class. For the purpose of this study, the term apparel will encompass the words "clothing", "garments" and "fashion clothing" while the term apparel industry includes the "clothing industry" and "fashion industry". Combinations of developments since the Industrial Revolution have only increased the significance of the environmental and social issues facing the industry today. Rising consumptions levels, the emergence of fast fashion and low-cost apparel along with a shift to offshore production have thrust the apparel industry into the spotlight as a major contributor to global environmental issues. The perceived obsolescence by the consumer has resulted in increasing the rate of consumption, disposal, and textile waste in landfills (Allwood et al., 2006; Madsen et al., 2007; Fletcher, 2008). Sportswear and mainstream apparel brands are progressively more influenced by fashion trends due to a greater interest in fashion by the average consumer. They also seek to stay competitive in an increasingly saturated market.

Rising labour costs and the increased expense of meeting environmental regulation associated with textile and apparel production were the primary reasons for the shift to offshore manufacturing (Allwood et al., 2006; Fletcher, 2008; Dickson et al., 2009; Sherburne, 2009; Siegle, 2011). Industrialized countries have essentially exported their environmental and social problems to developing countries that are eager to grow their economies by expanding their manufacturing sector (Welters, 2008). Environmental problems include an increased use of raw materials such as cotton and oil, the use of toxic chemicals, energy and water. The use of these toxic chemicals leads to their subsequent release through wastewater, contaminating nearby water sources. Social impacts include labour rights violations, the use of child labour, precarious employment, indentured servitude, earnings below a minimum living wage and major health and safety issues. Occupational health issues in the apparel industry include exposure to hazardous chemicals, fibre dust now known to cause many respiratory illnesses, noise and monotonous repetitive processes (Allwood et al., 2006; Dickson, Loker, \& Eckman, 2009; Fletcher, 2008). The constant growth in apparel volume production has increased the rate of environmental degradation and labour violations. These problems are compounded as developing nations have weak environmental and

labour legislation, operate mainly under contractual agreements with retailers and have little means to 
effectively deal with these growing issues (Allwood et al., 2006; Fletcher, 2008; Welters, 2008; Sherburne, 2009; Siegle, 2011).

Increased concern over the use of non-renewable resources, climate change, environmental degradation and ethical business practices has led to the emergence of more environmentally and socially responsible behaviours by certain apparel brands. In 2010, a group of industry leaders created the Sustainable Apparel Coalition (SAC) to begin addressing these problems. To date there has only been one systematic evaluation or case study research into these self-declared leaders of the apparel industry and their reported Corporate Social Responsibility (CSR) actions and initiatives. It was a comparative study of the CSR reports of Nike and adidas to the Global Reporting Initiative (GRI) guideline (Sherman, 2009). This research will analyze the 14 SAC apparel brands and whether their CSR reporting is as an effective measure of their CSR performance.

\section{2 - Organization of the Thesis}

The thesis is organized into seven remaining chapters. The following chapter contains a literature review exploring the development of the apparel and fashion industry, apparel's and fashion's role in society, the environmental and social impacts, CSR and the apparel industry and CSR reporting. The third chapter describes the research questions. The fourth chapter outlines the methods that were used to address the research questions: the data collection and analysis process, the selection of the sample, development of the indicators, and the elements of the apparel system model and rationale. The methods further detail the selection and categorization of the reported CSR indicators within the five elements of the model. The fifth chapter explains in depth the model and the five elements that make up the model: product sustainability, design practice, sustainable supply-chain management, consumer engagement and business innovation. The sixth chapter presents the findings of the research, tables and figures illustrating the number of indicators reported and indicator distribution among the apparel brands. The seventh chapter provides a discussion of the results. The last chapter presents a conclusion, contributions, limitations of the research and recommendations for future research. 


\section{2 - Literature Review}

The aim of this literature review is to provide a history of the apparel industry and how it relates to the development of the current problems that plague the industry today. The first section reviews the concept of clothing and fashion, influential fashion theories and how the industrial revolution led to the democratization of fashion and a steady growth in the consumption of apparel. This is followed by an exploration of two contemporary phenomena: globalized supply-chains, and fast fashion. The third section addresses the associated negative environmental and social impacts in the industry that have developed as a consequence of industrialization, global supply-chains and fast fashion. The final section examines the development of CSR, CSR reporting, codes of conduct and the use of indicators in the apparel industry.

\section{1 - History of Apparel and Fashion}

Apparel, clothing, fashion and the notion of identification through textiles, sewn in a manner to reflect one's self or a group, has existed for millennia. "Throughout recorded history, clothing, along with food and shelter has been recognized as one of the primary needs of mankind" (Horn \& Gurel, 1975:1). The idea of wearing clothing is a unique characteristic of human beings and a distinguishing feature of most societies. Apparel plays a physical or utilitarian role such as the need for protection or a uniform and is significant in reflecting lifestyles, status, class and identity (Horn \& Gurel, 1975; Calefato, 2004; Ross, 2008). We identify ourselves; we identify our membership to a certain group while distinguishing ourselves from other groups. Clothes are conveyors of meaning and value, giving shape to a system of objects (Calefato, 2004; Barthes, 2006; Fletcher, 2008; Wolfendale \& Kennett, 2011). There are many theories as to why, when and how clothing and fashion came to be, how we consume it, and the associated language and semiotics (Langener, 1959; Winakor, 1969; Bell, 1979; Barthes, 2006; Ross, 2008). There are two basic statements as to its use by people: "This is the person I am";" This is what I am doing" (Ross, 2008). While clothing and fashion may seem trivial to some, its importance within global society, the arts, science, and the economy must not be understated.

Apparel and apparel consumption has historically not been regarded as a subject related to serious academic pursuit in the same way mathematics or physics are. Even in contemporary society it can be regarded as a fringe academic subject, and a frivolous aspect of modern day life. It has, however, captured the attention of many intellectuals over the centuries. Philosophers Adam Smith (1759/2002), Immanuel Kant (1798/2006) Jean-Paul Sartre (1993), Georg Simmel (Svendsen, 2006), Roland Barthes (2006) and Ludwig Wittgenstein (2004) have debated its social meaning, specific functions, as a concept of taste, its literal meaning and the distinction between clothing and fashion. Gilles Lipovetsky (1994) speaks to the democratization of fashion and its contribution to capitalism while Thorstein Veblen (1899/2009) is a seminal author on conspicuous consumption. 
Along with the philosophical debates between clothing, fashion and consumption, the apparel industry has had several notable developments since the Industrial Revolution in the $18^{\text {th }}$ century. These developments include the introduction of the fashion magazine in the early $19^{\text {th }}$ century, the introduction of ready-to-wear designs from design houses such as Dior in the 1950s, the off-shore mass production of apparel that began in the 1980s and the fast fashion phenomenon of the 2000s (Abernathy, Dunlop, Hammond, \& Weil, 1999; Breward, 2003; Hethorn \& Ulasewicz, 2008; Siegle, 2011). These developments have been characterized by an increase in speed in the dissemination of fashion trend information, and the availability of fashion clothing to a broader range of consumers since the Industrial Revolution. Fashion clothing prior to the Industrial Revolution had previously been a luxury reserved for the elite due to the high cost of textiles and the time consuming nature of hand sewing elaborate fashionable garments (Breward, 2003; Welters, 2008). Essentially the wealthy and elite were the only ones who could afford to participate in fashion (Welters, 2008). This all changed with the Industrial Revolution, as the mass manufacturing of clothing and textiles along with the development of paper patterns, (Walsh, 1979) allowed for more affordable apparel. These developments along with the amplified dissemination of fashion trends led to a democratization of fashion, a notion that everybody can afford to be fashionable. Globalization and the Internet have further increased the dissemination of fashion of fashion trends (Gwilt \& Rissanen, 2011). The apparel industry, the concept of fashion, clothing, and how we interact with these ideas are still continually evolving, demonstrating how clothing and fashion are inextricably linked to society.

\section{2 - Democratization of Fashion and Apparel Production}

Production and consumption of apparel prior to the industrialization of the industry were activities that were connected to the home or village. All clothing was made by hand, passed on to family members or worn out to threads. Textiles were expensive as their production prior to industrialization was time and labour intensive, as looms had not yet been mechanized. Only the wealthy could afford to have many clothes and fashionable clothes (Kaiser, 2008). Production or the sewing of clothing gave value, as there was an appreciation for the time and labour involved. Industrialization followed by the subsequent democratization of fashion eroded the value once associated with the production-consumption relationship. Profit became the main purpose of production (Kaiser, 2008). What started as a means to release the time and labour intensity of what was once a basic need has spiraled into a complex production-consumption system driving and fulfilling human desires and over-consumption.

\subsection{1 - Early industrialization of apparel production}

It was the second half of the $18^{\text {th }}$ century that saw the development of early mechanization such as the processing of fiber into fabric in Europe (primarily Britain at first) and North America. It was these innovations in the textile sector that played a large part in the development of the Industrial Revolution 
(Wilson, 1979). By the 1820s, factories in Britain and the USA were producing cloth mechanically, which increased supply, and reduced costs. This new abundance of inexpensive cloth allowed for people to dress better than any other period in history. For the first time, the rate of fashion trends began to accelerate, wardrobes increased in size, and closets were introduced into homes (Welters, 2008).

It was during the second half of the $19^{\text {th }}$ century that noticeable negative environmental and social impacts developed in industrialized nations such Europe and North America. The wet finishing processes of textiles required the use of mordants to fix or bind the colouring agents in dye to the fabric (Welters, 2008). The most common mordants are iron, tin, chrome and copper. These were discharged directly into nearby rivers and streams along with other chemicals used in the wet processing of textiles such as organic solvents, surfactants, phenols and chloride. Many of the chemicals found in the wastewater were not easily degraded while dyes generally degrade into a more toxic form (Bisschops \& Spanjers, 2003; Welters, 2008). Working conditions were also problematic, manufacturers employed immigrants, mainly women and children, who were subjected to long hours, poor wages and occupational hazards (Ross, 2004; Welters, 2008). These initial characterizations of working conditions in the apparel industry are still prevalent today in developing countries.

\subsection{2 - Industrialization}

The fashion industry began to take form with the birth of the sewing machine, the development of the paper pattern industry, synthetic dyes, the first apparel factories, and the rising middle class during the mid-1800s (Abernathy et al., 1999; Ross, 2008; Welters, 2008). The emerging middle class aspired to move up the social ladder and one method was to consume the fashions of those at the top of the social strata. This encouraged the expanding spending habits of the middle class. Simmel's (2003) Trickle Down Theory attributes the increased pace and assumed power of fashion to the rise of the middle class. Social advancement became directly linked with fashion - the ability of the lower strata to imitate the upper strata led to the immediate discard of a particular fashion by the upper strata the moment the lower strata had adopted it (Simmel, 2003). Simmel links consumption and social equalization with its cycle of adaptation and discard as an expression of status, unlike Veblen who links consumption as the source of status (Veblen, 1899/2009). The common implication between Simmel and Veblen is that a major motivator for the consumption of fashion is status.

Moving from the $19^{\text {th }}$ century into the $20^{\text {th }}$, two extremely important developments had now been firmly established: capitalism, and conspicuous consumption. Capitalism, coupled with newly formed apparel factories, the introduction of the department store, and the standardization of sizing, allowed for the development of ready-made garments. Democratization of fashion, the notion that everyone can afford to be fashionable gained momentum, and apparel consumption increased. This was a direct result of capitalist industrialization and its ability to produce mass goods for a lower cost (Agins, 2000; Welters, 2008). As with any major change, criticism followed, and it was Thorstein Veblen and his Theory of the 
Leisure Class (1899/2009) that foresaw the pitfalls associated with rising consumption levels. He was extremely critical of the notion of production for profit, and saw the consumption of the new middle-leisure class as a wasteful activity that provided no contribution or productivity to society. Veblen coined the term "conspicuous consumption" to describe this attempt to impress, and gain status through the consumption of goods, which most notably included fashionable apparel (Veblen, 1899/2009).

The $20^{\text {th }}$ century saw a decrease in the formalities of attire, the introduction of casual wear, and a greater mix of gender, cultural and class codes (Breward, 1995; Welters, 2008). Advances in technology continually provided cheaper, more comfortable, and attractive garments to an increasing proportion of the population in Europe and North America. The rise of the fashion designer and fashion capitals such as London, Paris, and Milan established a regular seasonal presentation of fashion trends. These transformations resulted in an increased consumption of apparel (Breward, 1995).

This increased volume of apparel production and consumption has many negative environmental and social impacts. Environmental impacts include the use of toxic chemicals and the untreated discharge of these chemicals into nearby water sources. The most notable social impact is the use of sweatshop labour. Sweatshops are defined by poor and unsanitary working conditions with unregulated hours, forced overtime and pay that is below a living wage (Abernathy et al., 1999; Israel Rosen, 2002). A well-known tragedy in New York, the great Triangle Shirtwaist Fire of 1911, helped expose the large-scale use of sweatshop labour in the apparel industry. This tragedy was the impetus for union formation and the development of labour rights regulations in the USA apparel industry. However, it took many more decades for environmental regulations to appear in an attempt to curb the growing pollution caused by textile production. These regulations and legislation were aimed at many polluting industries as air and water pollution became a significant concern. With growing labour and environmental regulation, the cost of producing textiles and apparel began to increase while decreasing profits. Increasing costs along with the continued growth of this industry eventually led companies to less regulated and less costly offshore production facilities (Abernathy et al., 1999). Offshore production is the manufacturing of goods in foreign countries with inexpensive labour. It is generally seen as a way to lower costs and compete more effectively with low-cost imports (Stone, 2012).

The apparel industry has seen a dramatic reorganization, especially in supply-chain management, over the last thirty years since its shift to offshore production. What was once a linear system with clear delineation between supplier and customer has developed into a virtual, global, and fragmented organization where suppliers have multiple functions (Abernathy et al.,1999; Armstrong \& LeHew, 2011). This delocalization of production to emerging and developing economies has eliminated supply-chain transparency and exported all the environmental and social problems associated with apparel production (Abernathy et al., 1999; Welters, 2008; Steinberger, Friot, Jolliet, \& Erkman, 2009). This growth in apparel production and industrialization is also responsible for the industrialization process of many recently developing countries (Abernathy et al., 1999). The apparel industry, however, is limited 
in its ability to automate with the use of machines, many phases of its supply-chain. The sewing of garments is one phase that will most likely never be automated due to the continual change of garment styles. It is for this reason the apparel industry is continuously in search of a large, low-cost labour supply to sew apparel (Abernathy et al., 1999; Elliot \& Freeman, 2003; Allwood et al., 2006; Welters, 2008). This inability to automate the sewing of apparel without sewers makes apparel a typical starter industry for developing nations due to its low fixed costs (Gereffi, 1999; Allwood et al., 2006). Since the shift to offshore production, tens of millions of workers in the least developed countries have been provided employment through sewing apparel (Allwood et al., 2006; Gereffi \& Frederick, 2010). There are many negative environmental and social impacts associated with this continued movement of apparel companies in search of low-cost labour. However, the apparel industry does have the opportunity to create positive impacts by providing employment and developing an apparel manufacturing sector in developing nations. This economic stimulus can be positive as long as the associated negative environmental and social impacts can be eliminated.

\section{3 - Fast Fashion}

Fast fashion or as it is alternatively known, disposable fashion, is the continual purchasing of new and inexpensive apparel. This is due to fast changing trends, and planned obsolescence, leading to premature product replacement (Farrer \& Fraser, 2009). Fast fashion is a product of globalization, which has opened up a global marketplace that has provided access to new mass manufacturing markets of reduced quality goods (Allwood et al., 2006; Rudell, 2006; Goworek, 2007; Farrer \& Fraser, 2009). This phenomenon has transformed apparel and fashion into a trillion dollar global industry (Abernathy et al., 1999; Allwood et al., 2006). Fast fashion brands such as Zara, Topshop and H\&M can take as little as 1421 days from design room to retail floor for a new style, known as "just-in-time" manufacturing (Tiplady, 2006; Morgan \& Birtwistle, 2009). The concept of fast fashion has gained increased popularity selling the latest fashion trends at very low prices. As a result, consumers are easily swayed to purchase more than they need. The term "over-consumption" has emerged within the apparel industry to describe the abundant and more than necessary purchasing of fashionable clothing by the average consumer. To capitalize on this over-consumption trend, even basic garments have become fashionable, as there is an expectation that all clothing be up-to-the minute in terms of styling, trims, embellishments, and colour. It is not uncommon to see basic garments such as t-shirts, sweaters and socks be produced in the fashionable colours of a particular season along with the basic colours of white, grey, navy and black. Fashion basics along with the perpetual introduction of new styles into retail stores acts as a motivator for continual purchase by the consumer in an effort to stay up-to-date, and increase sales through impulse purchases (Law et al., 2004; Gwilt \& Rissanen, 2011).

Fast fashion has been demonized as being highly unsustainable due to its low-quality, low-price disposable nature. Fast fashion is increasingly responding to consumer desires while dramatically 
reducing the time-to-market and on-hand-inventory. The longer the time frame between conception and retail floor, the higher the risk a fast fashion product may not sell as it may have fallen out of favor with the consumer. However, it is unclear whether the ability to respond to consumer desires is measured by the retailer's capacity to offer the latest trends within weeks to days of the original inception, and whether this reduces the amount of styles that do not sell (Armstrong \& LeHew, 2011). It can be argued, however, that certain features of this model are sustainable due to its ability to reproduce on-trend items in weeks as opposed to pre-planning months in advance (Armstrong \& LeHew, 2011). This is a problem plagued by all commercial products, as there is no clear method to accurately predict what a consumer will buy.

Research shows that younger consumers are more engaged in the fashion process, which fulfills goals such as group conformity, self-expression, and aesthetic satisfaction; in other words their apparel consumption behaviours are motivated by fashion trends (Kim \& Damhorst, 1998). There is no doubt that fashion is more important and prevalent in society today as it has grown in magnitude, cultural, and economic significance (Brand et al., 2006, Stone, 2012). This can be seen in the increased dedication of resources and space to producing and selling clothes and the proliferation of fashion magazines, television shows, brands, blogs, and books. Prior to the mid-1990s, fashion's salience was reserved for those who worked within in the industry.

\subsection{1 - Rising level of consumption}

Global consumption of clothing has been on a steady rise especially with fast fashion taking form. In the mid-1990s American consumers purchased on average 29 garments (not including intimates) per capita while in China this number was estimated to be only two per capita (American Apparel Manufacturers Association (AAMA), 1996). By 2000, global sales of apparel had reached US \$1 trillion where two-thirds of the sales were from developed nations and almost a quarter from Asia (Allwood et al., 2006). There has been a notable increase in apparel consumption rates among developing nations such as India and China as the middle class continues to grow. The European Union Commissioner for Climate Action, Connie Hedegaard (Eco Textile News, 2012:35) stated in an interview "that there will soon be three billion middle-class people on the planet who will be consuming more and more commodities such

as clothing." Hedegaard acknowledged how "the paradigm for clean and green fashion now needs to move from the margins into the mainstream." China has been one of the fastest growing emerging markets. In 2007, they were the third largest consumer of apparel goods spending US \$84 billion after Japan at US $\$ 100$ billion and the USA at US $\$ 232$ billion (Kerschner \& Huq, 2011). It is estimated that the average person today has four times more clothes than in the 1980s, which is more clothes than any other time in history (Siegle, 2011).

The global shift to manufacturing in developing countries saw positive growth in these economies. World exports from developing nations increased from 18.3\% of apparel exports in 2000 to $37 \%$ in 2010 with $80 \%$ of the world's apparel exports being shipped to developed economies. Of all the worlds 
merchandise trade, apparel accounts for $2.4 \%$ and textiles account for $1.7 \%$ of which North America imports 3.4\% apparel from the entire global apparel trade. China has been leading apparel and textile exports for the last 15 years and in 2010 was the largest exporter of textiles (WTO, 2011). Other countries such as Bangladesh went from zero exports in 1980 to $4.5 \%$ of global clothing exports in 2010 and India increased to $4.2 \%$ in 2010 from $1.7 \%$ in 1980 (WTO, 2011). Apparel exports increased in many developing economies from 1980 to 2010 while developed economies saw a decrease in apparel exports and an increase of apparel imports within the same time frame (WTO, 2011).

\subsection{2 - Apparel consumption behaviours and environmentally friendly apparel}

Apparel consumption behaviours have been defined by Winakor (1969) as the acquisition, use, and disposal of clothing products. The consumer's point of contact is in the acquisition of apparel, and the impact in a garment's lifecycle is the use and disposal phases. While these actions may be local, they are connected to a chain that is global, and contribute to the momentum of the system. Therefore research into the apparel consumption behaviours is significant in developing sustainable practices in the fashion industry. The relationship between these over-consumption behaviours, fast fashion, and quick disposal conflict with the ideals of sustainability. It was not until the early 2000 s that academic research began to pick up the salient points of this over-consumption (Morgan \& Birtwistle, 2009). Fletcher (2008) suggests four reasons as to why consumption has continued to escalate:

- the pressure to compare ourselves to others by accumulating and displaying our latest acquisitions;

- the rolling replacement as every item requires a new one to "match";

- cultural obligations to experience everything and buy accordingly - a "you deserve it" mentality;

- the continuous process of identity formation requires constant consumption.

Research on apparel consumption behaviours and environmental attitudes has resulted in three major findings. The first is that there is a lack of knowledge of the negative environmental impacts of apparel products and production and this is directly related to consumption behaviours. The second finding is that there is a lack of knowledge of the negative environmental impacts during the consumer use phase (laundering), and the final finding is that fast fashion has led to a throwaway mentality (Butler \& Francis, 1997; Kim \& Damhorst, 1999; Birtwistle \& Moore, 2007; Morgan \& Birtwistle, 2009). While attitudes can generally be considered to be a good predictor of behaviours; however, when applied to environmentally friendly apparel consumption, consumers are quite neutral about their attitudes about the environment in relation to clothing (Butler \& Francis, 1997). Based on research by Butler and Francis (1997) and Connell (2010) a definition of environmentally friendly apparel consumption can be constructed as the following: during the acquisition process (purchase behaviour) the environmental impacts of apparel become part of the evaluative purchase criteria. An example of this would be a 
consumer's decision to purchase an organic cotton t-shirt versus a conventional cotton t-shirt due to the negative environmental impacts of conventional cotton over organic cotton.

It has been found that environmental attitudes are not a strong factor when competing against fit, style, and price (Joergens, 2006). Environmentally friendly products are generally more expensive than their regular counterparts, and, when it comes to clothing, are limited in availability, styles, sizes, and colours produced, and have low accessibility (Connell, 2010). A study by Joergens (2006) of adults aged 18-26 in Germany and England found that the participants had no knowledge about environmental or labour rights issues during the apparel production process. If was found that they would buy a garment made by an unethically acting company if they wanted the product because of its style. The participants, however, did not feel well informed on the ethical behaviours of apparel brands, and if a brand were receiving bad publicity it would influence their buying decisions. This is supported by studies that found Nike shares dipped nearly 50\% after the much-publicized sweatshop scandals in the 1990s (Carty, 2001; Rock, 2003). What can be concluded is that aesthetic qualities and personal desire outweigh environmental or ethical issues (Dickson \& Littrell, 1996; Butler \& Francis, 1997; Kim \& Damhorst, 1998; Carrigan \& Attalla, 2001; Shaw \& Tomolillo, 2004; Joergens, 2006; Rudell \& College, 2006; Gam, 2011). Many consumers deem ethical issues to be the responsibility of the corporate sector, and the government (Shaw \& Tomolillo, 2004; Joergens, 2006).

Environmentally friendly apparel first appeared in the early 1990s and was criticized for offering poor quality products at premium prices (Nakano 2007). These criticisms and consumer reaction led this introduction of environmentally friendly apparel to fall to the wayside as just another fashion trend. However, over the last decade, an "eco-fashion" or "sustainable fashion" movement (Shaw \& Tomolillo, 2004; Anaya, 2010; Goworek, 2011) suggests that this is in fact a movement and not just another fashion trend destined to fall out of consumer favor. Environmentally friendly (fashionable) apparel is clothing that considers the environmental and social impacts throughout a garment's lifecycle. While there is no industry standard on the use of terms such as "ethical", "green" or "eco", their wide use does give credence to the growing number of brands that are trying to capture the mainstream market with environmentally friendly fashionable apparel (Joergens, 2006). Mass-market retailers such as H\&M, Nike, Levi's, and Zara have introduced products that incorporate the use of environmentally preferred materials such as organic cotton, Tencel ${ }^{\mathrm{TM}}$, and recycled polyester. Environmentally preferred materials/fibres are produced in a way that has less negative environmental impacts than conventional materials/fibres.

Sustainability is still an emerging aspect of the industry, and remains quite small in market share, there is evidence that consumers do engage in environmentally friendly apparel acquisition (Connell, 2011; Gwilt \& Rissanen, 2011). Ultimately, with the widespread adoption of CSR principles and consumer engagement, the ideals of sustainability could become another common aspect of apparel design and development in the fashion apparel industry. However, it is important that professionals in the apparel 
industry gain perspective as to what consumers perceive to be environmentally and ethically sound apparel (Connell, 2011).

\section{4 - Environmental and Social Impacts}

The apparel industry has many negative environmental and social impacts that are complex, and occur at different stages of the apparel life cycle. The development of fast fashion has amplified the impacts due to the increased volume of apparel produced and sold at low prices (Allwood et al., 2006; Claudio, 2007; Hethorn \& Ulasewicz, 2008; Siegle, 2011). Apparel has a long and complicated production chain consisting of many phases including resource production and extraction, fibre and yarn manufacturing, textile manufacturing, apparel assembly, packaging, transportation and distribution, consumer use, recycling, and ultimate disposal. The environmental impacts of apparel are varied across the phases, difficult to assess for individual garments, and are subject to type of raw material used, dyeing, and laundering.

It wasn't until the 1990s that there was a greater awareness as to the severity of the negative environmental impacts of apparel production (Dickson et al., 2009). The major environmental impacts associated with the production and use of apparel throughout its life cycle includes wastewater emissions from dyeing, finishing and washing processes, increase in pollution, solid waste production, and significant depletion of resources from consumption of water, fossil fuels and raw materials (DEPA, 2003; Allwood et al., 2006; Fletcher, 2010). Energy is used for laundering, transportation, operations of machines for various processes, production of primary materials especially man-made fibres such as polyester (a petroleum based product), and yarn manufacturing of natural fibres such as cotton. Conventional cotton production has high water consumption, and employs the use of toxic chemicals that may harm human health and the environment (DEPA, 2003; Allwood et al., 2006). Chemicals are also released in wastewater from processes such as pre-treatments, dyeing, finishing, and laundry. These chemicals are disruptive to both the environment and aquatic-based life. Solid waste is produced during natural fibre yarn, textile and apparel manufacturing, and disposal of apparel products at the end of their life (DEPA, 2003; Allwood et al., 2006). There are significant issues with clothing waste as the majority of clothing and textile waste ends up in landfills as opposed to being recycled or reused (Allwood et al., 2006; Madsen et al., 2007; Fletcher, 2008). While cellulose based garments such as cotton t-shirts will biodegrade eventually, synthetic petroleum based garments such as a polyester blouse will never fully biodegrade. Synthetic clothing has been found to cause difficulties in African countries where waste is not managed well or in a contained location such as a landfill. The abundance of synthetic garments found discarded in municipal areas does not allow water to penetrate into the soil, increasing soil erosion, not allowing for groundwater to be replenished, and the standing water is a breeding ground for disease spreading mosquitoes (Allwood et al., 2006). The following sub-sections detail the environmental impacts of apparel throughout the stages of the life cycle. 


\subsection{1 - Fibres}

By the beginning of the $20^{\text {th }}$ century, cotton as a raw material accounted for more than $70 \%$ of all textiles (Shen, Worrell, \& Patel, 2010). Synthetic fibres such as polyester, a petrochemical product, entered the textile market mid-century and have steadily increased in production and use (Fletcher, 2008). Figure 1 illustrates the rising production and demand for fibres. Material diversity is a rising concern in the development of sustainability within the apparel industry as cotton and polyester together account for over $80 \%$ of textiles in the global marketplace and total world fibre demand in 2005 was 60 million tonnes for textile production (Plastina, 2005; Fletcher, 2008). This creates concentrated impacts in the specific agricultural or manufacturing sectors, reduces consumer choice, increases ecological risk, and demand is continually increasing (Fletcher, 2008). Apparel and textiles are produced using fibre, which can be natural (e.g. cotton, silk, wool), man-made bio-synthetics (e.g. viscose), and synthetic (oil is used to create polymers e.g. acrylic or polyester) (Allwood et al., 2006; Fletcher, 2008). A common misunderstanding is that natural fibres are environmentally friendly while synthetics are not. This preconception is due to a number of factors such as raw material renewability, biodegradability, and the associated stereotypes of factories and chemicals (Fletcher, 2008).

\subsubsection{1 - Natural fibres}

Prior to the $18^{\text {th }}$ century, cotton only accounted for $4 \%$ of all textiles used globally. The majority of textiles and apparel were made from wool (78\%), and flax (18\%) (Soth, Grasser, Salerno, \& Thalmann, 1999). It was the technical innovation of the Industrial Revolution that allowed for cotton textiles to proliferate. By the 1960s raw global cotton production had reached 10 million tonnes, and has more than doubled by 2010 at 25 million tonnes (Ferrigno, 2012). In the 1970s cotton consumption was 3.15 $\mathrm{kg} /$ person in North American and Europe, (Fairtrade Foundation, 2010) and by 2007 had nearly tripled with an annual average of $14.2 \mathrm{~kg} /$ person (Plastina, 2005). Cotton accounts for $85 \%$ of all natural fibres, had a value of US $\$ 400$ billion in 2009 , (World Wildlife Foundation (WWF), 2009) and $80-90 \%$ of all cotton production is used for apparel (Environmental Justice Foundation (EJF), 2009).

Cotton cultivation is extremely chemically intensive. Cotton accounts for $2.4 \%$ of global arable land use, utilizes 11-12\% of all global pesticides produced (Chen \& Burns, 2006; Ferrigno, 2012; WWF, 2012) and employs over 300 million people, 30 million of which are farmers (EJF, 2009). Pesticide use leads to damaged soils, loss of biodiversity, water pollution, decreased water tables, and increased salinity (Ferrigno, 2012). Cotton is produced in over 90 countries and $99 \%$ of cotton production is located in developed nations (Fairtrade Foundation, 2010; Ferrigno, 2012; WWF, 2012). A typical $0.25 \mathrm{~kg}$ t-shirt requires nearly $3,000 \mathrm{~L}$ of water and requires $0.15 \mathrm{~kg}$ of pesticides to produce (Ridoutt \& Pfister, 2010; Organic Trade Association (OTA), 2011) while one pair of jeans (roughly $1 \mathrm{~kg}$ ) can use 11,000 L to $20,000 \mathrm{~L}$ of water from cotton field to finished product (Soth et al., 1999; WWF, 2012). Cotton is the 
world's thirstiest crop utilizing 7,000,000 L $-9,000,000 \mathrm{~L}$ of water to produce $1,000 \mathrm{~kg}$ of cotton (IHE Delft, 2003; Mekonnen \& Hoekstra, 2010).

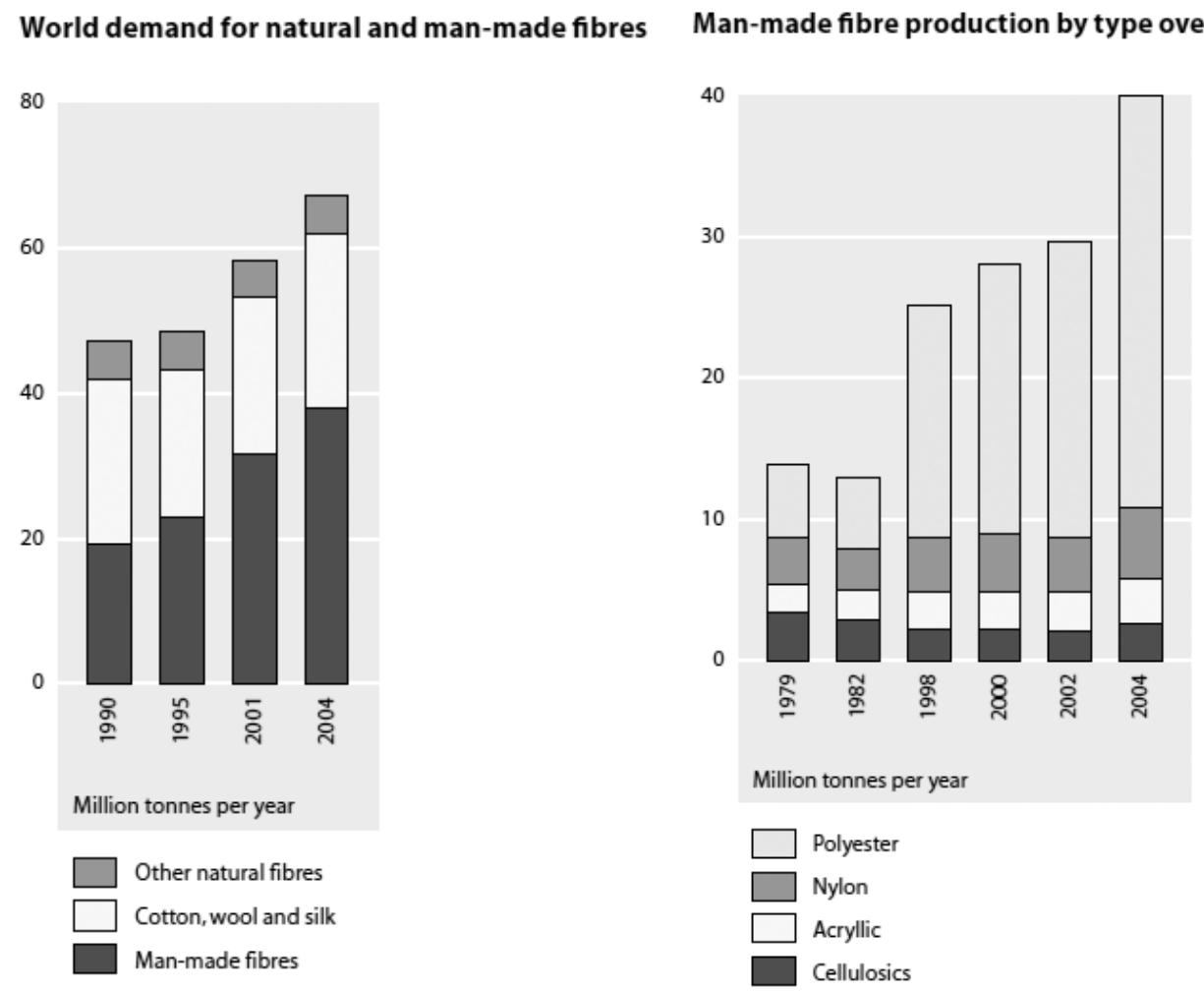

Figure 1: Fibre production and demand (Allwood et al,. 2006).

There are six dominate countries involved in cotton production. They account for $85 \%$ of global supplies: USA, China, India, Pakistan, Brazil, and Uzbekistan. All are disturbingly dependent on agrichemicals (EJF, 2009; Ferrigno, 2012). Cotton is a difficult crop with many natural predators such as boll weevils and thrips, and the drier the climate, the greater the need for pesticides and water irrigation to produce the necessary yields. India's cotton production accounts for less than $5 \%$ of land use but accounts for $50 \%$ of the country's pesticide use (Ferrigno, 2012). Roughly $73 \%$ of all cotton production utilizes irrigation, as the producing countries are mainly located in dry regions. Irrigation doubles the yield per hectare (Soth et al., 1999). Irresponsible cotton irrigation has contributed to one of the world's worst environmental disasters, the near disappearance of the Aral Sea. The Aral Sea was once the fourth largest inland body of water, and had a surface area of 1.8 million $\mathrm{km}^{2}$ within seven nations (Micklin, 2007). Uzbekistan had been using irrigation for many years but it was the expanding irrigation systems for cotton production that diminished the flow of the two main tributary rivers that feed the Aral Sea. It was this expansion to the main tributary rivers that led to the dramatic decrease of the Aral Sea's water levels. By the late 1980s, the Aral Sea had lost more than half of its volume, and by 1995 the surface area had decreased by half and three-quarters of the water volume had disappeared, and salinization had 
increased (Micklin, 2007; Siegle, 2011). This led to the near disappearance of the once abundant fish and wildlife population. Water was diverted to support cotton crop production in Uzbekistan and despite receding water levels Uzbekistan continues to produce cotton. The Uzbekistan government earns about US $\$ 1$ billion a year from cotton harvest, and is the third largest producer of cotton (Siegle, 2011; EJF, 2012).

As water scarcity increases, fibres such as cotton will increase in price, and will require alternative agricultural practices. This provides the opportunity for the use of other regional fibres such as hemp, nettle and flax (linen) and the innovation of new fibres such as bio-synthetics that are not as chemically and water intensive as cotton. Hemp grows rapidly, has a high yield, can be grown in cooler climates and does not require the high volumes of water and chemicals as cotton crops. Bio-synthetic textiles such as Lyocell are a cellulose based and typically made from the wood pulp of eucalyptus. The production process recovers $99.5 \%$ of solvent used, which is then purified and recycled back into the production process (Fletcher, 2008). Promotion, use and development of alternative and environmentally preferred fibres have a place in creating apparel products with less negative environmental impacts.

\subsubsection{2 - Synthetics fibres}

Synthetics are a continuously growing category of fibres since their introduction onto the market in the middle of $20^{\text {th }}$ century. Synthetic fibres are made from petrochemicals or polymers made from crude oil and include the following: nylon, acetate, polyamide, elastane/spandex, rayon, and polyester. Unlike the majority of synthetic fibres, acrylic is made from mineral oils or other hydrocarbons such as benzene, is more energy and water intensive than polyester, and produces $\mathrm{N}_{2} \mathrm{O}$ emissions (Laursen et al., 2007; Fletcher, 2008). Polyester demand has doubled over the last 15 years, and is the most widely used textile today (Allwood et al., 2006; Claudio, 2007). The production of polyester and other synthetics, unlike cotton, uses little to no water but consumes twice as much energy to produce $1 \mathrm{~kg}$ of fibre (Fletcher, 2008). Synthetics require large amounts of crude oil, and release volatile organic compounds (VOCs), particulate matter, $\mathrm{CO}_{2}, \mathrm{~N}_{2} \mathrm{O}$, hydrocarbons, sulphur oxides, carbon monoxide, acetaldehyde, 1,4dioxane, and acid gases like hydrogen chloride. Many of these emissions can cause or aggravate respiratory disease (U.S. Congress, Office of Technology Assessment, 1987; Claudio, 2007; Fletcher, 2008).

Whether polyester is produced from virgin or recycled materials, it requires the use of a catalyst during the chemical process. The most common catalyst used is the heavy metal antimony, a known carcinogen (Victor-Innovatex, 2003). Other heavy metals and chemicals used during the production of polyester are cobalt, manganese salts, sodium bromide, and titanium dioxide (Fletcher, 2008). The production of polyethylene terephthalate (PET), commonly used for PET textiles (a form of polyester), utilizes ethylene glycol as a raw material. The distillation or recycling process of ethylene glycol produces a still bottoms or sludge that when incinerated creates fly ash containing antimony, arsenic, and other 
heavy metals (Victor-Innovatex, 2003). When PET is recycled from virgin PET textiles or PET plastic bottles, it contains antimony, which is converted to antimony trioxide during the high temperature process (Victor-Innovatex, 2003). Antimony trioxide is emitted as a by-product of the recycling process, and is a suspected human carcinogen (Center for Disease Control (CDC), 2003). For these reasons, the Environmental Protection Agency (EPA) considers textile manufacturers to be hazardous waste generators (U.S. Environmental Protection Agency (EPA), 2002). Much like cotton, polyester and other synthetics have many negative environmental effects, and as oil reserves diminish, the price and availability of synthetic fibres made from crude oil will be affected. Availability of crude oil stresses the importance in developing synthetics made from alternative, environmentally friendly sources. Poly lactic acid (PLA) is thermoplastic polyester made from corn, is compostable and is one of the very few alternatives available. PLA unfortunately has a very low melting point, making it unsuitable for many processing routes such as transfer printing or ironing (Fletcher, 2008). New developments in fibres and textiles require time and financial investments to be available for large-scale operations as initial manufacturing costs are high and availability is limited.

\subsection{2 - Textile wet processing}

Textile wet processing includes dyeing, printing, and finishing to create colours, prints, patterns, and special performance characteristics. These processes have adverse environmental impacts due to the dyes and chemicals used such as solvents, and alkaline wastes (U.S. EPA, 2002). Textile processing occurs mainly in developing countries which presents a problem in the treatment and discharge of effluents as these countries generally have poor working conditions, weak or no regulation on environmental protection, and poor enforcement ex. wastewater treatment (Fletcher, 2008; Dickson et al., 2009). In developing countries, $70 \%$ of industrial wastewater is discharged into rivers and streams untreated (United Nations, 2003). This often contaminates municipal drinking water Environmental analysts Miller-McCune (Wood, 2009) found that one in four of China's 1.35 billion people drink contaminated water on a daily basis. This is a result of booming industries such as textiles where only about $10 \%$ of dye wastes are recycled and about a third flows directly into aquatic systems (Wood, 2009). Developed nations such as Canada as of 1999 found that $95 \%$ of textile mills discharged effluent to municipal wastewater treatment plants, only $4 \%$ had dedicated treatment systems and two mills were found to have discharged untreated effluent into the aquatic environment (Environment Canada, 2001).

Textile dyeing is resource intensive in terms of use of water, chemicals, and energy. Wastewater from dyes is a major source of heavy metal pollutants (such as zinc, copper, chromium, nickel, lead, antimony, mercury, tin, cobalt, and arsenic) (Laursen et al., 2003). Depending on the type of fibre and colour, dyes can contain acids, salts, heavy metal salts, reducing and oxidizing agents. Heavy metals and toxic chemicals are added to dye baths as a mordant to increase the affinity of dyes for textiles and colourfastness. 
Synthetics such as polyester and nylon are particularly difficult to dye, can only be achieved under pressure and pose risk to human health. Many of the disperse dyes used on polyester have been shown to cause allergic contact dermatitis (Chan \& Burns, 2006; Laursen et al., 2007). Azo dyes have been one of the most common dyes used. Some azo dyes are considered to be toxic, carcinogenic or genotoxic, and may contain heavy metals (Sweeney, Chipman, \& Forsythe, 1994). Conventional aerobic sewage treatment plants do not degrade azo dyes as they are resistant to biological oxidative degradation (Gottlieb, Shaw, Smith, Wheatley, \& Forsythe, 2003). The EU has banned the use of azo dyes within the manufacturing sector but they are still found in goods imported into the EU (Laursen et al., 2007). Up to $50 \%$ of the initial dye concentration can remain in the spent dye bath during the dye process, resulting in a coloured effluent (Chan, Wu, Juan, \& Teh, 2011). The darker the shade, the greater the amount of dye that is left and lost in the effluent (Fletcher, 2008).

Global water use by the textile industry is estimated at 378 billion litres of water each year (Clay, 2004) and The World Bank estimates that up to $17-20 \%$ of the worlds industrial pollution comes from textile dyeing and treatment (Chan et al., 2011). In China, in 2010, the textile industry discharged $2.46 \mathrm{x}$

$10^{12}$ billion litres of wastewater. This was the third highest of the 39 major industries in China, accounting for $11.6 \%$ of all discharged industrial wastewater (Institute of Public \& Environmental Affairs, 2012). An expert dyehouse will use $60 \mathrm{~L}$ of water to dye $1 \mathrm{~kg}$ of cotton whereas an inefficient dyehouse will use 800 L (Siegle, 2011). Use of such large volumes of water puts extreme pressure on already scarce water resources, and lack of wastewater treatment threatens the ecological health of aquatic systems and drinking water. This creates concern on the use of textile dyeing, as colour is one of the most important factors in the commercial appeal of apparel products (Eckman, Damhorst, \& Kadol, 1990; Fletcher \& Grose, 2012).

\subsection{3. - Consumer use}

The significance of the environmental impacts arising from the consumer use phase was first highlighted in 1993 in a study by Franklin Associates for the American Fiber Manufacturers Association (Smith \& Barker, 1995). They conducted a life cycle assessment (LCA) of a polyester blouse, and found that $82 \%$ of the energy use and $83 \%$ of the $\mathrm{CO}_{2}$ emissions are a result of the consumer use phase. This increases for natural fibres such as cotton and linen that require more time to dry. Linen can utilize $14 \%$ more energy than cotton due to the use of ironing for linen garments. Linen has similar results to the polyester blouse in that $80 \%$ of water and energy use during the life cycle are a result of the consumer use phase (Pariset, 2008). According to the Well Dressed? study, 60\% of the energy used in the life cycle of a cotton T-shirt is related to the laundering and high temperature drying (Allwood et al., 2006). Discrepancies in energy and water use are most likely due to the variations in the scope and method of these studies. Despite the variations, the consumer use phase has the highest energy impacts. Water use is another concern as the average washing machine in 2008 was found to use $150 \mathrm{~L}$ of water per load 
and $319 \mathrm{kwh} / \mathrm{yr}$ (Natural Resources Canada, 2010) while the average dryer uses $928 \mathrm{kwh} / \mathrm{year}$ (Natural Resources Canada, 2010). Energy Star estimates that the average North American family does 300 loads of laundry per year (Energy Star, 2012) resulting in an average of $45,000 \mathrm{~L}$ of water used per family per year.

Recently there has been rising concern over the subsequent release of chemicals used in manufacturing through laundering (Laursen et al., 2003; Allwood et al., 2006; Fletcher, 2008; Greenpeace, 2010; Siegle, 2011). Chemicals such as nonylphenol ethoxylates (NPEs) are used in textile manufacturing, and are found to remain in the clothing sold by major retailers. A significant percentage of the remaining chemical residue is released during consumer laundering, subsequently entering municipal water systems. Once released into these water systems, NPEs are subject to further breakdown into alkylphenols (APs). APs bioaccumulate, are more toxic and more persistent than NPEs (Besieux, 2012). NPEs are of concern as they may impair fertility, and they subsequently break down to form toxic nonphenol, an endocrine disrupter that is found to bioaccumulate (Laursen et al., 2003; Greenpeace, 2010).

A recent study by Browne et al. (2011) suggests that a large proportion of microplastic fibres found in the marine environment may be derived from sewage as a consequence of washing of clothes. Eighteen sites were investigated worldwide, and forensic evaluation found that the microplastic found in the shoreline sediment had the proportions of polyester and acrylic fibres found in apparel. The sites from which the shoreline sediment was sampled were habitats that receive sewage effluent and sewage discharges. Final conclusions suggest that a large proportion of the microplastic fibres found in these marine environments could be a result of apparel washing. Experiments conducted with a domestic washing machine found that the laundering of one garment produced upwards of 1,900 fibres per wash. As consumers continue to increase their use of sythetic textiles, this could result in the potential increase in marine habitat contamination (Browne et al., 2011).

\subsection{4 - Textile and apparel waste.}

One of the major contributors to the rapid generation of textile and apparel waste is the increased consumption rates and rapid obsolescence of apparel due to fast fashion. Products that become obsolete quickly are destined for landfills at a quicker rate as these garments are generally not left in a good enough condition to enter the second hand apparel market (Allwood et al., 2006; Hethorn \& Ulasewicz, 2008). A survey by Oxfam and Marks \& Spencer (M\&S) in the United Kingdom found that 1 in 10 people admitted to wearing just $10 \%$ of their current wardrobe and estimated that there were 2.4 billion unworn garments (YouGov, 2012). Almost three quarters of UK adults have thrown clothes away in the past year with one sixth of adults having only worn the items that they threw away once. Almost a quarter of consumers surveyed had discarded apparel items because they were "bored of them", $20 \%$ felt the items were "no longer fashionable", while $10 \%$ had bought on impulse (Holton, 2012; YouGov, 2012). The 
YouGov (2012) study found that apparel that is discarded after one wear generally costs under US $\$ 30$ and estimates that US \$145 million to US \$229 million worth of clothing is sent to landfills after only one wear. Another study in 2011 found that UK residents spent US $\$ 71$ billion on clothing, and $28 \%$ of people surveyed admitted to buying more than they need (Gracey \& Moon, 2012).

It is estimated that British consumers throw away an average of $30 \mathrm{~kg}$ of apparel per year (Minney, 2012) or 1.5 million tonnes per year. This textile waste results in more than three million tonnes of $\mathrm{CO}_{2}$ emissions (Siegle, 2011). According to Goodwill (2009) in 2009, 10.8 million tonnes of apparel was sent to landfills in the U.S. The U.S. EPA estimated that in 2010, 13.1 million tonnes of textile waste was generated which is the equivalent of $5.3 \%$ of total municipal solid waste generation. The recovery rate for textile waste is quite low, and in 2010 was only $15 \%$ of all textile waste generated or 1.96 million tonnes (U.S. EPA, 2012).

Consumer waste is an increasing issue but textile waste generated from apparel production is rarely addressed (Allwood et al., 2006). When cutting textiles from pattern pieces in preparation for sewing, there is an average of $15-30 \%$ textile waste produced per style (Fletcher, 2008). There have been no estimates as to the amount of textile waste generated from apparel production. This increased volume of textile and apparel waste is of concern as cotton produces large volumes of methane gas during decomposition while synthetic textiles do not decompose at all (Fletcher, 2008).

\subsection{5 - Social impacts}

Labour abuse is not a new problem for the apparel industry. Throughout the 1900s, workers in the United States, primarily immigrant women, were subjected to long hours of work, poor working conditions, low wages, and abuse of multiple natures. During the early 1900 s multiple strikes and protests forced apparel factories to recognize the right for workers to join unions (Von Drehle, 2003). The unions were formed to combat many of the issues facing the factory workers including forced labour, low wages, excessive hours of work, discrimination, health and safety hazards, psychological and physical abuse, lack of awareness of workers' rights, and lack of worker representation for negotiations with management (Dickson et al., 2009). While the unions and regulations strengthened over the decades, labour problems were still an issue, even into the late 1970s (Ross, 2004).

In the 1990s the fashion industry experienced a public backlash against the lack of social responsibility and accountability of factories located in developing nations (Hethorn and Ulasewicz, 2008). The use of sweatshop labour led to negative publicity that encouraged the industry to reassess, and introduce codes of conduct, sourcing policies and CSR policies and practices (Abernathy et al. 1999; Klein 2000; Park and Lennon 2006; Shaw et al. 2006). As was the case with many business sectors, the acknowledgment that companies in the fashion industry have a wide array of stakeholders has become increasingly commonplace. Freeman (1984) defined a stakeholder as a group or individual that can affect or is affected by the organization in achieving its objectives. Stakeholder acknowledgment has become 
part of the managerial and operational culture of many firms as the stakeholder model and stakeholder analysis became linked to organizational performance (Donaldson and Preston, 1995). The increased awareness and concern of stakeholders has led to a gradual response from the fashion industry to improve on the environmental and social impacts of its manufacturing processes (Chen and Burns, 2006). However, social impacts such as worker rights, poor working conditions, long hours, low wages, child labour, and health and safety issues are still problems of concern in the developing nations where apparel production is located (Madsen et al., 2007). The advent of fast fashion has increased the need for an increased labour pool, and it is estimated that there are currently 40 million garment workers worldwide (Siegle, 2011).

\section{5 - Corporate Social Responsibility}

The following section introduces the concept of CSR evolution within the apparel industry. The development and criticisms of CSR reporting are reviewed. The use of indicators is introduced, as is the development of codes of conduct and their use in the apparel industry.

\subsection{1 - CSR and the apparel industry}

CSR is a highly debated topic among corporations and in academic literature as there continues to be a struggle in achieving consensus on a clear definition (McWilliams \& Siegel, 2001; Van Marrewijk, 2002; Kakabadse, Rozuel, \& Lee-Davies, 2005). The debate surrounding CSR relates to many concepts such as sustainable development, corporate citizenship, sustainable entrepreneurship, and ethical business (Van Marrewijk, 2002). Howard Bowen was the first to use the term social responsibility and it was in the 1950s that this concept emerged in business literature (Dickson et al., 2009). A classic view of CSR would be Freeman's (1984) stakeholder approach, where he states that organizations are not only responsible to shareholders but to a variety of stakeholders in achieving the objectives of the organization. Stakeholders can include labour rights organization, environmental groups, nonprofits, community-based organizations, trade unions, industry associations, investors, academics, consumers, factory owners and managers, workers, and shareholders. A more contemporary description by The European Commission defines CSR as, "A concept whereby companies integrate social and environmental concerns in their business operations and in their interaction with their stakeholders on a voluntary basis" (European Commission, 2010:6). Definitions of CSR, in an attempt to be applicable to all types of organizations, have resulted in vague explanations open to interpretation. Van Marrewijk (2002) comments to the vagueness of current CSR definitions impeding corporate implementation, and providing no use to academic debate. For the apparel industry, CSR and social responsibility are not only new concepts but also still relatively new terms (Dickson et al., 2009).

With no standardized definition, Dickson and Eckman (2006) collected the views of 74 professors and grad students to establish a working definition of social responsibility for the apparel industry. 
"Socially responsible businesses consider the entire system of stakeholders associated with apparel supply chains, including production workers, sales help, and consumers, and the entire product life cycle from the inception of raw materials and components to product design, use and discard" (Dickson et al., 2009:30). Dickson et al. (2009) found that the lack of an industry-wide accepted definition has led to ambiguity over whether social responsibility includes the environment. For the apparel industry they have resolved that the environment is generally included under the umbrella of social responsibility, and the aim should be to balance ethics with profitability through the production of apparel that minimally harms humans and the environment (Dickson \& Eckman, 2006). This view is further strengthened by the Business for Social Responsibility (BSR), an organization that does work within the apparel industry, and whose goal is to assist business become socially responsible. The BSR has proposed that to achieve social responsibility, companies must integrate practices into every aspect of their operations. Businesses should be "achieving commercial success in ways that honours ethical values and respects people, communities and the natural environment" which is demonstrated through a set of policies, practices and programs for all aspects from business operations to supply-chains (Business for Social Responsibility, 2012).

Traditional business perspectives have a company primarily concerned with the financial considerations integral to its success. A common approach in the apparel industry is that the designer is responsible for creating a saleable product, generally within a set price point meeting market expectations, and constraints with manufacturing. Environmental or social issues are at best a peripheral concern (Gwilt \& Rissanen, 2011). However, as stakeholders become aware of issues such as pesticide use, worker rights, apparel waste, labour rights violations, the effects of fast fashion, and the environmental problems that occur while producing products in developing countries, apparel brands have increasingly scrutinized their business practices (Wong \& Taylor, 2000; Dickson \& Eckman, 2006; Birtwistle \& Moore, 2007; Goworek, 2011). Some stakeholders have a genuine concern over the irresponsible actions of corporations as they create a cost to society (Sutantoputra, 2009). Nongovernmental organizations (NGOs) have been increasingly examining apparel brands to reveal whether they have been complying with local laws and regulations in the countries where they operate. The offshore outsourcing of apparel production can be viewed as a contributing factor to the rising focus on the CSR activities and initiatives of apparel brands. For the purpose of this study an apparel brand is a company with a distinct identity attached to their apparel products. Outsourcing by apparel brands has created supply-chains that are complex, global, fragmented, and non-transparent. The adoption of CSR strategies by a company can be a result of any of a number of forces:

- the opportunity presented by ethical, green or eco marketing in response to consumer demand;

- the pressure to offer competitive products in a marketplace where others are having (or threatening) success in capturing market share with CSR-based promotions; 
- in response to public demands for industry response (e.g., ethics-based campaigns directed by non-government organizations (NGOs));

- a sense of a moral obligation;

- the potential to realize cost reductions - particularly related to production materials, waste handling, and/or liability; and

- requirements imposed by government regulation.

This has put more emphasis on the need for apparel brands to conduct ethical and responsible production, and their responsibility to stakeholders and society. This has resulted in CSR being increasingly implemented into business strategies of apparel brands in order to maintain healthy relationships with their stakeholders (Dickson et al., 2009). The focus, however, tends to be on social and environmental responsibility strategies related to particular aspects of the industry as opposed to a systematic appraisal of the entire supply-chain (Goworek, 2011). This is best exemplified by the introduction of organic cotton as a raw material. However, the subsequent use of toxic dyes and chemicals or issues with garment laundering and disposal are commonly not addressed. The effectiveness of initiatives aimed at a particular stage, and the effects throughout the entire chain have also not been well documented (Madsen et al., 2007). As companies develop these CSR strategies, the challenge is to integrate environmental and social matters with those of financial performance (Epstein \& Roy, 2003). Searcy (2011), states that internal and external stakeholders are increasingly placing pressure on corporations to adopt a more holistic view of business success as opposed to a solely profitdriven approach.

\subsection{2 - CSR reporting}

The 1987 report by the Brundtland Commission, Our Common Future, presented the most widely used definition of sustainable development as "meeting the needs of the present without compromising the ability of the future generations to meet their own needs" (World Commission on Environment and Development, 1987:1). Today, the term sustainability is commonly defined through three dimensions: environment, economy, and society. Carter and Rogers (2008) provide an extensive review of the literature on sustainability, and found that while the concept is well understood, corporations struggle with integrating the concept into CSR strategies. Corporations, NGOs, and nations, have adopted the term to demonstrate their environmental, social and economic performance through CSR reporting. The use of reporting as a means of communicating a corporations sustainability actions and initiatives has been growing. A variety of names have been adopted in reference to this type of reporting: "sustainability", "accountability", "sustainable development", "corporate social responsibility", "corporate responsibility", and "triple bottom line" reports (Roca \& Searcy, 2012). While there is abundant literature on CSR reporting, there is no widely accepted definition of a CSR report. There are also many difficulties and 
questions about the structure and the type of information to be included in a CSR report (Davis \& Searcy, 2010).

There has been an increased use of CSR reports to communicate the social and environmental actions in which a particular company has engaged (Bouten, Everaert, Van Liedekerke, \& De Moor, 2011). While the CSR report does communicate information there are questions surrounding the content and ability to satisfy the increasing demand for accountability by internal and external stakeholders (Adams, 2004; Bouten et al., 2011). Despite the difficulties and inconsistencies surrounding CSR reporting, it has been found to improve the competitive advantage of an organization, as it portrays the organization as behaving responsibly (Sutantoputra, 2009). The decision to report on CSR efforts may have the same drivers as financial reporting, as disclosing information on financial performance maintains healthy stakeholder relations (Sutantoputra, 2009). Recent research on American investors indicates that close to three quarters consider social responsibility when making decisions on investing (De Tienne \& Lewis, 2005). While CSR reporting can be beneficial with regards to stakeholder relations, CSR reporting and reporting practices are mainly voluntary, as very few geographic regions have regulation on CSR reporting and reporting practices (Sutantoputra, 2009). This voluntary disclosure can build trust and credibility among stakeholders. While companies may be reluctant to disclose poor performance, this voluntary disclosure can be an opportunity to soften the impact (Epstein, 2008).

Research to date has shown that there are many differing motivations and numerous methods for how a company can disclose CSR information to stakeholders (De Tienne \& Lewis, 2005). The Global Reporting Initiative (GRI), which was first released in 2000, is the most common and widely used framework for providing guidance on CSR performance disclosure. The framework outlines core content for reporting, and direction on how to report. The GRI has attempted to fill a void that had plagued previous attempts to disclose information on environmental and social efforts such as lack of uniformity, consistency, and comparability. In a response, the GRI developed a framework that follows the generally accepted accounting principles (GAAP) approach to financial reporting (Sherman, 2009). To remedy the one-size-fits-all approach, the GRI has developed specific sector supplements, and has recently released a pilot version specifically for the apparel and footwear industry. In this new supplement, the GRI Apparel and Footwear Sector Supplement (AFSS) provides a definition of CSR reporting as a "practice of measuring, disclosing and being accountable for organizational performance while working towards the goal of sustainable development...provides a balanced and reasonable representation of the sustainability performance of the reporting organization...positive and negative contributions" (GRI, 2011:55). For the purpose of this study, the definition of CSR reporting as provided by the GRI will be utilized.

Reporting that can be compared across multiple apparel brands becomes difficult if there are no standard definitions that will form the foundation for strategies, actions, initiatives and its subsequent reporting: eg., what does sustainability in the apparel industry mean or look like? This is not a flaw in the GRI but spotlights the difficulties in reporting on CSR performance when a consensus over a definition of 
CSR is lacking. Searcy (2009) proposes the idea that one of the biggest challenges corporations face is developing a shared consensus over what sustainability means in the corporate context. However, this development of a sector specific guideline does provide guidance on the type of indicators an apparel brand may want to develop to measure and report on CSR performance. A weakness of the GRI is that it does not provide direction as to how a company may integrate the indicators with existing initiatives (Searcy, 2009). It also attests to the need for further developments in regards to reporting, and environmental and social indicator development in the apparel sector.

Sherman (2009) performed a content analysis of Nike's and adidas's CSR reports which were prepared using the GRI G3 guidelines to compare and contrast the information communicated. An analysis of the report's compliance to the G3 reporting guidelines on the content and reporting style was conducted. Sherman found the content and reporting styles of the two sportswear's brands to differ, and revealed "disturbing inconsistencies" in how CSR performance information was disclosed. Sherman stated it was an unexpected result considering they are in the same industry and utilized the same reporting guideline. It was found that adidas's report had very little compliance with the G3 guidelines, and questioned why the company even referred to the guideline with so little compliance. There were no similarities in the type of metrics used to report CSR performance, and when similarities were found, such as auditing systems, the reporting of the results were very different. Sherman surmised that there was no way to effectively conclude which company was managing its supply-chain better, and that the G3 guidelines are not achieving their intended results. Sherman stresses that this is not the fault of the G3 guidelines but an illustration of the inconsistencies in the application of the guidelines. He states that even the same level of reporting would not solve the problem of comparability due to the way in which the common indicators were reported (Sherman, 2009).

There are many other factors to consider when reporting, such as the intended audience. This may make a difference in the type of information that is disclosed and how it is disclosed. It has been found that companies are moving beyond reports, and employing a variety of communication channels to interact with and inform their stakeholders on their CSR activities. For example, external audiences are now referring to corporate websites as a key source of information (CSR Europe, 2009), and as technologies and electronic dissemination of information evolve, a report and the length of a report may become increasingly less important. In 2005, adidas shortened its social and environmental report but expanded its CSR website content (Epstein, 2008). Epstein states that importance should be placed on providing information that is an easily accessible format while CSR Europe (2009) sees a key shift for the future of CSR reporting will be from informing to communicating, engaging, and learning.

\subsubsection{1 - Criticisms of CSR reporting}

Public relations or a maximizing on the perceptions of legitimacy in CSR performance disclosure is often cited as the chief criticism of CSR reporting (Deegan, 2002; Laufer, 2003). It has been found after 
reviewing CSR reports, a majority of reports disclose information on good performance but lack disclosure of non-compliance, unmet targets, and how codes are implemented and monitored (Hubbard, 2009; KPMG International, 2010). As De Tienne and Lewis (2005:359) state, "the jagged line between optimism and deceit is often difficult to distinguish." While the GRI provides a guideline on how to report, it is voluntary, and there are no formal standards on CSR reporting and content. A lack of formal standards allows organizations the freedom to measure and verify CSR performance and disclosure, making performance assessment difficult for readers of the report. This makes it extremely difficult to compare multiple organizations' CSR performance and reports (Hubbard, 2009; Sherman, 2009).

\subsection{3 - The use of indicators}

To measure CSR progress within the three dimensions of sustainability has resulted in the development of indicators. Indicators are a measure of performance, and inform in a quantitative or qualitative manner, information about a situation or results of an action (Thompson, 2002). Corporations are increasingly using indicators in their CSR reports to measure environmental, economic, and social performance. Adams and Frost (2008) mention the doubt that exists as to the complete and accurate extent of environmental and social impacts reported by corporations. One possible explanation may be that little research has been conducted on the indicators that are used to convey quantitative information in CSR reports. There is also a high degree of emphasis placed on qualitative information in CSR reports (Roca \& Searcy, 2012). In the GRI AFSS, indicators are structured around the three dimensions of the

Triple Bottom Line; economic, social and environmental. The GRI AFSS includes thirty-four industry specific indicators but does note that not all indicators will be applicable to all the various types of organizations that compromise this sector (GRI, 2011). The majority of the supplement is focused on the social responsibility aspects, as there are only seven performance indicators for reporting recommendations under the environmental section.

There is virtually no literature on the types or development of indicators used in the apparel industry that measure social or environmental CSR performance. There are studies that evaluate the use of performance indicators within the apparel industry however they refer to measuring operational, manufacturing and supply-chain management performance (Upton, 1998; Lee \& Kincade, 2003; Lohman, Fortuin, \& Wouters, 2004; Jin, 2006). There is one study that looked at the development of environmental performance indicators (EPI) for the textile industry and noted that sector specific EPIs are particularly underdeveloped (Rin, 2000). The study found that current EPIs have been developed mainly for communication and benchmarking purposes and lack the specificity to evaluate processes, technologies and products. Conclusions from the study address the difficulties in developing EPIs for textile products due to the great variation of products. EPls should address both product and process perspectives and the use of life cycle assessment with an increased focus on raw material production and disposal stages 
(Rin, 2000). These conclusions are easily extrapolated to apparel products and the apparel industry as the textile industry is considered a major component of the apparel industry.

A study by Roca and Searcy (2012) on the type of reported indicators within Canadian corporations found that indicators are widely disclosed and were aligned along the three dimensions of sustainability: economic, environmental and social or the Triple Bottom Line. The study found that while there was a large quantity of indicators reported, they were diverse and their frequency of occurrence was varied. Similarities did exist in the results in the broad sense that environmental indicators focused on energy and water, social indicators on labour practices and donations, and economic indicators on sales and benefits (Roca \& Searcy, 2012). The study offers many possible explanations for the observed variation of reported indicators but stresses two key factors: there are few mandatory requirements for sustainability reporting in Canada in 2008, and the practice of developing sustainability reports by corporations is still in the early stages. Roca and Searcy also acknowledge that there are relatively few studies that investigate the use sustainability indicators in corporations.

\subsection{4 - Codes of conduct}

CSR has expanded at both the national and international level as NGOs, governments, and organizations such as the UN Global Compact (UNGC) and International Labour Organization (ILO), have developed guidelines to encourage or ensure companies act as responsible corporate citizens (Bondy, Matten, \& Moon, 2008). The ILO has developed four core labour conventions that are widely viewed as the minimum standard for social responsibility (Elliot \& Freeman, 2003). The involvement of NGOs in preparing guidelines for social responsibility and accountability has been influenced by increased media attention. This includes media attention on such issues as labour rights violations in contracted factories that have a damaging effect on a company's brand value (Wong \& Taylor, 2000; Taylor, 2003; Kaufman, Tiantubtim, Pussayapibul, \& Davids, 2004; Fan \& Lo, 2012). Codes of conduct have been developed to "help apparel retailers and brands acknowledge their responsibility to the workers in their supply chains" (Fletcher, 2008:58). Codes are frequently developed by the company themselves and outline basic workers' rights and minimum standards (Fletcher, 2008). Bondy, Matten, and Moon (2008), identified two general types of codes, voluntary and mandatory but cautioned against the assumptions that codes are

primarily used as tool for governing CSR issues. After reviewing 150 corporations from three different countries, their study found that codes were often used as tools for governing traditional business issues such as bribery, corruption, ensuring compliance with laws and regulations, and improving corporate reputation.

The use of voluntary codes of conduct as a CSR tool within the apparel industry is growing (United Nations Industrial Development Organization, 2010). Voluntary codes are a proactive response that demonstrates commitment to a particular issue, such as sustainability. Voluntary adherence gains public trust while reducing the need for government regulation (Epstein, 2008). In May 2012, the UNGC in 
collaboration with the Nordic Initiative Clean and Ethical (NICE) announced the launch of its first sectorial initiative, a code of conduct for the apparel industry. The code was developed to align with the UNGC's ten principles but with additional content specific to the apparel industry (NICE, 2012). While the developments of these codes are voluntary, their compliance by suppliers is mandatory by a few brands such as Levi's, H\&M, Nike and adidas. However, while these codes are mandatory, a recent report by the Chinese Institute of Public \& Environmental Affairs (IPEA) found that Fu'an Textiles Mill, a factory contracted by SAC members Nike, H\&M, Levi's, adidas, Marks \& Spencer, and Gap Inc., was discharging 20,000 tonnes of untreated dye and printing wastewater daily directly into the Maozhou River from a hidden pipe located underneath the mill (Institute of Public \& Environmental Affairs, 2012; Marian, 2012). Dye levels in the discharged wastewater were found to be 19.5 times higher than the legal limit. The following quote is taken from the IPEA (2012) report stating Nike's response to the findings from the investigation:

Nike was the only one [of the retailers that contract Fu'an] that could show proof that they had checked the environmental situation at Fu'an previous to the sudden unannounced inspection by the Chinese government. Since 1999, Fu'an was able to pass Nike's water quality inspections. However, the inspections were voluntarily carried out and involved Fu'an sending their own sample to a laboratory commissioned by Nike to do the testing. Nike stated in an e-mail that Fu'an should take a sample under normal circumstances from their wastewater. However, Nike admitted that the sample was probably substituted in secret. However, Fountain Set Holdings said they did not falsify the sample. (p. 20)

Investigations and findings such as this one question the efficacy of these codes, the rigor of the auditing system put forth by apparel brands to ensure compliance, and remedial actions taken. While Nike and many other companies are quick to act with corrective action plans when these investigations are publicized (Institute of Public \& Environmental Affairs, 2012), it does attest to the difficulties in monitoring hundreds of contracted suppliers. Nike utilizes 1,034 contracted factories where $380(36 \%)$ are located in China (Nike Inc., 2012).

Research on the types of codes, the information and the effectiveness of these codes is largely unexplored in the apparel industry despite the prominence and development of codes to reduce the incidences of labour right violations, and occupational health and safety. A study by Emmelhainz and Adams (1999), reviewed 24 codes of conduct from prominent retail brands in the US. It was found that while many companies had developed codes, there was limited uniformity; they lacked specific details and operational guidelines to aide with implementation. To ensure compliance with codes, it is necessary to monitor and enforce through auditing. Audits fall into three categories: internal monitoring conducted by company employees, contracted auditing through private firms, and external monitoring through multistakeholder NGO's such as the Fair Labour Association (FLA) (Dickson et al., 2009). A study by the Clean Clothes Campaign (CCC) (Pruett \& CCC, 2005) argues that announced audits allow factories to hide violations, and is very critical of any audits performed by apparel brands/retailers or private firms. 
The CCC is a strong advocate of organizations such as the FLA or local organizations in conducting audits.

A major problem with the apparel industry and its shift to contracted suppliers is that suppliers are now faced with multiple codes from the various apparel brands whose products they produce. This creates audit fatigue, as each apparel brand will conduct routine monitoring to ensure compliance with their code of conduct. This also presents many challenges for the supplier who enters into multiple compliance agreements with various codes that are not uniform, do not provide operational guidelines or directly conflict with one another. Suppliers subsequently spend long amounts of time preparing and altering operations to meet various requirements when preparing for audits (Locke, Qin, \& Brause, 2007). The development of a sectorial code of conduct such as the UNGC-NICE code is an attempt to remedy problems such as audit fatigue and multiple code agreements. Hemphill (2004) proposes that if selfregulation in this global industry is to be successful, there is a need for strong accountability mechanisms, and the adoption of aggressive transparency policies for audits. The FLA is the most prominent external verification audit organization in the apparel industry. Audits performed on apparel brands belonging to the FLA are publicly available on their website. A survey of stakeholders found that formal external verification was the most important factor contributing to credibility and can improve reliability of information and accountability to increase stakeholder confidence (Epstein, 2008).

In 1999 companies such as adidas, Nike, Puma, H\&M, and American Eagle Outfitters formed the Fair Labour Association (FLA) "to find sustainable solutions to systemic labour issues" (FLA, 2012). The FLA believes that all products should be produced ethically and fairly. The FLA serves as a central body to perform independent third party audits and provide the results in a public forum (FLA, 2012). Today many codes of conduct are now based upon the internationally agreed human rights and environmental standards of the United Nations (UN) Declaration of Human Rights, the International Labour Organization (ILO) Declaration on Fundamental Principles and Rights at Work as well as other ILO conventions, UNGC and the Rio Declaration on Environment and Development (Dickson et al., 2009). While media coverage has lessened throughout the last decade, it is still a major issue within the industry (Dickson et al., 2009). Codes of conduct are implemented to contracted tier one or two suppliers that apparel brands work with directly. However the further down the supply-chain, the less control the apparel brand has on suppliers. Apparel brands rarely engage directly with raw material suppliers such as cotton farmers. Codes of conduct do not extend this far down the supply-chain. Unfortunately, many of the same problems exist such as the use of child labour for cotton harvesting in Uzbekistan (Environmental Justice Foundation, 2012). The WHO suggests that three million pesticide poisonings occur per year that result in 20,000 deaths in developing nations among the rural poor (Glin, Kuiseu, Thiam, Vodouhê, Dinham, \& Ferrigno, 2010).

Many major apparel companies began to develop codes of conduct as the primary means of addressing labour right violations (Dickson et al., 2009). The supplier code of conduct was meant to 
provide standards for fair labour practices, safe and healthy working, and eliminate the use of child labour (Esbenshade, 2004). Levi's was one of the first companies to develop a code of conduct for labour standards and working conditions, and implemented their code of conduct for their key suppliers. While many codes of conduct have been adopted by apparel brands, monitoring and enforcing is key. It is a concern that some codes are not enforced beyond requiring the supplier to sign off that the factory is in compliance with the code (Esbenshade, 2004). Although monitoring is the most common way to determine compliance with a company's code of conduct and their contract suppliers (Dickson et al., 2009), the effort is time consuming and difficult due to a lack of industry wide standards, and suppliers that must comply with multiple codes.

Companies like Nike, Levi's, adidas, Gap Inc., and Timberland have emerged as leaders in socially responsible apparel production and sourcing. These brands have suffered from significant reputational damage due to the highly publicized sweatshop scandals but have since implemented auditing protocols to reduce labour rights violations (Waddock \& Bodwell, 2004).

\subsection{5 - Sustainable Apparel Coalition (SAC)}

The SAC is a multi-stakeholder engagement, formed in 2011, by a group of global apparel and footwear companies and non-profit organizations representing nearly one third of the global market share for apparel and footwear. The SAC seeks to build a common approach for measuring and evaluating apparel and footwear product sustainability performance (Sustainable Apparel Coalition, 2012). It aims to develop common measurements, and a common environmental understanding of products' impacts across the industry by building on the Outdoor Industry Association (OIA)'s Eco Index ${ }^{\mathrm{TM}}$ and Nike's Environmental Design tool. The Eco Index ${ }^{\mathrm{TM}}$ is a standardized tool for measuring the environmental impacts of outdoor products such as boots, clothing and tents and evaluates the impacts in six key areas of a product's life cycle: materials, packaging, product manufacturing and assembly, transport and distribution, use of service, and end of life (Sustainable Apparel Coalition, 2012). Nike's Environmental Design tool measures the environmental impacts of apparel and footwear. Measuring performance of apparel and footwear products will spotlight priorities for action, and opportunities for technological innovation (Sustainable Apparel Coalition, 2012).

The Higg index 1.0 is an "indicator based tool for apparel that enables companies to evaluate material types, products, facilities and processes based on a range of environmental and product design choices" (Sustainable Apparel Coalition, 2012, "The Higg Index," para. 3). The scope for the desired outcome's of the SAC Higg Index 1.0 tool include improvements to: reduce water use and improve quality, reduce energy and emissions, minimizing waste, reduce chemicals and toxicity, and increase transparency for social and labour issues. The first version of the Higg Index 1.0 tool was released in June 2012 was based on life cycle thinking and is publicly available for any organization (Sustainable Apparel Coalition, 2012). The Index tool was developed to measure the environmental impacts of apparel 
products. The tool evaluates material type, products, and facilities and processes. By utilizing practicebased, qualitative binary yes/no questions, assessments can be made as to the sustainability performance of product and drive behaviour for improvement. By helping organizations standardize measurement and evaluation of environmental performance, the tool creates a starting point for engagement, education, and collaboration among stakeholders. Through self-assessment, organizations can better understand the environmental impacts that occur throughout the life cycle and the effect of design choices such as material type. Self-assessment can teach through identification of negative environmental impacts where opportunities for improvements exist (Sustainable Apparel Coalition, 2012). Future releases of the Higg Index will expand the scope to include footwear products, and social and labour impacts.

\subsection{6 - SAC apparel brands}

There are fourteen apparel brands belonging to the SAC: H\&M, Gap Inc., Nike, adidas, Puma, Patagonia, Mountain Equipment Co-op (MEC), Levi's, Hanesbrand, Marks \& Spencer (M\&S), Esprit, Columbia, Timberland and Loomstate.

Nike, Columbia, adidas and Puma are all sportswear performance companies producing footwear, apparel and sports equipment. Nike and Columbia are American companies while adidas and Puma are German companies. All four companies are publicly traded multi-nationals. Patagonia and MEC are outdoor apparel companies that are known for their commitments to environmental responsibility and environmental initiatives. Patagonia is a private retailer that is sold internationally. MEC is a co-operative that sells outdoor recreation equipment along with apparel and footwear. Their products are available internationally through their website but retail locations are limited to Canadian cities. Timberland is an American retailer that primarily a footwear retailer that also sells casual outdoor apparel products. Timberland is a publicly traded company that sells its products internationally.

Esprit and Loomstate are American casual apparel retailers that are committed to environmental responsibility. Esprit is a multi-national company while Loomstate is a small private retailer that sells internationally through their website. H\&M is a Swedish publicly traded company that is one of the world's largest fast fashion companies. H\&M is known for offering trendy fashion apparel products at an affordable price point. Gap Inc., Levi's and Hanesbrand are American casual wear companies that manufacture specialty apparel products for the mass market. Gap Inc. and Levi's manufacture apparel products but are well known for their denim jeans. Levi's, a private retailer, is an internationally known denim brand with a strong commitment to social responsibility. Hanesbrand is also a publicly traded multi national that specializes in basics such as t-shirts, underwear and socks. M\&S is a department store that sells fashionable mass market apparel at a low price point and is sold only in the UK. 


\section{6 - Motivation for Research}

The literature review highlights the development of the apparel industry and how it has led to increased rates of consumption, and significant environmental and social impacts. While there has been a response by the industry through the development of CSR, CSR reporting, and codes of conduct, there have been no evaluations as to the effectiveness of these responses. There is one case study that evaluated the CSR reports of Nike and adidas in comparison to the GRI G3 guidelines, highlighting the difficulties in comparing CSR reports that utilize the GRI guidelines. The GRI AFSS is the only guideline available to the apparel industry in aiding with sustainability indicator selection, and reporting. Any literature on CSR performance evaluation, the actions, initiatives, and the use of indicators is limited to the publicly available CSR reports put forth by the apparel brands themselves. Other than the study by Sherman (2009), there has been no other research that addresses the CSR actions and initiatives, summarizes the indicators used or attempts to provide a current understanding of CSR reporting in the apparel industry across multiple brands. There is a lack of literature that addresses the notion of sustainability in the apparel industry in a holistic manner, as many studies are limited to aspects such as consumer behaviours, textile disposal or environmental impacts. 


\section{3 - Research Questions}

This research seeks to review and explore the publicly available reported CSR reports of the SAC apparel brands. CSR indicators are used as a means to report the CSR actions and initiatives. Apparel brands that are members of the SAC are considered to be self-declared industry leaders in sustainability. SAC is the largest initiative undertaken by multiple stakeholders to address the environmental and social impacts of the apparel industry. The central research question and the related sub-questions are outlined below.

\section{1 - Central Question}

The central question for this research study is:

Is the current CSR reporting by the SAC apparel brands effectively measuring their CSR performance?

\section{2 - Sub Questions}

The following sub-questions have been developed to help address the central question.

- What CSR indicators are currently reported by the SAC apparel brands?

- What is the distribution of the reported CSR indicators within the five elements of the apparel system?

- Are the reported CSR indicators comparable across multiple SAC apparel brands?

- What is the total number of reported indicators by each SAC apparel brand?

- How do the SAC apparel brands compare based on number of reported indicators?

- Based on the reported indicators, what conclusions can be made as to the progress towards sustainability by the SAC apparel brands? 


\section{4 - Methods}

This research focuses on reviewing the content of the publicly available reported CSR information published by the 14 apparel brands belonging to the SAC. A qualitative analysis leads to the creation of a comprehensive database of indicators used by the apparel brands to report their CSR actions and initiatives. A model is constructed based on suggestions for transforming the apparel industry presented in Fletcher and Grose's (2012) Fashion \& Sustainability: Design for change, and the observed themes among the collected indicators from the SAC brands CSR reports. The model represents the five elements of the apparel system which a company would engage to progress towards sustainability. The indicators are categorized and grouped within the elements and an analysis is conducted to determine the type, distribution, and comparability of the reported indicators. The apparel brands are subsequently compared based on the number of reported indicators within the five elements and a cross case analysis is conducted. The analysis addresses the question as to the effectiveness of CSR reporting as a tool for measuring progress towards sustainability. A synopsis of the research method, modified from Noor (2008) is illustrated in Figure 2. Noor describes case study research into three stages: preliminary, analysis, and conclusion. Noor developed a theoretical framework to structure and guide case study research.

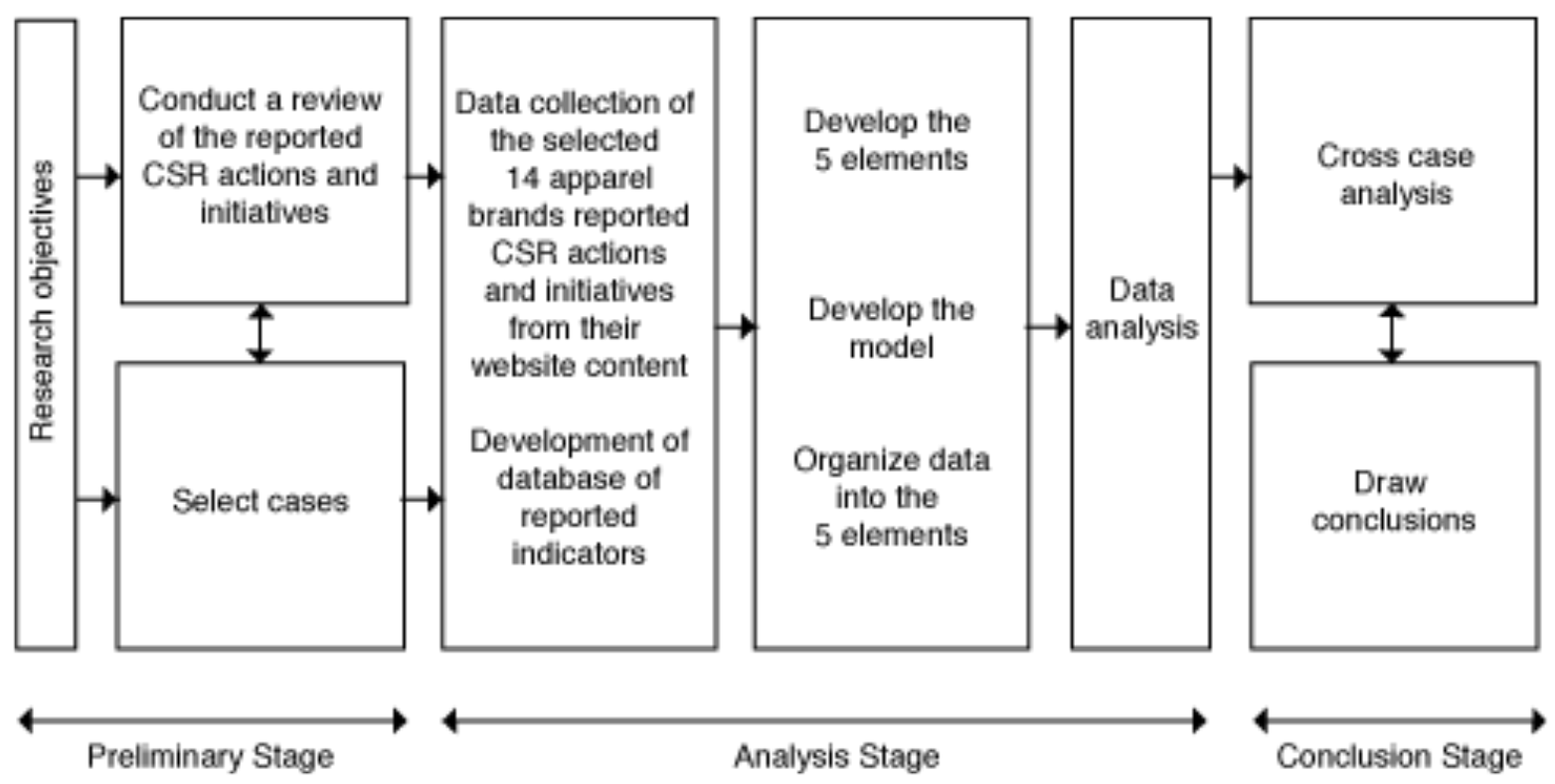

Figure 2: Synopsis of research method

\section{1 - Scope}

This research focused on the publicly available information regarding the CSR actions and initiatives of apparel brands belonging to the SAC. The SAC was founded by a group of sustainability leaders within the apparel and footwear industry. This multi-stakeholder collaboration's main objective is to develop an industry wide tool for measuring environmental and social performance of apparel products. 
This is the largest industry wide sustainability initiative to date. Publicly available information referred to all information found on the apparel brands' websites. This included annual reports, CSR reports, accountability reports, governance, environmental reports, interactive media, company blogs, news updates, and product information published on the website.

\section{2 - Multiple Case Studies}

This research is a qualitative multiple case study of all the apparel brands that are members of the SAC as of September 10, 2011. The SAC was chosen due to its recent creation by multiple apparel brands and other types of organizations in an effort to improve the environmental and social performance of the industry (Sustainable Apparel Coalition, 2012). Case study as a method of research is chosen because it allows for an in-depth study of a contemporary phenomenon within a real-life context utilizing multiple sources of evidence (Yin, 2009). The intent of a case study is to examine a particular issue, not an organization as a whole, and to investigate a contemporary phenomenon that has received little attention or focus in the past (Noor, 2008). A multiple case study research design is adopted to examine a number of cases within the same sector (Yin, 2009). The apparel brands that are members of the SAC are the case studies, and not the SAC as an individual organization. The apparel brands belonging to the SAC, as listed in Table 1, are a good representation of the various types of North American and European apparel retailers that make up the industry. Nike, adidas, Puma, and Columbia will provide insight into the challenges of making performance products sustainable. Timberland, Patagonia, MEC and Loomstate represent apparel brands where there is an intrinsic dedication to the environment. MEC is a co-operative while Loomstate would qualify as a small to medium enterprise, and is the only brand that has been recently founded. Levi's and Hanesbrand are casual wear companies that provide staple wardrobe basics such as t-shirts and jeans, and have a limited product range. Gap Inc., H\&M, M\&S and Esprit are fashion brands, and will present the difficulties in incorporating sustainability into a business model defined by selling high-volume, low-cost products. The challenges for fast fashion brands are in waste reduction, material quality, and the longevity of designs and trends. The contemporary phenomenon to be studied is the effectiveness of CSR reporting as a tool to measure CSR performance in progressing towards sustainability in the apparel industry.

Table 1: List of apparel brands belonging to the SAC, founding year, type of retailer and location of headquarters as per the corporate websites.

\begin{tabular}{llll}
\hline Apparel Brand & Founded & Type of Retailer & HQ Location \\
\hline adidas & 1949 & Sporting Goods & Germany \\
Columbia & 1938 & Active Outdoor Apparel & United States \\
Esprit & 1968 & Lifestyle & United States \\
Gap Inc. & 1969 & Specialty & United States \\
Hanesbrand & 1901 & Consumer Goods & United States
\end{tabular}




\begin{tabular}{llll} 
H\&M & 1947 & Fast Fashion & Sweden \\
Levi Strauss \& Co. & 1873 & Branded Apparel & United States \\
Loomstate & 2004 & Casual & United States \\
$\begin{array}{l}\text { Marks \& Spencer (M\&S) } \\
\text { Mountain Equipment }\end{array}$ & 1884 & Department & United Kingdom \\
Co-op (MEC) & 1971 & Co-operative Outdoor & Canada \\
Nike & & & \\
Patagonia & 1964 & Athletic Apparel \& Footwear & United States \\
Puma & 1965 & Active Outdoor & United States \\
Timberland & 1948 & Sports \& Lifestyle & Germany \\
\hline
\end{tabular}

\section{3 - Data Collection and Model Development}

The first objective of this study was to compile a database of all reported CSR information and indicators by the 14 SAC apparel brands. For the purpose of this study, indicators refer to a measure of performance and inform in a quantitative or qualitative manner, information about a situation or results of an action (Thompson, 2002). Therefore all CSR information that represents the CSR actions and initiatives of the SAC apparel brands is considered to be an indicator of the SAC apparel brand's progress towards sustainability. First, all the CSR-related information was read meticulously in its entirety. CSR information is collected from the websites; including all CSR reports, annual reports, frequently asked questions, blogs, social responsibility sections, product information, and interactive media of the SAC apparel brands. The websites included the corporate websites and country specific websites. For example, Levi's and Hanesbrand have American, European, and corporate websites. While the majority of the CSR information is on the corporate website, certain information related to products is found on the country-specific website. For example, Hanesbrand uses organic cotton in its European product line only, and information regarding organic cotton use was limited to the European website.

Web based reporting was chosen as the Internet has become a key form of communicating information. Information presented on websites is intended for stakeholders, is publicly available, and easily accessible. Whether an apparel brand has chosen to develop a CSR report or not, there is an expectation that the type of information available will be somewhat consistent in the form of environmental and/or social actions and initiatives such as reduction of energy use, water use, and partnerships with environmental or social organizations. The format and delivery of the information, however, is not consistent, as certain SAC apparel brands did not have a formal CSR, sustainability or environmental report. Many apparel brands have chosen alternative methods for reporting their actions and initiatives such as a blog, a dedicated social responsibility section or interactive media. These alternative methods are used in the absence of a formal report or in conjunction with a formal report.

Initial data collection resulted in the construction of a comprehensive database with a total of 300 reported indicators and CSR information. This initial database is not limited to CSR indicators and includes descriptive information such as number of employees and countries with retail locations. Integrity 
of the language used in the reported CSR information was maintained. This includes the use of phrases and terminology such as capacity building for non-compliant suppliers. A complete list of the collected information that forms the database is provided in Appendix A. As the collected information is reviewed, multiple categories emerged based on observed similarities, and the information was subsequently grouped into these categories. The observed similarities resulted in the following categories as listed in Table 2.

Table 2: Categories resulting from the observed similarities from the database of collected information.

\title{
Observed Categories
}

\author{
CSR Descriptive \\ Profile \\ Share Listings \\ Employees \\ Suppliers/Vendors/Factories \\ Public Policy \\ Codes of Conduct \\ Audits \\ Collaborations/Multi-Stakeholder Initiatives/Memberships \\ Certifications \\ Consumer Engagement \\ Raw Materials \\ Goals/Targets \\ Progress \\ Energy Efficiency and Climate Change \\ Water Conservation \\ Waste \\ Hazardous Chemicals \\ Design
}

The second objective of the study is to devise a model that depicts the apparel industry elements where engagement is necessary to progress towards sustainability. The reasoning for the model is a result of a logical deduction; CSR reporting is a communication of CSR performance, and CSR performance is a combination of actions, initiatives, and indicators that represent progress towards sustainability. Fletcher and Grose (2012) discuss in their book Fashion \& Sustainability that the current apparel system is unsustainable, and to extrapolate upon the current system with the expectation of achieving sustainability is not feasible. Sustainability will only be achieved with change to the system (Fletcher \& Grose, 2012). Armstrong and LeHew (2011) support the notion that the apparel industry has begun to progress towards sustainability but a shift of the entire system is necessary. Therefore the rationale is to develop a model that incorporates the core elements of the apparel system as illustrated in Figure 2. The five elements that make up the model are a disaggregation of the three major aspects that Fletcher and Grose present. These three aspects are: transformation to design practice, transformation of 
the apparel system, and transformation of fashion products. Ideas such as consumer engagement, garment end-of-life strategies, innovative business strategies, and sustainable supply-chain management are embedded within the three aspects that Fletcher and Grose cite as required transformations to achieve sustainability. However, this resource is developed for designers, therefore the focus and organization of these common elements to the apparel industry such as sustainable supply-chain management differ.

The purpose of this research is to look at the effectiveness of the current CSR reporting by the SAC apparel brands in measuring their CSR performance and progress towards sustainability. This study will analyze the associated indicators used to measure the SAC apparel brands CSR actions and initiatives. The five elements in this devised model are a representation of the core aspects related to sustainability and the apparel industry as observed from the reported CSR information collected, and those presented by Fletcher \& Grose (2012). The categories that emerge within the database of the collected CSR information are quite similar to those presented by Fletcher \& Grose (2012). The categories from the database are aggregated and aligned with ideas presented by Fletcher \& Grose (2012) to develop the final five elements. The five elements are: sustainable supply-chain management, design practice, product sustainability, business innovation, and consumer engagement. Sustainable supply-chain management is further sub-divided into environmental and social responsibility. The model is arranged to show which elements an apparel brand has direct control over, those elements where there is less control, and the relationship between the elements. A detailed explanation of the individual elements is provided in chapter five. The elements of the apparel system model is illustrated in Figure 3.

The use of the model will aid in fulfilling the third and fourth objectives of this study that address the research questions. Indicators are categorized within the elements, which will then provide a general understanding of the distribution of the reported indicators. The apparel brands will then be compared based on the number of reported CSR indicators. The reported information is not a complete reflection of an apparel brands CSR actions and initiatives, as the disclosure of CSR information is a voluntary act. It can be inferred however, that the reported CSR indicators reflecting an apparel brands CSR actions and initiatives are representative of their efforts, and the areas related to these efforts. Essentially the model is used to provide clarity as to which aspects of the apparel industry the brands are reporting indicators.

Categorization of the indicators within the five elements is based on a systematic approach. The initial database was used as a reference point as the categories that emerged in the database are reflections of how the indicators were categorized by the apparel brands. For example, the use of audits to monitor factory and supplier compliance was categorized as either social responsibility or supply-chain management. If the indicator was categorized by the apparel brand under social responsibility, a subheading indicating this was a supply-chain action was present as well. Therefore many of the indicators were already organized into a category. The Apparel and Footwear Sector Supplement (AFSS) pilot version by the GRI is utilized as a reference as to the type and categorization of indicators that are 
specific to the apparel industry. While the GRI is an important and widely accepted tool for sustainability reporting, the GRI AFSS indicators are limited to 34 sector-specific performance indicators. These indicators fall into four categories: supply chain standards and practices, economic, environmental and social (GRI, 2011). The AFSS pilot version by the GRI recognizes that not all indicators may be applicable to the various organizations that compromise the apparel sector (GRI, 2011). There is no other industrywide guideline that addresses CSR reporting, development of indicators or on sustainable development.

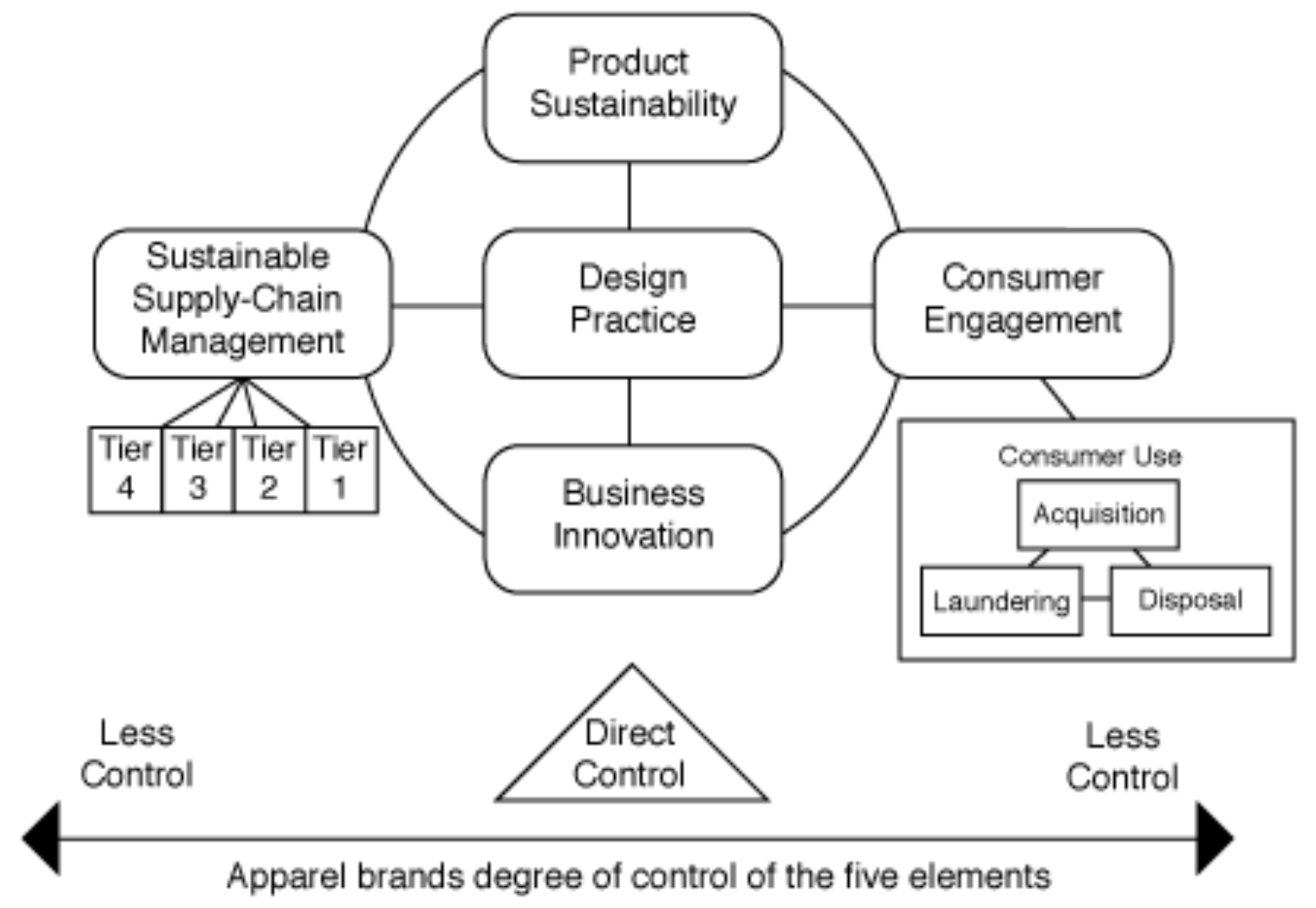

Figure 3: Illustration of the elements of the apparel system.

In the original database there are redundancies and areas where information could be amalgamated to streamline the data. The following example illustrates the approach used to streamline the data into the final 87 indicators that are categorized and analyzed. The SAC apparel brands report differently on their use of organic cotton. H\&M reported the use of organic cotton with a metric eg., in 2010 organic cotton use was 15,000 tonnes. Nike reports the use of over 10 million $\mathrm{kg}$ of organic cotton in 2010, Patagonia has only used $100 \%$ organic cotton since 1996 and Puma stated it had used larger volumes of organic cotton in 2010. Therefore to assign an indicator that can amalgamate the various forms of reported information, a binary yes/no question was developed; does the apparel brand use organic cotton? Many indicators in the initial database did not have comparable metrics. Indicators associated with social responsibility have no standardization as to the metrics to be used, and an apparel 
brand may not use the same metrics every year. An example of this is one apparel brand may report hours of collective agreement training for employees at contracted supplier facilities. While another apparel brand may report the number of contracted employees who received training for collective agreements at supplier facilities. This type of reporting makes comparability extremely difficult. However, these indicators could be interpreted as symbolic in showcasing good citizenship to stakeholders. H\&M reported that since 2008, 440,000 workers in Bangladesh have received training on their rights. Puma reported on workers' rights in two different manners. In Egypt, 57 workers were educated on their rights while in Turkey, training on the awareness of women's and worker's right was mainly focused on female staff. This example highlights the difficulty encountered in comparability of the same indicator by one apparel brand in the same report as illustrated in Table 3. Therefore the indicator that was developed to represent worker training within the supply-chain was a simple binary yes/no question; does the apparel brand provide training for workers in their supply-chain? It is acknowledged that there are varying degrees to the participation of each apparel brand, and any given indicator. For example, one brand may use $5 \%$ organic cotton in all cotton products while another uses $50 \%$ organic cotton in $25 \%$ of its product. The scope of this research, however, is to determine a baseline of reported indicators. This helped to provide insight on the CSR actions and initiatives of the SAC apparel brands and whether current CSR reporting is effectively measuring their CSR performance and progress towards sustainability. This approach is utilized for the entire database and resulted in the final 87 indicators: product sustainability (17), design practice (25), sustainable supply-chain management (45), consumer engagement (9), and business innovation (7). A list of the 87 indicators is provided in Table 4.

Table 3. Excerpt from Puma Annual Report 2010, training and certification of Puma's suppliers (Puma, 2011:45)

\begin{tabular}{|l|l|l|}
\hline Workers' Rights in Egypt & Egypt & $\begin{array}{l}\text { Workers awareness training conducted at an apparel supplier in Egypt. Topics: Human, women and workers' } \\
\text { rights issues. The training was carried out with } 3 \text { trainers and } 2 \text { coordinators, with coordination of a local NGO } \\
\text {-BASHAR. The training covered } 57 \text { employees and took place in one working day. }\end{array}$ \\
\hline Workers' Rights in Turkey & Women's rights and workers' rights awareness training, mainly focusing on female staff. \\
\hline
\end{tabular}

Many of the indicators were categorized into more than one element based on the role and relationship of that indicator to the elements. For example, the use of organic cotton as an indicator places it into three elements: sustainable supply-chain management, product sustainability, and design practice. The use of organic cotton versus conventional cotton renders a product more sustainable, the use of organic cotton is a decision made during the design process, and reduces environmental and social impact in the supply-chain. This decision also references the context in which apparel brands report on organic cotton use. When reporting, the reduced environmental impact of organic cotton is always mentioned; the apparel brands explain the benefit of their decision to use organic cotton. The use of the term "product" and "sustainable" are also used in reference to the use of organic cotton. At this point in 
the research, keyword searches on the brands websites were utilized to verify the categorization of the data into these refined indicators and elements. Each indicator was assessed as to its role and relationship to the five elements, and was subsequently categorized into the elements where a relationship exists.

Table 4: Complete list of final 87 indicators and their categorization within the five elements of the apparel system.

\section{List of indicators}

Categorization

$\mathrm{PS}=$ product sustainability; $\mathrm{DP}=$ design practice $; \mathrm{SSCM}=$ sustainable supply-chain management;

$\mathrm{CE}=$ consumer engagement $\mathrm{BI}=$ business innovation

\begin{tabular}{|c|c|}
\hline Use organic cotton & PS, SSCM \\
\hline Use certified organic cotton & PS \\
\hline Use Better Cotton (BCl) & PS \\
\hline Use environmentally preferred cotton & PS \\
\hline Do not use Uzbekistan cotton & PS, SSCM \\
\hline Phasing in recycled polyester & PS \\
\hline Use recycled polyester & PS, SSCM \\
\hline Use certified recycled polyester & PS \\
\hline Use other environmentally preferred materials & PS, SSCM \\
\hline Use up to $5 \%$ environmentally preferred materials within products & PS \\
\hline Use up to $10 \%$ environmentally preferred materials within products & PS \\
\hline Use $50 \%$ or more environmentally preferred materials within products & PS \\
\hline Use $100 \%$ environmentally preferred materials within products & PS \\
\hline Use cotton/polyester blends & PS, DP \\
\hline Have a special collection for sustainable products & PS, CE \\
\hline Limit PVC use/phasing out & PS \\
\hline No PVC's in products & PS, DP, SSCM \\
\hline Have sustainability training/education for designers & DP \\
\hline Review current research & DP \\
\hline Have conducted a LCA & DP \\
\hline Use/reference a LCA & DP \\
\hline Use a index tool & \\
\hline Design for environment approach & DP \\
\hline Have sustainability initiatives integrated throughout product ranges & DP \\
\hline Have a sustainable product guideline & DP \\
\hline Have a material guideline/database & DP \\
\hline Have a restricted substance list & DP, SSCM \\
\hline Phasing out PVCs & DP, SSCM \\
\hline Reduce number of colour used & DP \\
\hline Reduce color combinations & DP \\
\hline Reduce material combinations & DP \\
\hline Reduce product range/styles & DP \\
\hline Increase pattern efficiency & DP \\
\hline Reduce/use textile waste & DP \\
\hline Have an environmental guidelines regarding textile wet processing & DP \\
\hline Use Bluesign $\AA$ standard & DP, SSCM \\
\hline Use Safe Chemistry & DP \\
\hline Have a sandblasting ban for denim products & DP, SSCM \\
\hline
\end{tabular}


Use environmentally preferred materials

Use of low-impact dye

Use key performance indicators (KPI)

Reducing water use

DP

Use waterless dyeing

DP, SSCM

Phasing in waterless dyeing

Committed to Greenpeace Zero Discharge of Hazardous Materials campaign

SSCM

SSCM

SSCM

VOC reduction

SSCM

SSCM

Waste reduction

SSCM

GHG measurements/reduction

SSCM

Reducing energy use in manufacturing

SSCM

Use environmentally preferred rubber

Use recycled material

Have a packaging reduction target

Have a Code of Conduct for suppliers

SSCM

Code of Conduct is publicly available

SSCM

SSCM

SSCM

SSCM

Have a policy for subcontractor approval and compliance to the Code of Conduct

SSCM

Compliance with local laws

SSCM

ILO/UN/FLA guidelines used for Code of Conduct development

SSCM

Have an implementation guide for Code of Conduct

SSCM

Perform audits on suppliers

SSCM

Perform unannounced audits on suppliers

SSCM

Implement capacity building and corrective actions for non-compliance

SSCM

Use a supplier ranking system

SSCM

Encourage EMS implementation amongst suppliers

SSCM

Supplier list is publicly available

Use traceability/'String' programs

Use alternative to conventional cotton (Better Cotton, Fairtrade)

Have requirements for silica levels

Member of the Global Compact

SSCM

SSCM

SSCM

SSCM

SSCM

SSCM

Member of the Fair Factories Clearinghouse (FFC)

SSCM

Member of the Better Cotton Initiative

SSCM

Member of the Organic Exchange

SSCM

Member of the Fair Labour Association

SSCM

Member of the International Labour Organization

SSCM

Member of the ILO Better Work

SSCM

Member of the Leather Working Group

SSCM

Encourages washing/drying behaviours that have less

CE

negative impact on the environment

Have a clothing take-back program

Have a footwear take-back/recycling program

Encourage donation/re-use/re-sell of products

Have a product take/back/recycling program

$\mathrm{CE}$

CE

CE

Have a permanent product take-back/recycling program

CE, BI

Provide special care and repair services/instructions

$\mathrm{CE}, \mathrm{BI}$

Have a label/logo identifying sustainable products

$\mathrm{CE}, \mathrm{BI}$

Design/product project collaboration

CE

Collaboration for end-of-life product recycling/re-use

Share best practices within the industry

Implementing closed loop/C2C strategies

$\mathrm{BI}$

BI

BI

BI 


\section{4 - Data Analysis}

A qualitative analysis was conducted on the initial data set and the collected information was organized into categories. These data were reduced to a final set of 87 indicators that are presented in a binary yes/no question format. This final set of data was categorized into the five elements of the apparel system model and subsequently entered into Microsoft Excel. Multiple spreadsheets were created, one for each element. Each spreadsheet contained the selected indicators and the SAC apparel brands. The following coding was used in Excel: $0=$ indicator not reported and $1=$ indicator reported. Figures and tables were created using the data sets in the spreadsheets for each element. An analysis was conducted to answer to the research questions in section 3. 


\section{5 - Elements of the Apparel System Model}

The following chapter describes the rationale of the apparel system model. The following subsections describe the elements of the apparel system and descriptions of the indicators found within each element.

The goal of sustainable apparel is to create a system that can be supported indefinitely in terms of economics, environmental, and social responsibility. The dominant business model in the apparel industry has for the past two decades, been reliant on producing and selling vast amounts of apparel. This business model benefits from large economies of scale that maximize profits with significant negative environmental and social impacts; an unsustainable apparel system (Fletcher \& Grose, 2012). Meadows (2008) describes a system as an interconnected set of elements that are coherently organized in a manner that achieves something and creates its own pattern of behavior over time. Application of Meadows (2008) definition of a system to the apparel industry is logical as the apparel industry is a functioning system with interconnected elements and its own set of distinct behavioural patterns. Fletcher and Grose (2012) state that the current apparel system is unsustainable and to extrapolate on the current system will not lead to a sustainable system. The current apparel system and its distinct behavioural pattern must transform. Meadows (2008) explains that once the structure of a system is identified and understood, the relationship between structure and behaviour can be explored. Understanding the relationship between structure and behavior allows for understanding of how the system works, what makes them produce poor results, and how to alter for better behaviour patterns (Meadows, 2008). The rationale for the apparel system model as illustrated in Figure 3 , is to better understand the elements that make up the apparel system and their interconnected relationships.

The elements represent various aspects of the apparel system. Addressing problems within the individual elements, while recognizing its interconnections in the system, a new system can begin to be developed. Addressing the problems within a single element will not significantly alter the system. If a product is sustainable but the system itself is not sustainable, the full potential of the product is underutilized. For example, a biodegradable t-shirt cannot simply be discarded but must be composted under ideal conditions (Fletcher \& Grose, 2012). Benefits arising from improvements to the sustainability of apparel products are subject to restrictions by the production system, business models that market and sell apparel products and the behaviours of consumers who purchase these apparel products. Therefore, all elements within the apparel system require transformation to achieve whole system transformation. By categorizing the 87 reported indicators within the elements, a better understanding of the distribution of the CSR actions and initiatives by the SAC apparel brands will be provided.

While financial responsibility is a vital element of any business, this is one aspect that does not

require transformation. The responsibility to remain profitable is a core business operation. Within sustainability, financial responsibility could be viewed as equally important as environmental and social 
responsibility, as a non-profitable company would cease to exist. CSR reporting is a means of communicating CSR performance in progressing towards sustainability. However, definitions on CSR highlight a discrepancy as to whether financial responsibilities are considered a part of CSR. Carroll's (1991) Pyramid of Corporate Social Responsibility shows that corporations have economic responsibilities. The economic responsibilities are the foundation for all other responsibilities: legal, ethical and philanthropic. Carroll (1991) includes economic and legal responsibility into his definition of CSR and thereby questions the voluntary act of CSR. In contrast, the EU defines CSR as a concept that integrates environmental and social responsibility into business operations on a voluntary basis. The economic and legal responsibilities of a corporation are considered business operations (EU, 2011). For the purpose of this study and the development of the apparel system model, CSR is defined as per the EU. Therefore the model does not address economic responsibility as an element of the apparel system but an inherent responsibility of an apparel brand.

While the apparel systems model is holistic in its approach, it is imperative to have a complete understanding of the five elements. Understanding of the individual elements creates a better understanding of how these elements interconnect, the resulting behavioural patterns, and how the system functions as a whole.

\section{1 - Product Sustainability}

Product sustainability is the easiest aspect to alter for an apparel brand, as this is where a company has the most and direct control through design and product development (Armstrong \& LeHew, 2011; Fletcher \& Grose, 2012). Transforming product sustainability may be achieved via various aspects such as fibre/textile selection, processing methods, use behaviours, and reuse/recycle strategies. Fibre/textile selection is often the first step that designers and product developers will take in reducing the environmental impact of a garment, as it is a quick and can be on the sales floor within months. Environmentally preferred fibres/textiles can significantly reduce the environmental impact, and increase the resourcefulness of an apparel product throughout the garments life cycle without change to design practice or product development processes (Graedel \& Allenby, 1995; Ljungberg, 2007; Fletcher \& Grose, 2012). Alternative fibre/material selection can be limited by the supply-chain and the business system of which the fibres/materials belong to. Offering consumers an alternative choice is not dealing with the deeper issues such as increasing consumption rates (Fletcher \& Grose, 2012).

Product sustainability is quite variable as it can range from a simple shift to an environmentally preferred material to altering product characteristics such as end-of-life strategies. End-of-life strategies such as recycling or decomposition require a holistic approach that work in tandem with other aspects of the apparel system; altered design practices, sustainable supply-chain management, consumer engagement, and business innovation. These sustainability initiatives generally take form as specialized "eco" collections, which are quite visible to the consumer or are integrated throughout various products 
eg., introducing a 5\% organic cotton blend into all cotton products. At the moment, aside from environmentally preferred materials, there is limited visibility to the consumer of other sustainable characteristics such as the use of low-impact dyes or the absence of sandblasting techniques on denim. This could be due to current labeling schemes, as there is no requirement or regulation concerning this type of information. Most countries do not even have regulation in place for organic fibre content of clothing,

The indicators that have been chosen to represent achievements in product sustainability were developed as a direct observation of the reported information from the corporate websites, and fibre content of products available from the selected apparel brands. The majority of the indicators refer to the use and amount of environmentally preferred materials such as recycled polyester, organic cotton or Better Cotton, which incorporates environmental and social responsibility into its agricultural practices. The Better Cotton Initiative $(\mathrm{BCl})$ is a global voluntary multi-stakeholder initiative whose aim is to develop sustainable global cotton production practices. They define sustainable cotton production to be financially profitable for the growers while reducing the negative impacts of water and pesticide use on human and environmental health $(\mathrm{BCl}, 2012)$. The organization functions by the principle of continuous improvement and education as they strive to build a better cotton industry. Indicators that looked at various amounts of environmentally preferred materials were included to provide an indication of a level of commitment in using these materials. The content percentages (e.g. $5 \%$ environmentally preferred material and $10 \%$ environmentally preferred material) were developed from observations made as to the percentages most commonly used by the apparel brands belonging to the SAC. An indicator that looks at whether the apparel brand utilizes cotton from Uzbekistan was included as there is much controversy surrounding its use. This is mainly due to the child labour that is employed by the Uzbekistan government and the excessive use of pesticides and water that has resulted in the massive diminishment of the Aral Sea (Environmental Justice Foundation, 2012; Fletcher \& Grose, 2012), Many apparel brands in an effort to be more ethical have banned the use of cotton originating from Uzbekistan under a pledge by the Responsible Sourcing Network (Kilner, 2011) This is difficult as most apparel brands are unaware of where their cotton originates from due to a lack of transparency in the supply-chain that reaches the raw material suppliers (Dell, 2011). The use of polyvinyl chloride (PVC), a known carcinogen, has been included as it forms dioxins upon incineration. Certain PVCs are composed with phthalates (an endocrine disrupter), and many apparel/footwear brands have committed to phasing PVC out since the early 2000s (Kamila, 2003; McDonough, Braungart, Anastas, \& Zimmerman, 2003; Moore, 2011). The cotton/polyester blend indicator was utilized to assess a level of commitment to producing sustainable products. A cotton/polyester blend is deemed unsustainable as it cannot be recycled or decomposed due to the mixing of biological and technical nutrients (fibres) (Braungart, 2002; Fletcher \& Grose, 2012). 


\section{2 - Design Practice}

The design phase and product development processes are key phases where modifications can have a significant impact. These processes present many opportunities for designers to introduce and integrate the dimensions of sustainability (Dickson et al., 2009; Armstrong \& LeHew, 2011). The greatest opportunity to reduce environmental and social impacts occurs through the decisions designers makes during these key phases. However, sustainable approaches to design and product development are still relatively new (Walker, 2006). The Centre for Sustainable Fashion (2008) found that while designers are becoming more aware of and rethinking their role in creating sustainable fashion, they are finding it difficult to work within a sustainable framework. This could be due to the fact that research shows characteristics such as colour, style, price and fit are the strongest predictors for apparel acquisition as opposed to social or environmental considerations (Dickson \& Littrell, 1996; Kim \& Damhorst, 1998; Kim \& Damhorst, 1999; Shaw \& Tomolillo, 2004; Joergens, 2006). Research by Kim and Damhorst (1998) indicated that regardless of consumers having a pro-environmental attitude, it was rare that they engaged in eco-conscious apparel acquisition. This highlights the importance of a designer creating apparel, which appeals to consumers purchasing the product, thereby ensuring financial goals while pursuing objectives of enhancing environmental and social sustainability.

A challenge for designers will be to approach design with a systems view where the relationships between producers and consumers are better understood. It is important for designers to consider the behaviours of consumers from acquisition, use, and disposal, to design a product where the consumer understands the added environmental and social value. Producing apparel with the intention of consumer engagement to repair, recycle or reuse is futile if the garment is of low quality with a low price point. These garments deteriorate more quickly and there is no point in trying to repair them when they are ready to be thrown away. It is just as cheap to re-purchase new garments as opposed to repairing, and they usually cannot be reused because they are un-wearable. Designing for recyclability is affected by textile and fibre choice, which ultimately affects how the consumer will use and dispose of the garment. For example, as the price of cotton continues to increase, there is a greater use of cotton blends such as cotton/polyester to keep manufacturing costs low. This blending eliminates the recycling and decomposition potential as it is a mix of biological and technical nutrients that cannot be separated at end-of-life (Braungart, 2002; Fletcher \& Grose, 2012). Recycling of apparel becomes difficult if garments are screen printed, contain zippers or other metallic hardware, thread, labels, buttons and/or fusings. Therefore the only indicator that is not a direct observation from the apparel brands CSR reporting is one that looked at whether the apparel brands utilized biological/technical blends. Removal of these types of blends would be indicative of a high level of sustainability-orientated design.

The use of index tools such as the Outdoor Industry Association's Eco Index ${ }^{\mathrm{TM}}$ (Sustainable Apparel Coalition, 2012) or material databases with rating systems can aid designers in selecting materials with less environmental and social impacts right from the outset. The selection of a material that 
is less carbon-intensive from the onset can affect change up and down the supply-chain (Fletcher \& Grose, 2012). Betsey Blaisdell, a senior manager of environmental stewardship for Timberland explains,

It's like preventive health care...It's hard to say to a factory, You have to do the clean-up, if the product is designed to create pollution. But when we can provide designers and developers with credible, practical, and universal standards for measuring environmental performance, then they can make more sustainable choices. (Sustainable Apparel Coalition, 2012).

Design for Environment (DfE), is a systematic approach where considerations concerning the environment and human health are made at the product design stage (Pui-Yan Ho \& Choi, 2012). Cradleto-Cradle (C2C) design is a biomimetic approach that incorporates the principles of how ecosystems function and works under the motto "waste = food" (Braungart, 2002). Essentially creating systems where there is no waste, and products when recycled should not lose value. For example, a biodegradable tshirt requires thought at the design stage because every effort should be made to extract the same value from the garment (i.e. recycling) as opposed to biodegradation where value is lost (high-energy garment vs. low-energy compost) (Fletcher, 2008). Figure 4 shows a cradle-to-cradle or closed-loop product life cycle developed by the United Nations Environmental Program. These alternative approaches allow suppliers to focus more on sustainable solutions rather than audits and testing. For example, designing a graphic on a t-shirt to achieve certain effects is determined by method and type of ink used such as plastisol which contains PVC. The decision to eliminate the use of phthalate and plastisol inks can influence the design or can lead to innovations in alternative processes to achieve the same effect. The use of alternative inks and processes will affect the recyclability of the garment and fibre at end-of-life. The decision to eliminate PVC relieves the supplier from the subsequent environmental and occupational health and safety impacts from using the PVC, testing by governing bodies for the presence of PVC and audits.

\section{3 - Sustainable Supply-Chain Management}

The apparel life cycle commonly includes seven stages (Figure 5), and the supply-chain consists of phases from raw material acquisition to the retail environment. A supply chain is all the activities that are involved in moving goods from the raw material phase to the end consumer. Apparel brands have direct control typically over the design, distribution, retail sales, and any other business orientated activities such as the marketing of apparel products. Apparel brands seldom manufacture any of the products they sell under their brand name as it is subcontracted to suppliers, and mostly located in developing nations (Jones, 2006) (Sherman, 2009). The supply-chain can be further segmented into tiers as illustrated in the apparel systems model (Figure 2). Apparel brands typically organize suppliers into these tiers for organizational purposes. Tier 1 (manufacturing) is where apparel brands will typically have a moderate to high influence. As we move further down the chain to tier 2 (outsourced processes), tier 3 
(textile and fibre processing/mills) and tier 4 (raw materials), lack of control increases and transparency decreases (Jones, 2006; Fletcher, 2008; Lim \& Phillips, 2008). The difficulty in exerting influence over tier 2,3 , and 4 suppliers is that apparel brands do not deal directly with these suppliers; a disadvantage of a fragmented supply-chain. Once the product is sold to the consumer, the apparel brand virtually loses all control over the rest of the life cycle. This lack of influence and control over the two opposite ends of the life of an apparel product creates challenges in implementing sustainability initiatives and actions.

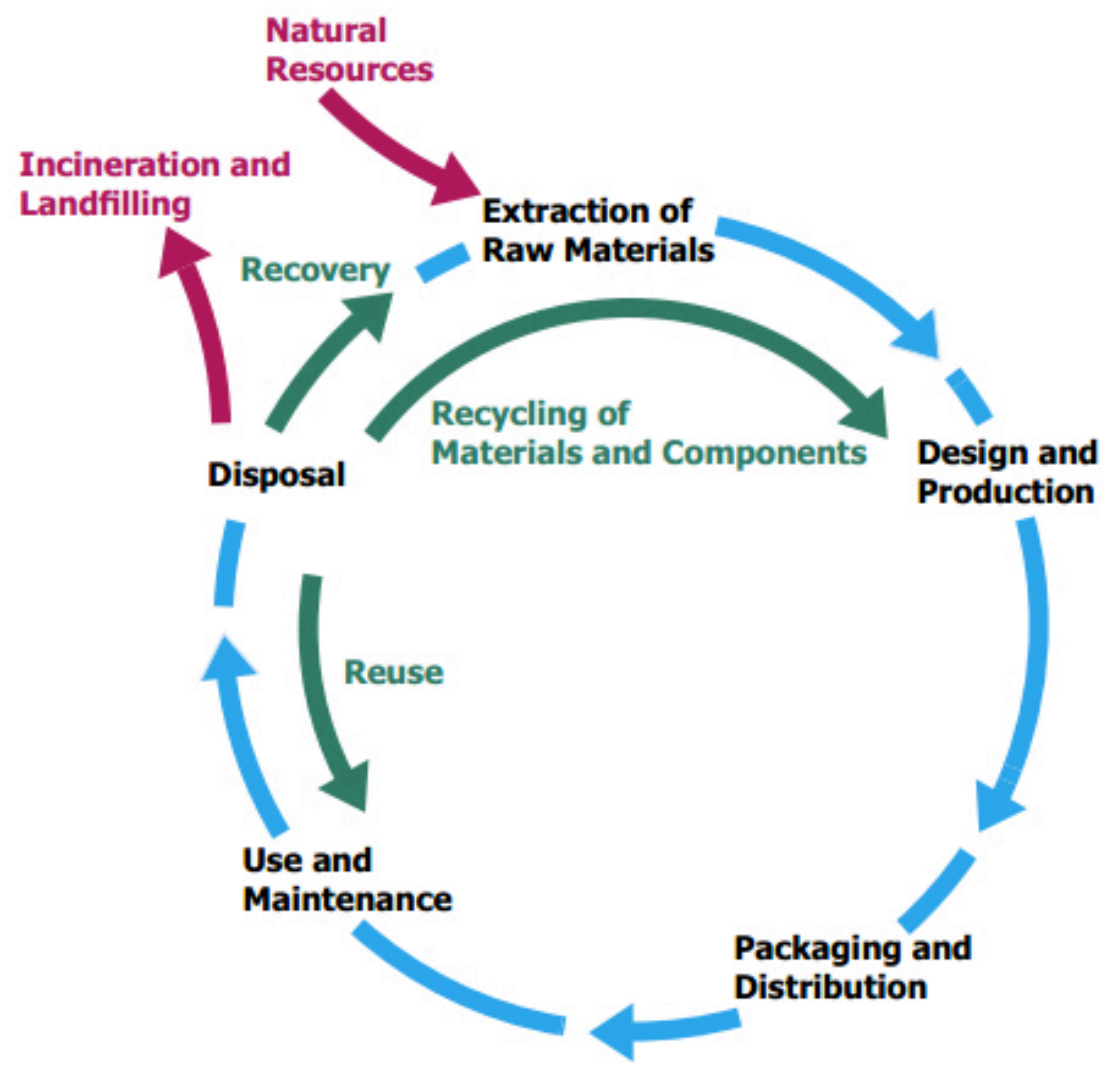

Figure 4: The Product Life Cycle as developed by the United Nations Environmental Program (Remmen, Astrup, \& Frydendal, 2007)

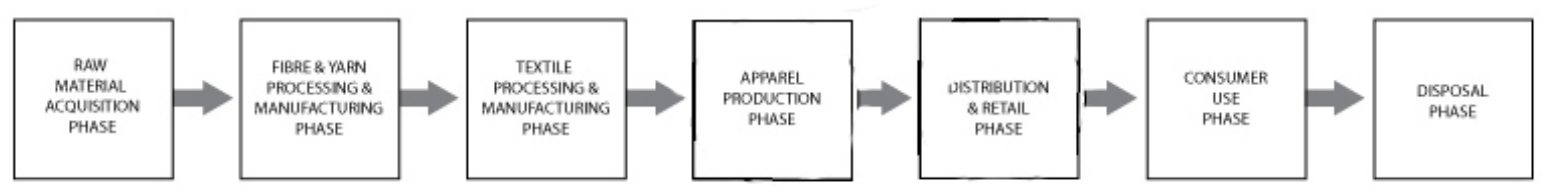

Figure 5: The apparel supply-chain. 
Despite sustainable supply-chain management gaining prominence in CSR strategies there are still many questions as to what a sustainable supply-chain is, and what the defining characteristics that make a supply-chain sustainable are. Some of the key characteristics mentioned in the literature are transparency, development of codes of conduct, auditing, and capacity building (Wong \& Taylor, 2000; Allwood et al., 2006; Carter \& Rogers, 2008; Fletcher, 2008; Bhaduri \& Ha-Brookshire, 2011; GRI, 2011). Transparency is a significant factor in developing a sustainable supply-chain. Transparency is important in building customer loyalty, brand image, business legitimacy, safety standards, and product quality as it shows the movement of source materials, processes involved, contracted suppliers, and distribution channel members (Carter \& Rogers, 2008; Strutnin, 2008). It allows consumers to see how and where the products that they purchase are produced (NICE, 2012). Transparency engages stakeholders as to the business practices of an apparel brand and allows for accountability.

The indicators for sustainable supply-chain management have been divided into two subelements: environmental and social responsibility. The environmental indicators look at reductions and measurements at the supplier level for waste, water, energy, and greenhouse gases such as employing waterless dyeing processes, measuring greenhouse gases or utilizing key performance indicators. The use of hazardous chemicals is determined through the employment of Bluesign ${ }^{\circledR}$ textile standards, the most rigorous and holistic textile standard, a public pledge to Greenpeace's Zero Discharge campaign, use of a restricted substance list, and reductions to volatile organic compounds (VOCs). Indicators such as those looking at PVC use are repeated through multiple phases, as the impacts are not limited to one area. PVC use affects product sustainability, design practice, manufacturing processes, and has occupational health and safety issues.

The social indicators assess the use of codes of conduct for suppliers, their implementation and compliance, audits, audit reviews, and ranking of suppliers to distinguish those with better compliance records. Capacity building is included as many of the apparel brands indicated a preference to work towards compliance before terminating a relationship and to reward those with high-standing compliance. Occupational health and safety issues have been included such as the ban of the sandblasting to distress denim, a popular process since the 1980s that gives jeans a "worn-in" look using silica sand. This technique is extremely hazardous to worker's health when exposed to silica dust, which can lead to an acute and fatal form of silicosis, a serious pulmonary disease (Akgun et al., 2005; Riddselius, 2010; Clean Clothes Campaign, 2012). Researchers in Turkey had found that $83 \%$ out of 145 sandblasters had respiratory problems and over half developed silicosis after an average work period of 1-120 months (Akgun. et al., 2008). In the Akgun (2008) study it was found that workers typically worked for ten hours a day, six days a week and when production orders were high they would work twelve hour days, seven days a week. A typical worker could sandblast 250-500 pairs of jeans a day or 3,000-5,000 skirts/day. Workers were generally provided with one mask a day, in some places none were provided. Conservative estimates suggest that the Bangladesh garment industry employs over 2,000 workers as full-time 
sandblasters for garment exports (Clean Clothes Campaign, March 2012). Sandblasting is quick and extremely cheap comparatively to alternative methods, resulting in its widespread use throughout the apparel industry. While there is very strict regulation on the use of sandblasting in manufacturing in the $\mathrm{EU}$, this regulation is avoided as the majority of apparel is produced in developing countries. These countries not only lack the regulation to protect workers, it has been found they are rarely provided with the adequate safety equipment and the process is usually performed in un-sealed environments (Akgun, 2008; Riddselius, 2010; Clean Clothes Campaign, 2012). While there are many occupational health and safety issues related to sandblasting, it also speaks to the volume of clothing being produced. As a modest calculation, if one worker on average sandblasts a minimum of 250 jeans a day, 6 days a week for a year that is 78,000 pairs of jeans a year per worker. Bangladesh employs approximately 2,000 sandblasters. At an estimated 78,000 pairs of jeans per worker completed, this equates to $156,000,000$ pairs of jeans sandblasted in Bangladesh at a minimum.

Issues such as sandblasting only reinforce the need for transparency and accountability in the apparel supply-chain. This is a significant aspect for consumers because without transparency and supplier disclosure it is impossible for a consumer to tell if an item has been sandblasted. Therefore, other indicators such as public availability of supplier lists, membership to NGOs that support worker rights, and new product tracing methods have been included. Memberships to certain organizations such as the Fair Labour Association (FLA) that perform and publish external audit results (FLA, 2012) are indicative of a higher level of commitment, as it opens up FLA member brands to increased transparency, accountability, and acknowledges the importance of collaborative efforts. Contracted supplier of FLA members must submit to regular unannounced audits by FLA auditors and must commit to implementing required changes. Indicators for social responsibility performance are the most developed as worker rights violations were the first publicized shortcomings of the apparel industry. The development of codes of conduct was one of the first and widely applied CSR initiatives within the apparel industry. The GRI AFSS lists twenty-two out of 34 indicators that are related to social responsibility (GRI, 2011).

\section{4 - Consumer Engagement}

While the fashion and apparel industry offers very positive results economically from the perspective of the apparel brands, the environmental and social aspects have suffered. The behaviour of apparel brands must change for the betterment and sustainable development of the apparel system. Apparel brands are responsible for the structure of the system, the movement to off-shore production and the subsequent shift to cheaper, low-quality goods that evolved into a quantity over quality driven consumer behaviour. This is a result of years of molding consumer behaviour to purchase new styles on a weekly basis, and refresh their wardrobes seasonally with inexpensive, accessible apparel. Now the industry is attempting to reverse these behaviours while maintaining the same structure. This is not to say that the consumer is exempt from any responsibility concerning the state of the current apparel system. 
The relationship between apparel brands and consumers is extremely important in the pursuit of sustainability. Engaging with stakeholders such as the consumer can help in establishing a vision for social responsibility (Dickson et al., 2009). This process is fundamental for improving social responsibility and subsequently sustainable development. Achieving sustainability requires all participants in the apparel system to recognize that extrapolating on the current system will not work because the current system and the relationship between consumers, apparel brands, and apparel products is the very antithesis to sustainability (Fletcher \& Grose, 2012).

It is not just behaviours that have changed but how consumers have defined value. Consumers have learned to value quantity and attribute little value to the resources needed to produce these goods. Consumers need to learn how to make more sustainable choices in the purchase, use, care of, and disposal of apparel items by informing, creating awareness, and value. Economist Herbert Simon, describes bounded rationality as "people can make reasonable decisions based on the information they have, however, they may not have information on all parts of a system, especially the distant parts" (Meadows, 2008:106). This is how the consumer functions within the apparel industry, information of the distant parts of the system such as the environmental impacts of cotton or viscose, sandblasting processes, and labour abuses are beyond their scope, thus not affecting the decision-making process or behaviours in consuming apparel products. "The least obvious part of the system, its function or purpose, is often the most crucial determinant of the system's behaviour. Interconnections are also critically important. Changing relationships usually changes system behaviour" (Meadows, 2008:17). Today, decisions regarding purchasing of apparel products are based on information that is prominent and widely available. In Western countries this is generally trend-based fashion information and what is needed to achieve the latest look. While consumers are familiar with terms like "organic" or "fair trade" they are commonly attributed more widely to food products such as produce or coffee, as opposed to clothing. As the apparel industry progresses towards greater environmental and social consciousness, the involvement of consumers in the process and eco-conscious consumption of apparel is equally important (Connell, 2011).

Hethorn and Ulasewicz (2008) mention that the role of apparel brands within the market, and ultimately the consumer needs to be viewed differently to progress towards sustainability. Hethorn and Ulasewicz specifically promote a holistic approach to defining consumer preferences and that successful eco fashion requires that the consumer be placed as a focal point in the design process. Gaining insight into the environmentally friendly apparel consumption behaviours will aid apparel brands in developing strategies that promote these behaviours (Connell, 2011). Hustvedt and Dickson ( 2009) found that the acquisition of environmentally friendly apparel increases when consumers understand how apparel production affects the environment. However, efforts need to extend to altering use and disposal behaviours as those have the largest environmental impacts of apparel consumption. Hethorn and Ulasewicz (2008) argue that fashion is an excellent platform to create awareness for sustainability as it is 
embedded in a system of communication and is ubiquitous. New processes and concepts are needed to alter how apparel is designed, used, disposed, recycled or reused; extending the life span of the products and the meaning they bring (Hethorn \& Ulasewicz, 2008).

\subsection{1 - Extended producer responsibility}

Extended producer responsibility (EPR) is a CSR trend that is expressed through design change in packaging, apparel maintenance and disposal. It is defined by the Organisation for Economic Cooperation and Development (OECD) (Stevens, 2004) as an environmental policy approach where a producer's responsibility for a product extends to the post-consumer phase of that product's life cycle. The intent is to provide incentives for companies through design change to reduce waste, improve recyclability and reusability. The challenge with EPR is that it requires the consumer to be informed and engaged in the EPR innovations and strategies of an apparel brand. The degree of innovation can take various forms, product or production processes such as the return of products for recycling. However, for this strategy to function and work effectively depends on the citizen to actively place the disposing product into the right container for the respective system (collection or recycling). Therefore consumer awareness

is key in informing and motivating consumers to participate in recycling or collection systems. The main reasons for consumers not participating are insufficiency of the current collection systems and lack of information (Quodon, 2004). Currently there are no EPR policies in place for the apparel industry but it can take advantage of other EPR policies in place for other products. Investments into recycling PET bottles led to the development of polyethylene terephthalate (PET) fleece highlighting the unpredictable innovations that can create a new product or market (Stevens, 2004).

However, as an apparel brand moves forward, it is evident that consumer engagement is vital in promoting sustainable consumption behaviours and creating a sustainable apparel system.

\section{5 - Business Innovation}

Over-consumption and the negative environmental and social impacts are a result of how the apparel industry operates today. It is clear the business, structure and operation of the apparel system needs to change (Fletcher \& Grose, 2012). Developing a transparent supply-chain and substituting more environmentally friendly materials are not enough to alter the current operational methods of the industry into one that is sustainable. Apparel brands must change their relationships with stakeholders along the entire supply-chain, including consumers. It has to be more than just offering and choosing a better product; consumption, design and business relationships and behaviours must change. If a garment is designed to be recycled, the apparel brand must engage the consumer to promote return of the product. A system must also be in place to allow for the full exploitation of the recyclability of the product (Fletcher \& Grose, 2012). The system itself must be adjusted to accommodate the sustainability of the product from design through to disposal. 
The fashion industry routinely references historical fashions as a source of inspiration for current collections. It should be looking towards the heritage of fashion for inspiration on how to become more sustainable and not just for the purpose of aesthetics. Apparel and fashion dating to pre-industrial times was about quality, repair, longevity, the reuse of garments and embodied the idea of slow fashion. Apparel brands are beginning to offer repair services but it is limited to those specializing in outdoor apparel or non-fashion items. This does beg the question whether the industry should move towards better and smarter consumption or could apparel exist in a closed loop system that sustains the current disposable, throw-away approach. Meadows (2008:3-4) states "a diverse system with multiple pathways and redundancies is more stable and less vulnerable to external shock than a uniform system with little diversity." Conceivably the industry could move toward multiple business strategies that encompass the ideals of sustainability where apparel is produced in a manner with no environmental or social impacts. The creation of a diverse system employing cradle-to-cradle and design for environment ideologies could satisfy consumer's appetite for all types of apparel from sportswear to fashion. Therefore the indicators in this element look at the various strategies that apparel brands have undertaken thus far which are limited to the idea of diverting apparel waste from landfills. 


\section{6 - Results}

The results are presented below in several subsections. Section 6.1 briefly presents some background CSR information on the SAC apparel brands. This is followed by section 6.2, which presents a summary of the CSR indicators per element, reflecting the actions, and initiatives of the SAC apparel brands. Section 6.3 presents the results of the analysis of the distribution of the indicators within the five elements while Section 6.4 provides a comparison of the apparel brands based on number of reported indicators.

\section{1 - Background CSR information}

Of the 14 apparel brands analyzed only eight had developed a CSR report that was in a downloadable .pdf format and publicly available on their website. Of those eight apparel brands, six had referred to the GRI G3 guidelines. Out of the six who referenced the GRI G3, Timberland, H\&M and adidas also utilized the GRI AFSS. Out of the 14 apparel brands, 10 are publicly traded and only four (H\&M, Nike, adidas and Puma) trade on the Dow Jones Sustainability Index. While it is common for publicly traded companies to develop annual or CSR reports, four of the publicly traded apparel brands did not publish CSR reports (Hanesbrand, Levi's, Esprit and Columbia). Table 5 illustrates the reported indicators per apparel brand.

Table 5: CSR descriptives

\begin{tabular}{|c|c|c|c|c|c|c|c|}
\hline $\begin{array}{l}\text { Apparel } \\
\text { Brands }\end{array}$ & $\begin{array}{c}\text { CSR } \\
\text { Report }\end{array}$ & $\begin{array}{c}\text { GRI } \\
\text { G3 }\end{array}$ & $\begin{array}{c}\text { GRI } \\
\text { AFSS }\end{array}$ & $\begin{array}{c}\text { CSR } \\
\text { Team }\end{array}$ & $\begin{array}{c}\text { Conduct } \\
\text { review/verification/ } \\
\text { gap analysis of } \\
\text { CSR report }\end{array}$ & $\begin{array}{c}\text { Publicly } \\
\text { Traded }\end{array}$ & $\begin{array}{l}\text { Dow Jones } \\
\text { Sustainability } \\
\text { Index }\end{array}$ \\
\hline H\&M & $\checkmark$ & 2 & $\sqrt{2}$ & $\sqrt{ }$ & $\checkmark$ & $\checkmark$ & $\sqrt{ }$ \\
\hline GAP Inc. & $\checkmark$ & & & $\sqrt{ }$ & & $\checkmark$ & \\
\hline Nike & $\checkmark$ & 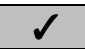 & & $\checkmark$ & & $\checkmark$ & $\checkmark$ \\
\hline adidas & $\checkmark$ & $\sqrt{ }$ & $\sqrt{2}$ & $\checkmark$ & & $\checkmark$ & $\checkmark$ \\
\hline Puma & 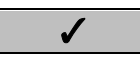 & 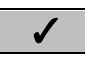 & & $d$ & $\sqrt{ }$ & $\checkmark$ & $\checkmark$ \\
\hline Patagonia & & & & $\sqrt{ }$ & & & \\
\hline MEC & $\checkmark$ & & & & & & \\
\hline M\&S & $\sqrt{ }$ & $\sqrt{ }$ & & $\sqrt{ }$ & $\checkmark$ & $\checkmark$ & \\
\hline Hanesbrand & & & & & & $\sqrt{ }$ & \\
\hline \multicolumn{8}{|l|}{ Levi's } \\
\hline Esprit & & & & & & $\checkmark$ & \\
\hline Timberland & $\sqrt{ }$ & $\sqrt{ }$ & $\checkmark$ & $\sqrt{ }$ & & $\sqrt{ }$ & \\
\hline Columbia & & & & & & $\checkmark$ & \\
\hline \multicolumn{8}{|l|}{ Loomstate } \\
\hline TOTAL & 8 & 6 & 3 & 8 & 3 & 10 & 4 \\
\hline
\end{tabular}




\section{2 - Indicators per Element}

\subsection{1 - Product sustainability}

H\&M has the most reported indicators within this element with 17. MEC has the second highest amount of reported indicators (15), followed by Timberland (14), adidas (13), Nike (12), Patagonia (11) and Puma and Hanesbrand with nine. The remaining six apparel brands (Gap Inc., M\&S, Levi's, Esprit, Columbia and Loomstate) reported less than half of the indicators. Table 6 provides a summary on the number of apparel brands that reported each indicator within the product sustainability element.

Table 6: Summary of reported indicators within product sustainability

Indicator

\begin{tabular}{ll}
\hline Use cotton/polyester blends & 13 \\
Use organic cotton & 11 \\
Phasing in recycled polyester & 11 \\
Use environmentally preferred cotton & 10 \\
Use recycled polyester & 9 \\
Use 100\% environmentally preferred materials within products & 9 \\
Use certified organic cotton & 8 \\
Use up to 5\% environmentally preferred materials within products & 8 \\
Use 50\% or more environmentally preferred materials within products & 8 \\
Limit PVC use/phasing out & 8 \\
Do not use Uzbekistan cotton & 7 \\
Use other environmentally preferred materials & 7 \\
Have a special collection for sustainable products & 7 \\
Use Better Cotton (BCI) & 6 \\
Use up to 10\% environmentally preferred materials within products & 5 \\
Do not use PVC & 4 \\
Use certified recycled polyester & 3 \\
\hline
\end{tabular}

Eight apparel brands reported on the limited use and phasing out of PVCs in their products and only four apparel brands reported on the elimination of PVCs in their products. There are nine apparel brands (H\&M, MEC, Timberland, adidas, Nike, Patagonia, Puma, Esprit and Loomstate) that offer 100\% organic and/or recycled polyester products. The use of organic cotton and the phasing in of recycled polyester were the two most commonly reported indicators across all the apparel brands. Product sustainability was highly correlated to the use of alternative environmentally preferred materials with organic cotton and recycled polyester being reported the most. Eleven out of the 17 indicators within this element are related to fibre selection. There was very little disclosure as to the hazardous chemical aspect in product sustainability other than PVC use.

Loomstate is the only apparel brand that uses $100 \%$ environmentally preferred materials such as organic cotton or Tencel ${ }^{\mathrm{TM}}$ and do not use cotton/polyester blends in any of its product ranges. Patagonia has introduced a more sustainable blend such as cotton/Tencel ${ }^{\mathrm{TM}}$, cotton/modal and all cotton products 
are $100 \%$ certified organic. MEC is the only other brand that offers $100 \%$ certified organic cotton through all cotton product ranges. There was one indicator that assessed the level of sustainability of products produced by the apparel brands, the use of cotton/polyester blends. Of the 14 apparel brands, 13 offer a cotton/polyester blend and/or cotton/spandex blend. While there were many reported indicators for product sustainability, they were predominately variations on the substitutions of environmentally preferred materials and the phasing out of PVCs.

\subsection{2 - Design practice}

adidas has the most reported indicators with 20 out of the 25 indicators within this element. Ten of the brands, while reporting a design for environment approach, mostly subscribe to alternative environmentally preferred materials and dye substitutions for a limited product range. Columbia, for example, has initiatives that are limited to substitutions such as the use of recycled polyester and ColorCore $^{\mathrm{TM}}$. Color-Core ${ }^{\mathrm{TM}}$ is a process for dyeing synthetic materials that utilizes $80 \%$ less water. One of the highest reported indicators by 10 of the apparel brands is the use of a RSL, the use of a sustainable product guideline, a design for environment approach, and the increased use of textile scraps and waste being integrated into other products.

The lowest number of reported indicators dealt with more advanced design practices that increase product sustainability. These included the use of Bluesign ${ }^{\circledR}$, Safe Chemistry, elimination of PVCs, sandblasting ban for denim, reducing colour and product ranges, increasing pattern efficiency, and looking at colour and material combinations. Patagonia was the only one who did not report on the use of a index tool in supplementing the design practice. Patagonia reported very little information on design practice in comparison to the other apparel brands. Table 7 provides a summary on the number of apparel brands that reported each indicator within the design practice element.

Table 7: Summary of reported indicators within design practice.

\section{Indicator}

\section{Number of apparel brands that reported}

\begin{tabular}{lc}
\hline Use environmentally preferred material & 13 \\
Use cotton/polyester blends & 13 \\
Design for environment approach & 10 \\
\hline Have a sustainable product guideline & 10 \\
Reduce/use textile waste & 10 \\
Have sustainability training/education for designers & 9 \\
Have sustainability initiatives integrated throughout product ranges & 9 \\
Have a restricted substance list & 8 \\
Phasing out PVC's & 8 \\
Use of low-impact dye & 8 \\
Review current research & 7 \\
Have conducted a LCA & 7 \\
Use a index tool & 6 \\
\hline
\end{tabular}




\begin{tabular}{ll} 
Use/reference a LCA & 5 \\
Have a material guideline/database & 5 \\
\hline Have an environmental guideline regarding wet textile processing & 5 \\
\hline No PVCs in products & 4 \\
Reduce colour combinations & 3 \\
Use Bluesign® standard & 3 \\
Reduce number of colours used & 2 \\
Reduce product range/styles & 2 \\
Increase pattern efficiency & 2 \\
Have a sandblasting ban for denim products & 2 \\
Reduce material combinations & 1 \\
Use Safe Chemistry & 1 \\
\hline
\end{tabular}

\subsection{3 - Sustainable supply-chain management}

Sustainable supply-chain management is comprised of two subsections: environmental and social.

\subsubsection{1 - Environment}

Of the 19 indicators, Nike reported on 15 followed by adidas, Puma and MEC with 14, H\&M (12), Timberland (11), Levi's (9), Patagonia (8), M\&S (7), Loomstate (5) and Gap Inc., Columbia and Esprit with four, three and two respectively. Packaging reduction targets are reported on by 12 of the 14 apparel brands while 10 apparel brands reported the use of key performance indicators (KPIs) for suppliers and GHG measurements and/or GHG emission targets.

Eight out of the 14 apparel brands reported on the phase out of PVCs from products, while three out of the eight have completely eliminated PVCs. The use of RSL is reported by 10 apparel brands while Puma, Patagonia and MEC utilize the Bluesign ${ }^{\circledR}$ standard. Only six apparel brands, H\&M, Nike, adidas, Puma, MEC and Levi's have publicly agreed to participate in Greenpeace's Zero Discharge campaign. Eight of the 14 SAC brands produce footwear and two out of the eight reported the use of environmentally preferred rubber.

\subsubsection{2 - Social}

Levi's had 24 reported indicators out of the possible 25 . Nike was second with 23 , followed by H\&M and adidas with 21 and Timberland with 20. Gap Inc. reported 14 along with M\&S while Columbia reported 13 indicators. The lowest reports were Loomstate and Esprit with three reported indicators.

The use of a code of conduct is reported by every apparel brand and are publicly available by all except for Esprit and Loomstate. Every apparel brand is also a member of the FLA, however Esprit and Loomstate are the only two brands that do not report as to the use of the FLA labour guidelines in developing their code of conduct. Every apparel brand except for Esprit and Loomstate reported on the 
use of audits, a supplier ranking system, improving transparency/traceability, capacity building and remediation actions for non-compliance. Eleven of the brands reported on performing unannounced audits. H\&M, Levi's and Timberland all reported on their ban to eliminate the use of sandblasting on denim and have silica level requirements for their suppliers. Membership to labour rights NGOs like FLA and ILO was greatest in regards to social responsibility within sustainable supply-chain management. Many of these organizations are collaborative efforts to reduce the incidences of labour rights violations and improve the auditing process. The majority of the brands had high levels of engagement for this element other than Esprit and Loomstate. Table 8 provides a summary on the number of apparel brands that reported each indicator within the sustainable supply-chain management element.

Table 8: Summary of reported indicators within sustainable supply-chain management.

\section{Indicator \\ Number of apparel brands that reported}

\section{Environmental}

Have a packaging reduction target 12

Use organic cotton 11

Use key performance indicators (KPI) 10

GHG measurement /reduction 10

Use recycled polyester $\quad 9$

Phasing out PVCs $\quad 8$

Waste reduction $\quad 8$

Have a restricted substance list $\quad 8$

Use recycled material $\quad 8$

Use of low-impact dye $\quad 8$

Use other environmentally preferred materials $\quad 7$

Reducing water use $\quad 7$

VOC reduction $\quad 7$

$\begin{array}{ll}\text { Reducing energy use in manufacturing } & 7\end{array}$

Phasing in waterless dying $\quad 5$

Committed to Greenpeace Zero Discharge of Hazardous Materials campaign 5

No PVCs in products $\quad 4$

Use Bluesign ${ }^{\circ}$ standard 3

Use environmentally preferred rubber 2

Use waterless dying 0

\section{Social}

Have a Code of Conduct for suppliers $\quad 14$

Member of Fair Labour Association 14

Code of Conduct is publicly available 12

ILO/UN/FLA guidelines used for Code of Conduct development 12

$\begin{array}{ll}\text { Performs audits on suppliers } & 12\end{array}$

Implement capacity building and corrective actions for non-compliance 12

Use a supplier ranking system 12

Use alternative to conventional cotton (Better Cotton, Fairtrade) 12

Perform unannounced audits on suppliers 11 


\begin{tabular}{lc} 
Have a policy for subcontractor approval and compliance to the Code of Conduct & 10 \\
Have an implementation guide for Code of Conduct & 10 \\
Compliance with local laws & 9 \\
Member of organic exchange & 9 \\
Encourage EMS implementation amongst suppliers & 8 \\
Use traceability/'String' programs & 8 \\
Member of International Labour Organization & 8 \\
Supplier list is publicly available & 7 \\
Do not use Uzbekistan cotton & 7 \\
Member of Fair Factories Clearinghouse (FFC) & 7 \\
Member of Better Cotton Initiative & 6 \\
Member of Leather Working Group & 6 \\
Member of Global Contact & 5 \\
Member of ILO Better Work & 5 \\
Have a sandblasting ban for denim products & 3 \\
Have requirements for silica levels & 3 \\
\hline
\end{tabular}

\subsection{4 - Consumer engagement}

MEC had the highest reported level of consumer engagement with eight reported indicators out of nine. Patagonia and H\&M reported six indicators followed by Timberland, Hanesbrand and Puma with five and Nike, adidas, M\&S and Levi's who reported four. Loomstate and Gap Inc. reported two and Esprit and Columbia did not report. Nine out of the 14 apparel brands reported having a product recycling and takeback program. Environmentally preferred laundering behaviours for consumers is one of the lowest reported indicators as was special care and repair to increase the longevity of a garment. Seven of the apparel brands produce special eco collections where six identify these collections with a special label or logo. Six brands encourage donation or resell of garments. This element had very little reported indicators by the majority of the apparel brands. Table 9 provides a summary on the number of apparel brands that reported each indicator within the consumer engagement element.

Table 9: Summary of reported indicators within consumer engagement.

\begin{tabular}{lc}
\hline Indicator & Number of apparel brands that reported \\
\hline Have a product take-back/recycling program & 9 \\
Have a clothing take-back program & 7 \\
Have a permanent product take-back/recycling program & 7 \\
Have a special collection for sustainable products & 7 \\
Have a footwear take-back/recycling program & 6 \\
Encourage donation/re-use/re-sell of products & 6 \\
Have a label/logo identifying sustainable products & 6 \\
Encourage washing/drying behaviours that have less negative impact on environment & 3 \\
Provide special care and repair services/instructions & 2 \\
\hline
\end{tabular}

\subsection{5 - Business innovation}


Nike, Patagonia, MEC and Timberland reported five indicators out of a possible seven. Puma had four reported indicators while adidas, M\&S and Levi's all had three. This element, along with consumer engagement has the lowest number of reported indicators among the apparel brands. The indicator most often reported by nine of the 14 brands is the implementation of a recycling or take-back program. There is an indicator that further distinguishes between take-back programs that were limited to a time period and those that are collaborative efforts such as Gap Inc.'s Recycle Your Blues campaign with Cotton Incorporated, Bonded Logic and Habitat for Humanity. Only five brands reported the phasing in of closed loop, C2C practices while only four of the apparel brands, Nike, Levi's, Timberland and Columbia reported initiatives to share best practices. Patagonia and MEC were the only two brands that offer repair services or provide information on how to repair and extend the life of their garments. Hanesbrand did not report on any of the indicators within this element. Table 10 provides a summary on the number of apparel brands that reported each indicator within the business innovation element.

Table 10: Summary of reported indicators within business innovation.

\begin{tabular}{lc}
\hline Indicator & Number of apparel brands that reported \\
\hline Have a product take-back/recycling program & 9 \\
Have a permanent product take-back program & 7 \\
Collaboration for end-of-life product recycling/re-use & 7 \\
Design/product project collaboration & 6 \\
Implementing closed loop/c2c strategies & 5 \\
Share best practices within the industry & 4 \\
Provide special care and repair services/instructions & 2
\end{tabular}

\section{3 - Distribution of Indicators}

There are a total of 87 indicators developed from the reported CSR information of the 14 SAC apparel brands. The majority of the indicators are categorized within the sustainable supply-chain management element, which consisted of 45 of all reported indictors as illustrated in Figure 6 . Of the 45 indicators, 25 were related to issues of social responsibility while the 19 were related to environmental responsibility. Product sustainability has 17 indicators while design practice has 25 . Consumer engagement and business innovation have the lowest amount of indicators with nine and seven respectively.

\section{4 - Summary of Total Reported Indicators}

Nike and adidas had the highest number of total reported indicators with 75 . Esprit had the lowest number of reported indicators with 14. The mean of the reported indicators was 51.9 with a standard deviation of 21.6. Figure 6 provides the number of total reported indicators per apparel brand. 


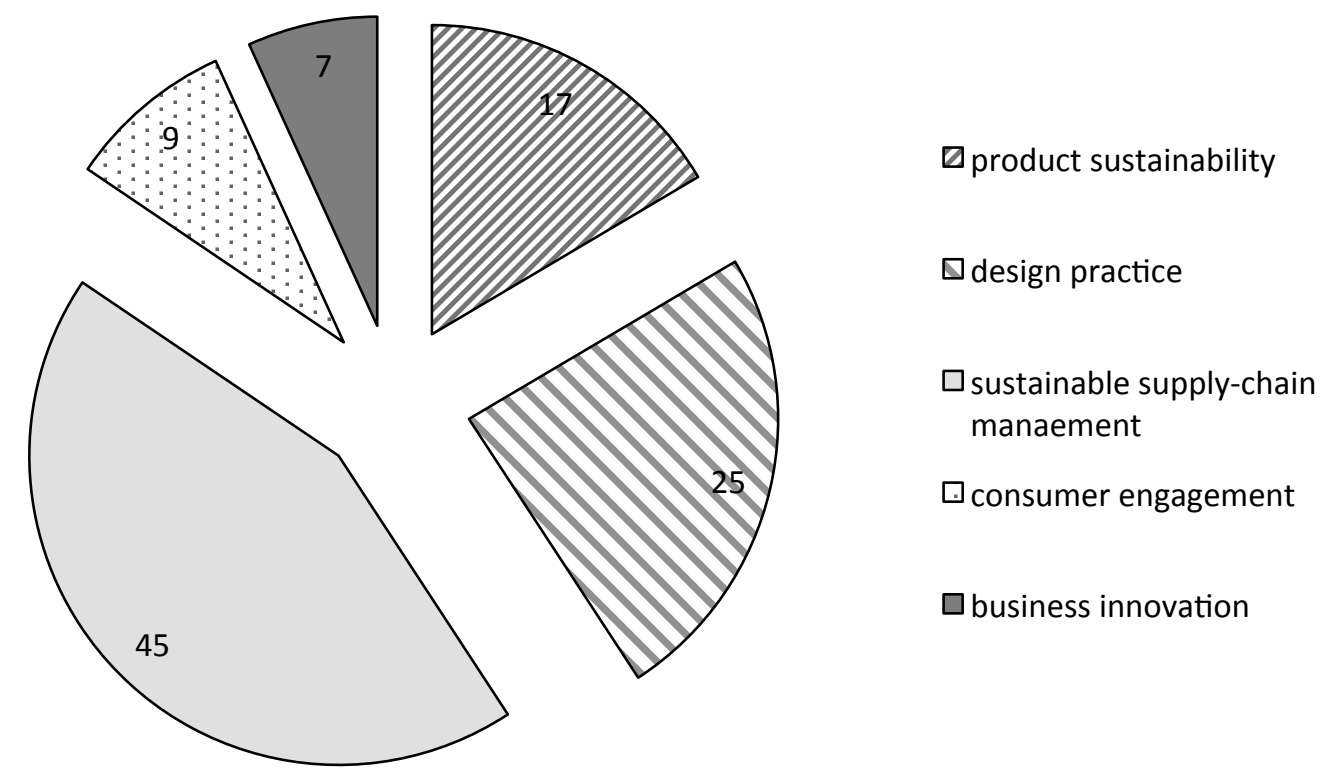

Figure 6: Number of reported indicators per element.

A large proportion of the reported CSR information related to sustainable supply-chain management was based on indicators that utilized metrics. Design practice and product sustainability were mainly qualitative based indicators and have the second and third largest proportion of reported indicators. These two elements are dependent on the apparel brand, as some reported more on design practice while others on product sustainability. There was very little information on consumer engagement and sustainable business innovation. The majority of the reported CSR initiatives and actions did not have metrics fixed to them as they are either too difficult or complex to measure or the results are qualitative. Figure 7 and Table 11 show the breakdown of each apparel brands reported indicators per element. Figure 8 shows the total number of reported indicators of each apparel brand per element. Table 12 provides the mean number of reported indicators per element. 


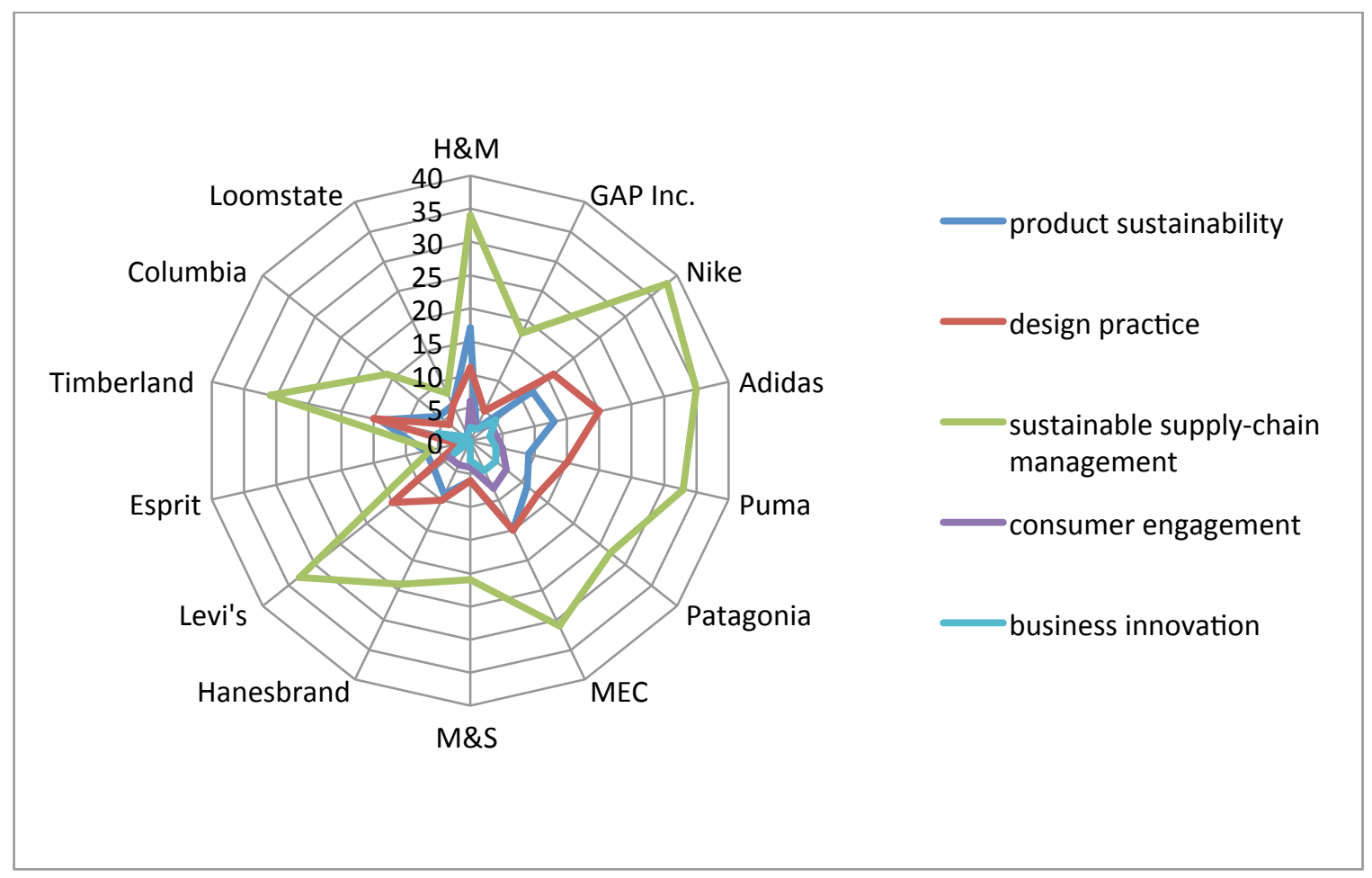

Figure 7: Breakdown of reported indicators per apparel brand and element.

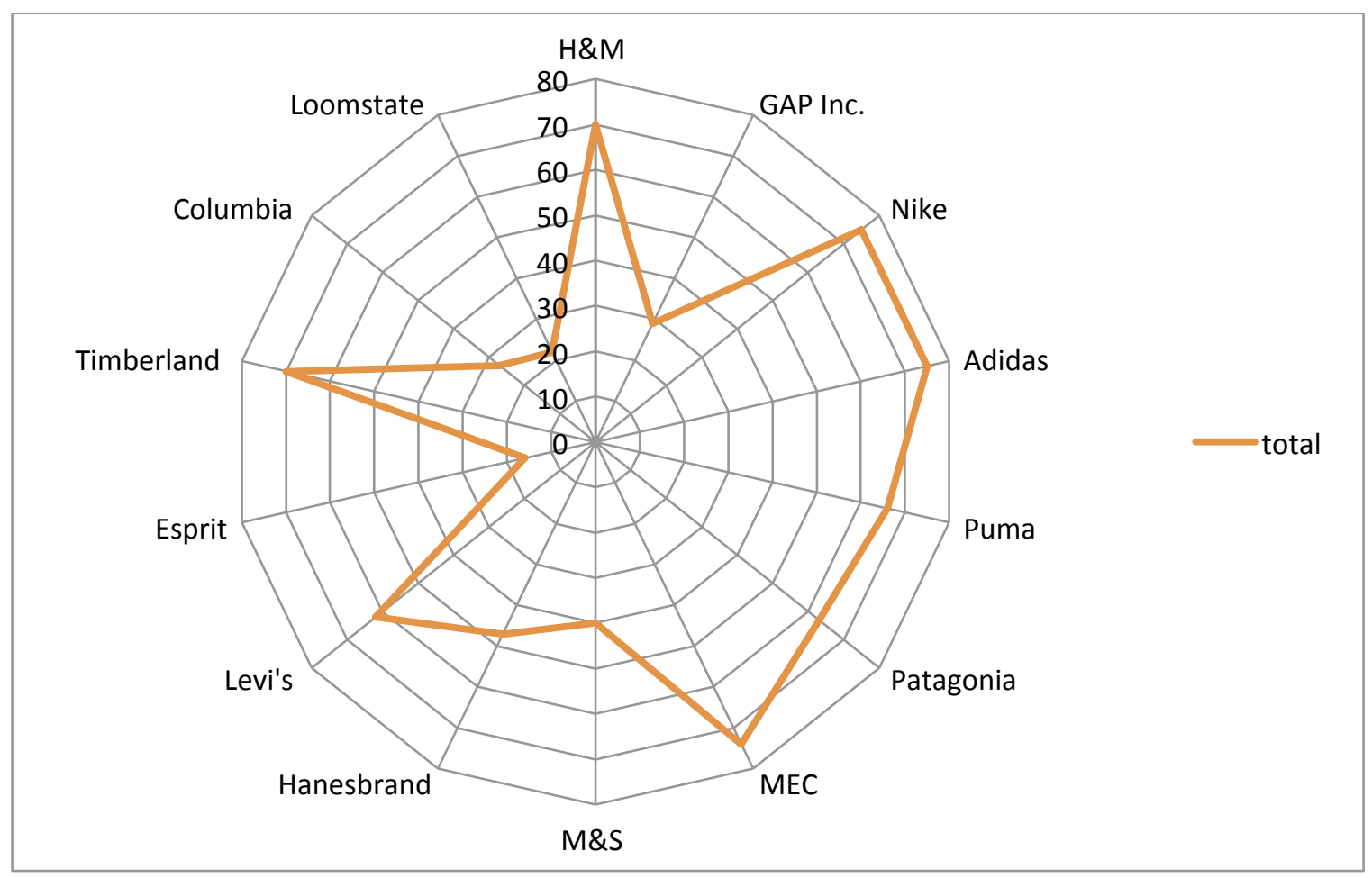

Figure 8: Breakdown of total reported indicators per apparel brand. 
Table 11: Breakdown of reported indicators per apparel brand

$\mathrm{PS}=$ product sustainability; $\mathrm{DP}=$ design practice $; \mathrm{SSCM}=$ sustainable supply-chain management; $\mathrm{CE}=$ consumer engagement $\mathrm{BI}=$ business innovation

\begin{tabular}{lcccccc}
\hline Apparel brand & PS & DP & SSCM & CE & BI & Total \\
\hline H\&M & 17 & 11 & 34 & 6 & 2 & 70 \\
Gap Inc. & 2 & 5 & 18 & 2 & 2 & 29 \\
Nike & 12 & 16 & 38 & 4 & 5 & 75 \\
adidas & 13 & 20 & 35 & 4 & 3 & 75 \\
Puma & 9 & 15 & 33 & 5 & 4 & 66 \\
Patagonia & 11 & 13 & 27 & 7 & 5 & 63 \\
MEC & 15 & 15 & 31 & 8 & 5 & 74 \\
M\&S & 6 & 6 & 21 & 4 & 3 & 40 \\
Hanesbrand & 9 & 10 & 24 & 4 & 0 & 47 \\
Levi's & 7 & 15 & 33 & 4 & 3 & 62 \\
Esprit & 7 & 2 & 6 & 0 & 1 & 16 \\
Timberland & 14 & 15 & 31 & 5 & 5 & 70 \\
Columbia & 6 & 4 & 16 & 0 & 1 & 27 \\
Loomstate & 6 & 6 & 8 & 1 & 1 & 22
\end{tabular}

Table 12: Average number of indicators reported per element.

\section{Element}

Reported indicator average

Product sustainability

Sustainable supply-chain management 


\section{7 - Discussion}

The following chapter discusses the results presented in chapter six. The first section discusses the types of indicators reported by the SAC apparel brands and is divided into five subsections that correlate with the five elements of the apparel system model. Section 7.2 examines the distribution of the indicators while section 7.3 examines the comparability of the reported indicators within the five elements. Total number of indicators reported by the individual SAC brands and how they compare against each other is discussed in section 7.4. Section 7.5 looks at what conclusions can be drawn based on the reported indicators as to the apparel brands progress towards sustainability within the apparel industry.

\section{1 - Type of Indicators Reported}

There were many indicators reported by the SAC apparel brands. The initial data collection revealed several trends as to the type of indicators reported by these brands. The relevance as to the type of indicators reported can provide some insight into the current CSR actions and initiatives and their progress towards sustainability. The discussion on indicators is divided into five subsections, one for each element of the apparel system model.

\subsection{1 - Product sustainability}

Fourteen of the 17 indicators within the product sustainability element referred to the use of environmentally preferred materials. This appears to be a key means to increasing product sustainability for the SAC apparel brands. The substitution of more environmenatlly friendlymaterials such as organic, cotton, recycled polyester, Tencel ${ }^{\mathrm{TM}}$ or environmentally preferred rubber is the one of the easiest and quickest tactics to increase product sustainability. The use of environmentally preferred materials also has positive effects throughout the supply-chain. The use of organic cotton reduces environmental and social impacts while the use of recycled polyester reduces energy use. Increased use of these types of fibres and textiles helps build this emerging market and can foster the development of other environmentally preferred materials/fibres. Increasing product sustainability can have positive effects on a brands reputation and if labeled accordingly, is visible to the consumer and communicates environmental responsibility.

The use of environmentally preferred materials appears to be H\&M's largest initiative. H\&M utilizes the largest variety of environmentally preferred materials out of all the brands, such as Tencel ${ }^{\mathrm{TM}}$, organic linen, recycled wool, organic hemp, recycled polyamide and recycled polyester and offers organic cotton blends from $5 \%$ to $100 \%$. H\&M blends $5 \%$ organic cotton into a wide range of its cotton products but does not identify the $5 \%$ organic cotton on its label or as part of their "Conscious Collection". While H\&M has introduced material diversity into its "Conscious Collection", the majority of their apparel products are still made from conventional cotton. In 2011, H\&M increased its use of organic cotton by 
more than $20 \%$, representing $7.6 \%$ of its entire cotton use (H\&M, 2012). While this is a positive step towards product sustainability, the volume of clothing being produced alongside its perceived obsolescence is of concern. It is estimated that $\mathrm{H} \& \mathrm{M}$ produces 550 million pieces of clothing a year (Siegle, 2012). The ability to offer cheap and fast fashion apparel is made at the expense of quality and through the use of economies of scale. Poor quality apparel does not stand the test of time and apparel that is very trend driven is limited to the time span of that particular trend. This type of garment is usually destined for landfills (Fletcher, 2008; Siegle, 2011). They also do not report on the use of any other processes or practices that would increase a product's sustainability such as the use of low-impact dyes. A sustainable product would be one that could ideally be recycled or reused, made from high-quality materials that increase the longevity of the lifespan and have durability in design, not highly trend driven (Fletcher \& Grose, 2012). H\&M based on reported information appears to do well in terms of product sustainability. However, when examined within a broader context, product sustainability could be easily debated. This appears to be the case for other multinational brands such as Nike, adidas, Puma, Levi's and Hanesbrand. Reporting on product sustainability is limited to material selection and the phasing out or elimination of PVCs.

Patagonia does not report much and does not report in great detail as to the sustainability of its product. An explanation for this is that environmental consideration and sustainability are inherent principles of their business operations. Patagonia may not feel the need to report on product sustainability as it is an inherent principle of the business and is targeted for environmentally-conscious consumers. Patagonia has been a leader in sustainable apparel since 1990s as they were the first to use PET fleece. Patagonia's latest campaign actually encourages consumers to not buy their products unless absolutely necessary (Patagonia.com, 2012).

It was not surprising to see that the emphasis of reported indicators was on the use of a more sustainable cotton: organic, Better Cotton or Fairtrade. Better Cotton incorporates both environmentally and socially responsible farming practices. A possible explanation for the reported use of a more sustainable cotton is that it is easily understood by the consumer. While Tencel ${ }^{\mathrm{TM}}$ may be more environmentally friendly than organic cotton, Tencel ${ }^{\mathrm{TM}}$ is a fairly new textile in the mainstream apparel market. Consumers may not realize the environmental benefits of this textile, while the presence of organic cotton on an apparel label is easily identifiable and understood as a more environmentally friendly product.

\subsection{2 - Design practice}

Indicators related to design practice have the most variability across the apparel brands. Apparel brands had a variety of different strategic approaches, indicators and targets. The most common reported indicator was the use of environmentally preferred materials by 13 apparel brands. Ten apparel brands reported reducing textile waste within the supply-chain, the use of a sustainable product guideline and 
design for environment approach. A probable reason for the wide variety of indicators within this element is the design process itself is quite variable; designers and apparel brands have their own distinctive methods. This is a creative industry therefore it is not surprising to see a wide variety of approaches in adapting their design practice. What was a noticeable trend was the reporting of training and education on sustainability for designers. H\&M reported that it provided its buyers and designers with a total of 3,600 hours of sustainability training in 2011. Information presented in this manner is impressive as a time commitment but ambiguous as it does not provide insight into how many hours each person receives. It also does not allow for comparability in a meaningful way over a period of time. H\&M does not provide any further information into how this translates to better design practices or product sustainability. Nine of the apparel brands reported sustainability training or education for their designers, but like H\&M, information was presented in a meaningless form. The reporting of sustainability training and education is not surprising as designers are central in modifying the process and designing more sustainable products.

What is significant about these findings is the number of indicators and strategies reported in design practice. The decisions made during the design phase can have significant impact on the sustainability of a product. To recycle a product, it has to be designed to be recycled (Braungart, 2002). adidas and Timberland have approached shoe design with the intent of creating modular designs for easily assembly and disassembly. The adidas FORMOTION ${ }^{\mathrm{TM}}$ heel design uses $50 \%$ less material waste, which reduces the weight and $\mathrm{CO}_{2}$ emissions from transport. The heel design requires the use of less glue, which results in fewer toxic emissions, and the modular system allows for the mould base to be shared between products thus reducing material mould waste. Many of these changes to design practice echo through the supply-chain such as modular designs, reductions in styles produced per season and reducing the number of colours used. MEC looks to create longevity in their products that strike a balance between style and function. The aim is to design products that can be disassembled and recycled back into another high-value use product to close the loop on a garment's life cycle. However, only adidas, Nike, MEC, Patagonia and Timberland reported the incorporation of sustainable strategies into their design practice.

adidas reported more indicators regarding sustainable design practices than any other brand. By 2015 adidas has committed to reducing their colour library by $50 \%$ ( 800 to 400 ), a $20 \%$ reduction in the colour-material combinations and reduce energy emissions by $10-15 \%$ per product output at core suppliers. adidas utilizes an eco-index tool, continues to build upon its materials database and guidelines to better enable designer's to make better choices and has implemented intensity measured metrics to set targets. Intensity measured metrics such as energy emissions per product output is a type of indicator that is comparable across apparel brands. An indicator like this allows brands to compare progress yet their method for reducing energy emissions is determined by the brands individually. adidas did not report what the current ouput per product is and they were the only apparel brand to report this indicator. The most interesting initiative is the $20 \%$ reduction of product ranges which can help reduce environmental 
impacts through the supply-chain and eases the pressure on suppliers which can reduce the chances of labour rights violations. adidas reported on another aspect of the design process that no other apparel brand has: reduction in samples. Samples create a lot of waste as multiple versions are created for every style that a brand is considering to produce. Factories generally produce multiple swatch samples of one colour with slightly different hues for designers to choose from per material, as polyester will uptake the colour differently than cotton will. They produce fabric swatches for quality and then full sample garments for fit. adidas has developed a virtualization project to help drive reductions in their samples. The initiatives put forth by adidas reflect a progressive transformation in how their design team functions as they move ahead towards their reported targets.

Ten out of the 14 apparel brands reported reducing textile waste through design. A likely reason for this is the increased media attention on the rising growth rate of textile waste due to expanding production volumes of apparel. Hanesbrand and Puma had similar approaches as their main achievements, which were motivated by recycling textile scraps from their supply-chains into new products. All Hanesbrand black socks contain $74 \%$ recycled EcoSmart ${ }^{\mathrm{TM}}$ cotton that is recovered textile waste from all cutting operations. Puma's Re-Suede material is comprised of $100 \%$ recycled polyester fibers from the scrap waste that is created during manufacturing processes. Re-Suede is produced via a chemical recycling process that reduces both the energy consumption and the $\mathrm{CO}_{2}$ emissions when compared to the production of virgin polyester. While these products are made with environmentally preferred materials, textile scraps, the products themselves are not recyclable or sustainable. The idea of sustainable design is lost on the product as a whole as they contain no other known elements of sustainability such as low-impact dyes or water based solvents or adhesives.

Patagonia reported that in $2008,45 \%$ of its fall and $28 \%$ of its spring product line was recyclable. In 2009 , these numbers increased to $65 \%$ and $38 \%$ respectively. Since 1996 , all cotton products have been $100 \%$ organic cotton. However, Patagonia does not disclose recent numbers on the use of recyclable materials, nor does it provide a total percentage on the use of environmentally preferred materials. MEC on the other hand, reports a $4 \%$ use of recycled polyester in all polyester garments and looks for opportunities at the design phase to maximize potential for disassembly and recycling. Even among brands that are similar in product, design ethos and intrinsic environmental business strategies, comparability is extremely difficult due to the nature of reported CSR information.

Nike reports reducing fabric waste through pattern efficiency. This however is a strategy that many apparel brands and suppliers will employ as efficient marker making is a cost savings strategy. Marking is how pattern pieces are arranged to minimize material loss. A general rule of thumb is that there is a $15-30 \%$ material waste loss per style (Fletcher, 2008). Nike looks to reduce material waste by utilizing omni-directional textile designs. This allows for more versatility during the marker making process as pattern pieces can be placed in two directions versus one direction for a one-way textile designs. Polka dots, for example are an omni-directional design whereas a design that uses objects, stripes or logos can 
only be placed one way or you can end up with pieces that are right side up and upside down. Nike only reports on reductions made with footwear and not apparel. Loomstate was one of the lowest reporting apparel brands but designs and produces some of the most innovative products. They have a very limited product line and work in collaboration with Parson's New School for Design on projects such as the 'ZeroWaste Project'. This project challenged design students to create a garment using Timo Rissanen zero waste pattern drafting methodology and manufactured the winning design. This collaboration takes the notion of pattern efficiency one step further. The design of the garment is inextricably linked with the pattern and must be worked on in tandem. Normally a garment is designed and then a pattern is created. Zero-waste pattern drafting must be taken into account at the same time as the garment is designed. The pattern drafting may even drive the design of the garment as the ultimate goal is to have zero material waste. The result is pattern pieces that interlock like a puzzle, forming a square or rectangle. Along with the "Zero-Waste Project" and elimination of fibre blends, they have a patent-pending 321 line where every item can be worn in multiple ways creating up to 12 looks from one item. While the reported information is limited, the brand definitely conveys a sense of innovative, sustainability driven business and design practices.

The leading footwear and sports shoes brands (Nike, adidas, Puma and Timberland) are also examining their designs because of the impact of footwear on the environment. In 2011, Americans discarded more than 300 million pairs of shoes. When these shoes break down in landfills, the toxic glue that holds the shoes together can leak into the water supply and the atmosphere (Soles4souls, 2012). For a typical everyday "sports" shoe (sneaker), it is not uncommon for this product to contain up to 20 or more materials when uppers, soles, linings, fasteners, reinforcements and foams are all taken into account (Hubbard, 2012). Nike reports using an average of 30-plus materials per single pair of shoes. Designers today are looking at reducing the amount of component parts, utilizing less toxic chemicals and allowing for the shoe to be disassembled for recycling (NIKE Inc., 2012). It was not surprising to see that eight of the brands have reported the phase out of PVCs from their product lines. Nike states that they design for recyclability however they do not specify whether it is for shoes or for apparel. The only recycling that is reported of shoes is from their take-back program. Shoes are recycled into Nike Grind, a surface for physical activity. Timberland's Earthkeepers ${ }^{\circledR} 2.0$ boots are designed to be up to $70 \%$ recycled into new footwear.

Considering this sample of apparel brands all belong to the SAC, an initiative aimed at developing a index tool for industry wide use, only six apparel brands reported the current use of an index tool to evaluate sustainability performance of apparel products. The best-case possible explanation as to why they would not report the use of a index tool is that they have not developed their own index tool and are waiting for the SAC metric index tool. The findings on the reported indicators for this element suggest there are many ways an apparel brand can begin to alter its design practice to produce more sustainable products. Reducing textile waste and designing for recyclability are key reported findings. 


\subsection{3 - Sustainable supply-chain management}

It was not surprising to see that the majority of CSR indicators were directed at social responsibility in sustainable supply-chain management. Labour rights issues have been a chronic problem in the apparel industry for decades. This has been a highly publicized issue in the media and apparel brands have had time to develop indicators to measure their progress. However despite the development of codes of conduct, auditing schemes, goals, targets and indicators to address these issues, the problem still exists. Rising volumes of product production, the use of multiple contracted suppliers in various countries makes monitoring compliance a challenging task. This could be a possible explanation for the increased reporting of increasing transparency and disclosing of supplier lists. By making their supplier list publicly available, it shows they are not trying to hide their production activities. By highlighting their transparency, this action could hopefully mitigate any public media allegations or criticisms when violations are discovered at a contracted supplier. Thirteen of the SAC apparel brands reported on auditing contracted factories. Loomstate was the only brand to not report on auditing. Loomstate had very limited reporting and there could be many reasons for not reporting such as their size and recent founding. This does not necessarily mean they do not audit.

While indicators associated with supplier compliance were the most developed, comparability is extremely difficult. $H \& M$ and Nike were the only two brands to use a comparable metric: number of audits/per factory. While H\&M conducted 1.23 audits/factory in 2011, Nike reported an average of 1.77 visits/factory/year. It is interesting that these brands can report the exact same CSR performance yet delivers the information in a slightly different manner resulting in incomparability. adidas distinguishes between performance, environmental and FLA audits while MEC only reports on social compliance audits. M\&S reported performing 1178 ethical audits in 2011 but does not indicate whether it encompassed all products sold (apparel, food or home furnishings) or specific product suppliers. Nine out the 13 apparel brands that report on auditing provide the number of contracted suppliers as a reference point. Frequency of audit visits was the most surprising revelation as it was surprisingly low for those who reported. Levi's contracted factories are audited once a year, Nike audits every 12-18 months, H\&M audits 1.23 times per year per factory. Puma audited 42 factories more than once out of 540 factories in 2010. It is not astonishing that non-compliance is an issue considering the volume of contracted factories and the relatively low reported auditing frequency.

There is a clear shortcoming in the monitoring schemes currently used by apparel brands. In Locke, Qin, \& Brause's (2007) study on Nike's internal audits found that the average compliance score (100 point scale) was $66 \%$ for apparel factories and $68 \%$ for footwear factories. This is fairly low considering Nike is one of the leaders in social responsibility with strong commitments to monitoring and remediation. Nike does list the most common incidences of noncompliance, however, they do not publicly disclose the average compliance score as discussed in the Locke, Qin, \& Brause's (2007) study. Nike 
does however highlight progress through percentages of supplier scores e.g. suppliers with an E (worst) rating decreased from 29\% to $9 \%$ from 2010 to 2011. Many of brands reported the use of unannounced audits when monitoring for compliance, however for many of these brands, it was unclear as to whether the apparel brands were performing the unannounced audits themselves or these were the unannounced audits that the FLA performs for its member brands. H\&M was one of the only brands to report a percentage of unannounced audit visits. Since all the SAC members are also FLA members, if they do not distinguish as to who is conducting the unannounced audits there is no way to tell.

The FLA is a result of the collaborative efforts of all apparel brand SAC members and non-profits in an effort to achieve human rights objectives regarding poor labour conditions in the apparel industry. Membership results in adoption and promotion of the FLA Workplace Code of Conduct, which is built upon collaborative action, remediation, third-party compliance, innovations in labour compliance, transparency, public reporting and greater accountability (FLA, 2012). However, while the FLA does conduct unannounced audits on behalf of its member brands, these audits take place quite infrequently with a large lapse of time in-between visits. This is most likely a result of the fact that many of these apparel brands contract the work of hundreds of suppliers. A quote from an interview with Helena Helmersson, head of sustainability at $\mathrm{H} \& \mathrm{M}$, summarizes the problems in utilizing such a large number of suppliers.

I don't think guarantee is the right word...A lot of people ask for guarantees: Can you guarantee labour conditions? Can you guarantee zero chemicals? Of course we cannot when we're such a huge company operating in very challenging conditions. What I can say is that we do the very best we can with a lot of resources and a clear direction of what we're supposed to do. We're working really hard. (Siegle, 2012)

This same attitude is reflected in the common phrase that was utilized by apparel brands in reporting their protest against the use of Uzbekistan's cotton; "we do not knowingly source cotton from Uzbekistan". This type of phrasing and the quote from Helena Helmersson signify the need for greater transparency throughout the supply-chain from tier 1 to tier 4 suppliers (raw materials) to ensure these types of objectives can be met. Only with transparency can the apparel brands become more aware of the conditions within their supply-chain but can be increasingly held accountable. There are other methods for reducing the negative social impacts within the apparel supply-chain. Both Nike and H\&M acknowledged that to reduce pressure on factories where possible they will attempt to reduce last minute colour and fabric changes. Nike is also looking to reduce the number of styles in each category and align styles globally to reduce style pressure. These are changes that are made in the design practice but are echoed through to the labour conditions in the contracted factories within their supply-chains. While acknowledging the need for increased transparency, these apparel brands are also using the right phrases and language to distance themselves from accountability. 
Greenpeace in 2011 launched a highly publicized and global campaign targeting major retail brands to eliminate the use of hazardous chemicals within their supply-chains. The campaign publicly targeted brands such as H\&M, Nike and adidas and challenged them to detoxify their supply-chains by 2020. Five of the SAC apparel brands (Nike, adidas, H\&M, Puma, Levis's) committed to this challenge and it is not surprising that this CSR initiative is reported by all five brands. A combination of the Greenpeace Zero Discharge campaigns and articles on the toxic chemicals polluting aquatic systems by The New York Times (Witkin, 2012) offer a possible explanation for chemical management reporting. Eight apparel brands reported on the development and use of RSL for suppliers and the use of low-impact dyes. Considering the reported increase in transparency and public disclosure of suppliers that there are many reported indicators regarding energy and water use and GHG emissions. Ten apparel brands reported on reducing GHG emissions and indicators to establish baseline measurement and measure reduction progress. However the way the information is presented is ambiguous and renders it incomparable. H\&M reports targets for a 5\% reduction relative to sales based on 2010 levels. Adidas reports a 15\% carbon footprint reduction target by 2015 while Nike reports a $20 \%$ absolute reduction for US operations by 2015.

adidas was the only brand that reported on a whole-system approach to supply-chain management by continuing to move deeper into the supply-chain by working with ginners and spinners directly. Other brands such as H\&M acknowledged the importance and need of increasing transparency by working with tier two, three and four supplier directly. What stood out was adidas's use of the phrase 'whole-system' in describing their strategies in moving forward towards transparency. adidas had some of the more aggressive timelines for targets however, they use terms such 'relative environmental footprint' yet do not inform or explain the term. adidas also reports on increasingly collaborative activities such as establishing an industry-wide recognized audit protocol and certification scheme for dye-houses by 2015. However, this was not reported by any of the other SAC member brands. Currently brands such as Nike commits to reduce the use of toxic chemicals during the wet-processing phases. However, Nike reports that it encourages suppliers to reduce chemical use but it is voluntary and the use of toxic chemicals are based on self-evaluation. Situations such as these allow companies such as Nike to report the monitoring of suppliers in their use of toxic chemicals but may not be entirely effective as it is quite easy for these suppliers to fake compliance. This is not entirely the fault of suppliers, as they may not have the capital to invest into technologies that can reduce environmental impact or in countries such as Bangladesh, the infrastructure may be a physical barrier to implementing sophisticated machinery. It raises questions as to who should bear the costs in implementing the new machinery or processes to reduce environmental impact. If a company like Nike requires a certain level of compliance but is the only brand out of the many brands that contract the work of that supplier, there may be very little motivation for the supplier to comply. This point was raised in a current article in EcoTextile News. A major concern to SAC apparel brands that have commitment to Greenpeace's Zero Discharge campaign is cost. While commitments 
were made and publicly disclosed, the issue of cost has not been explicitly addressed. There are still many questions as to whether brands will absorb the costs of pollution control technology, greener chemicals, and auditing schemes at the sacrifice of profit margin and will undoubtedly affect the apparel brands reported CSR performance in meeting their targets towards zero discharge (EcoTextile News, 2012).

\subsection{4 - Consumer engagement and business innovation}

Consumer engagement has very little reporting and was limited to a few initiatives. The most surprising revelation was the limited reporting on more environmentally friendly washing/drying behaviours. Seven apparel brands conducted a LCA and recognized the significant impact on the environment resulting from consumer use. However only four provide information and/or encourage more environmentally friendly laundry behaviours. It is interesting that more of SAC apparel brands do not encourage better behaviours as this is very easy to do and at no cost to the apparel brand. An alternative explanation could be that they feel it is not their responsibility to educate consumers on washing/dryer behaviours. Yet all apparel has washing and drying guidelines on the label, these, however, are aimed at maintaining garment performance and quality.

It is the same scenario for encouraging donation/re-use or re-selling of garments. This indicator was only reported by six apparel brands yet it is relatively easy and would have very little associated costs. Both Patagonia and MEC offer online platforms for their consumers to re-sell or swap garments with other consumers. Patagonia and MEC are also the only two brands to offer repair services and special care instructions to their consumers to extend the life of their garments. It is not surprising to see these types of business strategies from these two brands considering environmental responsibility is at the core of their business operations.

Business Innovation is the crossover point where the apparel brands begin to demonstrate their sustainability efforts from the design phase through to production and then into engaging the consumer. This is also an element where brands have direct control. The implementation of take-back and/or recycling programs was reported by nine of the apparel brands but only seven have a permanent takeback program. These initiatives are significant as textile waste is becoming a big concern and consumer engagement is needed to facilitate these business strategies orientated around product return. Recycling may be the easiest form to engage consumers because consumers are aware of recycling through other means whether it is recycling plastic or metal containers, paper based product or glass. The problem with these programs is that they are not standardized throughout the business. Puma and adidas have introduced take-back programs for their footwear and apparel but this initiative is limited to a few locations. Puma only has a take-back program in Berlin where they have bins for both apparel and footwear that they then donate. adidas has recently introduced a take-back bin in Brazil for sports footwear. This project is in collaboration with RCR Environmental, a waste management company that 
uses the shoes for power generation and is almost entirely emission-free. This program was developed to minimize the environmental impact of improper shoe disposal into landfills or incineration, which releases toxic emissions. The program also looks to engage consumers and educate them on the practice of conscious disposal that falls in line with the principles of the Brazilian National Law on Solid Waste. adidas will take-back footwear from any brand and while currently only available in Sao Paulo, adidas has plans to expand throughout the entire country. They have not however reported on any expansion plans beyond Brazil (Adidas Group, 2012). Nike does have take-back bins in all Nike flagship stores such as the Bloor St. location in Toronto. They will take any type of shoe, work in collaboration with industry leading surfacing companies to create running tracks, playground surfaces, basketball courts and any other surfaces that promote physical activity. They have collected 28 million shoes since 1990, which is a start but with over 300 million shoes being discarded annually in the USA, the program could benefit from further consumer engagement (Nikereuseashoe, 2012; soles4souls, 2012).

Gap Inc. and Levi's had both implemented take-back programs for denim jeans, however, it is unclear as to whether this program is continuing and which locations participate. While the Levi's store in Toronto had the take-back program, it was only available for a limited time and is no longer in place despite being reported on its website as an active initiative. This discrepancy makes it difficult to evaluate or trust the initiative with incomplete reporting as to where the initiative currently stands. The Gap Inc. program only ran in 2010 in 1,000 locations in the US and collected over 360,000 pairs of used jeans. Consumers received a 30\% discount in exchange for their donated denim. Gap Inc.'s program was a collaboration with Cotton Incorporated and a fibre insulation manufacturer Bonded Logic. The donated denim was used to create home insulation that was then further donated to Habitat for Humanity, proving that business innovation does have positive consequences. The "Recycle Your Blues" campaign for Gap Inc. was extremely successful and may have contributed to the $56.5 \%$ increase in their stock price after a dismal previous year (NRDC, 2011). It is unclear why they would abandon what is a seemingly successful program.

M\&S has launched a highly publicized take-back campaign to further engage their consumers in donating used clothing. It has until recently only offered the program through the charity Oxfam. By donating used M\&S apparel to Oxfam the consumer would receive a voucher for five pounds. The apparel did have to be in "wearable" condition, which is a problem with low-cost, low-quality fashion items such as those produced by M\&S. This was also not a well-advertised program as it was only written on the caretag label of their garments. Not all used apparel is in wearable condition. Recently, M\&S, along with celebrity endorsement, has launched their "Shwop" campaign where donation bins are now available at M\&S locations. This campaign is much more engaged with the consumer and on the M\&S website they highlight items that are most in need by Oxfam and how the clothing donations translate to positive social actions. For example, a pair of donated jeans will raise five pounds, which can help buy a water container for four families in Niger. They also have a live counter of money raised to date and have collected over 
10 million garments since 2008. While being an extremely engaging and educational program, they do promote "ditching" items that are not being worn and purchasing another M\&S garment (M\&S, 2012). Theoretically if the garments could be recycled into new ones, this type of message may not be as detrimental as many items donated in developed nations are not helpful in developing nations, which are mostly located in warm climates. As only a "wearable" items can be re-sold in the same market where they are donated. Un-wearable items are shipped to Africa where they are sold in the black market. Unfortunately, Africans are not in need of our un-wearable winter parkas, skinny jeans or other fashion items that are predominately the type of clothing that is discarded or donated. These programs may also encourage consumers to shop more; by placing donation bins inside the stores this could be a strategic move to draw consumers in. Donate, feel good and replace the donated items with new ones.

Timberland's Earthkeepers ${ }^{\circledR} 2.0$ boots is part of Timberland's product range that can be mostly recycled into new shoes. Consumer engagement is key for this business strategy, however, they require the consumer to mail the shoes back to them. This is where this business strategy seemingly falls short, as it requires a serious effort on the part of the consumer to return the shoes to Timberland. They are the only brand that does not have take-back program within their retail location and do not report as to how many shoes they have collected for recycling.

With design being a key component to longer-term sustainability efforts, the majority of brands were lacking in collaborative efforts as only six brands participated in some sort collaboration. Collaborations by H\&M and Loomstate were limited to one-time projects. In a highly competitive, profit driven market, the collaboration of designers would not be a priority and this was evident through the reported indicator. Puma's award winning "Clever Little Bag" is a perfect example of design innovation through collaborative design efforts with a significant impact to the environment. An investment of twentyone months into the design process has netted Puma with a concept that has reduced the amount of shoe cartons dramatically, eliminated the use of tissue paper in the carton, eliminated the need for a plastic bag at the point of purchase and has provided the end consumer with a recyclable and reusable bag to carry their purchase home. The far reaching effects of this innovation include the savings of 8700 tons of paper annually by the reduction in the carton tops and paper tissue, 275 tons of plastic from the elimination of bags in addition to the savings in fuel costs for shipping and water costs associated with production.

The significance of these findings is that there is obvious benefit to the apparel brands in reducing costs by retrieving materials and reputation from philanthropic actions. Reporting of these actions and initiatives is severely underdeveloped. There is no consistency in how this CSR information is reported. It seems that this would be the type of information a brand would want to highlight, measure and show progress in a comparable format. The results show that these two elements have limited reporting by all the SAC apparel brands. Considering the significant environmental impact associated with consumer use, based on CSR information reported, there appears to be very little action. A possible explanation for this 
lack of reporting is apparel brands may be underestimating the stakeholder's interest in this CSR information. Apparel brands may not want to invest into reducing environmental impacts resulting from consumer use and disposal. They may only report minimally to gain from reputational benefits of seemingly philanthropic activities.

\section{2 - Distribution of Indicators}

There is a noticeable imbalance that exists in the distribution of the indicators across the five elements. The distribution pattern, however, was similar across the 14 apparel brands. The majority of reported indicators were related to sustainable supply-chain management and this was consistent for all brands except Loomstate and Esprit. It is not surprising that this pattern does not extend to these two brands as they have so little reporting. This is similar to findings by Sherman (2009) where the most reported indicators were related to labour, environmental and human rights followed by product responsibility by both Nike and adidas. The findings of this study are significant as they highlight the elements where reporting is weak and where it is fairly developed. It is interesting that in the elements where reporting is high and fairly developed that comparability is almost non-existent.

\section{3 - Comparability of Indicators}

Upon the initial data collection of CSR information, the data were found to be incomparable. The type of indicators reported, how the CSR information and indicators were presented, the format and the metrics did not allow for comparability. A lack of standardized CSR reporting does not allow for comparability among the SAC apparel brands. This finding is supported by similar findings by Sherman (2009) in a study that compared the CSR reporting of Nike and adidas to the GRI G3. Sherman states that the use of the G3 guideline should allow for comparability to some degree, what seems to be occuring is an inconsistent application of the guideline. This inconsistent application is a direct result of the voluntary nature of CSR reporting. Even the common reported indicators were not reported in the same way resulting in incomparability (Sherman, 2009). Even the authors tone and language conveyed a sense of frustration in attempting this comparison.

Four of the apparel brands when referring to their use of recycled polyester do so in a manner that highlights the number of plastic bottles diverted from landfills. Hanesbrand kept 57 million plastic bottles out of landfills but does not specify whether this is since the inception of their EcoSmart ${ }^{\mathrm{m}}$ polyester or yearly. This is the same case for Nike, reporting 82 million plastic bottles have been diverted. H\&M in their 2011 Conscious Actions report that they used 9.2 million post-consumer plastic bottles to create their recycled polyester. Although it is not explicitly stated, because it is in a published report for a specific year, it would be assumed that this figure represents bottles recycled in 2011. Patagonia does provide a time period, stating that over the course of 13 years they have diverted 86 million bottles from landfills into their $\mathrm{PCR}^{\mathrm{TM}}$ garments. Timberland reports in a completely different manner that engages the 
consumer in a more direct way by stating per product the amount of bottles used to make a particular garment. A men's medium polar fleece for example utilizes twenty-one $55 \mathrm{cL}$ plastic bottles and caps per garment. The information is available with the product description but is limited to the European TimberlandPro website (TimberlandPro, 2012). An explanation for the use of an indicator that uses a number of plastic bottles diverted from landfills is that it seems to have been developed for the purpose of consumer or other stakeholders such as NGOs. While conveying CSR performance, it appears to be more aligned as a marketing or Public Relations strategy. These brands also dismissed other factors such as the origin of these bottles. If diverted from North American landfills, how does transportation to Asian factories affect the environmental footprint? Nine of the apparel brands reported the use of recycled polyester, yet how they reported the use of this material in their product ranges and amount had no basis for comparability. An explanation for developing CSR reports that are incomparable is that the apparel brand cannot be held accountable. If they are a self-declared leader in sustainability and cannot be compared, their claim and/or reported CSR information cannot be challenged. While the claim or report may not hold any merit, the consumer or other stakeholders may not be concerned with merit or accountability.

MEC reported its progress in developing product sustainability by providing the number of styles that were produced using environmentally preferred materials. In 2011, 371 styles of MEC-brand products and 273 styles of non-MEC brand-products were made with environmentally preferred materials, for a total of 645 product styles (up from 635 in 2010). M\&S reported in a similar manner in regards to cotton products sold. In 2011/12 M\&S sold over eight million items made from Fairtrade, organic, recycled or Better Cotton Initiative cotton, equivalent to $3.8 \%$ of M\&S' total cotton usage. This method of reporting product sustainability progress does not allow for comparability for the brand on a yearly basis nor does it allow for comparability across multiple brands. For example, if MEC has a goal to produce all apparel using $100 \%$ environmentally preferred material. The following year they have a $2 \%$ increase in product styles and a $2 \%$ increase in apparel styles produced utilizing environmentally preferred materials. If progress is measured by counting styles produced using environmentally preferred materials on an annual basis, the number of styles will increase but no real progress would have actually been achieved. MEC provides data on the volume of environmentally preferred styles produced but does not provide data on the volume of conventional apparel products produced. This creates ambiguity in their CSR performance reporting.

Five of the apparel brands report targets for organic cotton use, H\&M aims to increase organic cotton use by 50\% every year until 2013 (from 2010), Puma aims to produce 50\% of international collections using organic cotton, Cotton Made in Africa and recycled polyester by 2015. M\&S aims to increase its organic cotton use to $25 \%$ by 2015 and $50 \%$ by 2020 , adidas is committed to using $100 \%$ sustainable cotton by 2018. However without any standardization on reporting it becomes extremely difficult to compare. If one company uses $25 \%$ organic cotton in $75 \%$ of its product versus another who 
uses $5 \%$ in $95 \%$ of their product range raises the question: which company is performing better? None of these brands report on total volume of apparel produced providing no baseline or context for their reporting on organic cotton use. There is also no accountability as to whether or not they achieve their reported targets. This is a common problem among all the SAC apparel brands with the exception of Gap Inc., Esprit and Loomstate due to their limited reporting.

The use of the model and the normalization of the data to basic demoninators did allow for comparabiltiy. However, the results of the analysis do not seem to provide a clear picture of the CSR performance and progress towards sustainability amongst the brands. What this study does find is that comparability is possible and conclusions can be drawn. Eleven of the apparel brands use organic cotton, all 14 have codes of conduct for contracted suppliers and seven publicly disclose their supplier list. It is however, only a basic comparison and indicators with metrics remain incomparable. As long as CSR information is voluntarily disclosed, publicly available CSR reporting will continue to have a shadow of doubt. This study highlights the need for standardized reporting guidelines, a consistent application and interpretation of guidelines and an established means of assessing reported CSR information. Currently among these apparel brands, there is no benchmarking or baseline development of CSR performance.

\section{4 - Total Number of Indicators}

Comprehensive reporting (i.e. reporting many indicators) does not seem to accurately reflect an apparel brand's CSR performance. More comprehensive reporting does not necessarily mean that an apparel brand is progressing towards sustainability any better than brands that report less or do not report. H\&M, Nike, Adidas and Puma all had extensive reporting and many reported indicators but are also multinational corporations with means and resources to produce a comprehensive CSR report. As stated in section 7.1, H\&M extensively reports on their CSR performance while Patagonia provides limited information on their CSR performance comparatively. While at this point there is no means to accurately compare and measure CSR performance or progress towards sustainability, Patagonia is considered to be a progressive sustainable apparel brand. H\&M encourages consumption while Patagonia discourages consumption and has implemented business strategies to encourage reuse, repair and reselling of their products. H\&M is a fast fashion brand with low-quality products, perceived obsolescence and a business strategy built on large volume productions that would not be considered sustainable practice strategies. Patagonia is an active outdoor lifestyle brand that produces low volume, high-quality performance products built for longevity and durability. An explanation for comprehensive reporting by multinational brands such as H\&M, adidas, Gap Inc. and Nike is that they are typically more open to public and media criticism. As stated in the literature, media attention on issues such as sweatshop labour can be quite damaging to a company's reputation. In the case of Nike, damaging media attention led to a decrease in their share prices (Carty, 2001; Rock, 2003). More comprehensive reporting may be a means to mitigate negative public and media attention. 
Esprit and Loomstate had very little to no reporting of CSR performance, actions or initiatives yet both apparel brands have environmental responsibility as core business strategies. Loomstate only produces sustainable products made from either $100 \%$ organic cotton or Tencel ${ }^{\mathrm{TM}}$ and are a small scale apparel brand. Esprit was one of the first mainstream retail brands to adopt more environmentally friendly practices in the early 1990s. Esprit produced its first eco-collection in 1992 and actively encouraged its customers to not buy their clothing.

The direction of an environmentally conscious style is not to have conspicuous consumption written all over your attire. We believe this could be best achieved by simply asking yourself before you buy something (from us or any other company whether this something you really need.) (Treehugger, 2008)

Recently Esprit has partnered with Asian fashion NGO, ReDress, to launch a new consumerfacing eco-label. This label verifies that retailers, brands or designers recycle the textile waste or unused clothing from their apparel production into new recycled products for their brand (EcoTextile News, 2012). The introduction of the ' $R$ Certificate' is aimed at reducing waste in Asia's apparel industry. Stipulations of the label include: garments are manufactured using a minimum of $20 \%$ recycled fibres, producing facilities must hold a Global Recycle Standard (GRS) certificate, and can demonstrate full traceability throughout the supply-chain (EcoTextile News, 2012). Consumers can visit the R Certificate website for detailed information on certified Esprit products (ReDress Limited, 2012). Esprit is the first retailer/brand to be issued the certificate and launched a 'Recycled Collection by Esprit' in May 2012 in Hong Kong (EcoTextile News, 2012). What is interesting is that Esprit does not report this information on their website. Loomstate, Esprit and Patagonia have a strong environmental commitment yet report very little on their CSR performance. It could be that they do not feel compelled to prove their commitment or do not have the resources to continually update these public forums. A small company such as Loomstate may not have the resources to develop a CSR report or a comprehensive website.

A major finding is that comprehensive reporting and reporting many indicators does not provide a complete representation of an apparel brands CSR performance or progress towards sustainability. Indicators are not the only means for reporting CSR performance. The GRI AFSS suggests reporting on aspects such as strategy, analysis, management approach, governance and commitments. Also, it depends what indicators an apparel brand chooses to report. Some indicators may provide meaningful information such as water reduction throughout the supply-chain while others may be ambiguous and meaningless. Puma's reporting on worker rights in Turkey is a good example of an ambiguous indicator that also has no basis for comparison, “Women's rights and workers' rights awareness training, mainly focusing on female staff" (Puma, 2011:45). These results highlight how the use of indicators and CSR reporting require more development if they are to provide an accurate reflection of apparel brand's CSR performance and progress. 


\section{5 - Progress Towards Sustainability}

A very surprising revelation is that it would be expected an apparel brand would report and perform in areas where they have more direct control over the activities. The apparel system model shows the elements within the direct control of apparel brand's activities and elements of less control. Sustainable supply-chain management and consumer engagement are elements within the apparel system where brands typically have little control or influence. What was interesting was that proportion of CSR reporting dedicated to sustainable supply-chain performance, an element of little control. While consumer engagement another element of little control had very little reporting amongst the brands. Business innovation, which is directly tied to the business operations, also had limited reporting. It is possible that apparel brands may be able to exert more influence over suppliers than consumers. Reporting on the supply-chain may also mitigate public and media allegations and criticisms. The use of contracted suppliers and the resulting environmental and labour violations and boycott campaigns are frequently featured in the media (Spar \& La Mure, 2003; Klien, Smith, \& John, 2004).

Based on the reported indicators, the results show that there is progress towards sustainability. Unfortunately, it is difficult to gauge the measure of progress. The findings reveal what apparel brands have reported on and the extent of their reporting. Progress is difficult to measure as the brands can only be compared against themselves as the CSR information reported is determined by the brand itself and is voluntary. There was, however, a noticeable increase in the amount and type of CSR information (actions and initiatives) found in the first CSR reports to the latest and most current CSR reports by the SAC apparel brands. This would suggest that there is an increase in CSR activities and initiatives and therefore some progress towards sustainability. The results of this study have shown those who report more comprehensively may not have better CSR performance than those who report little.

The results highlight that the stages where an apparel product has the most environmental impact is under-developed in terms of reporting. Consumer engagement and business innovation is lacking. It would seem logical that if an apparel brand had good CSR performance in these elements, why would they not report it? The benefits from social responsibility are supported by the literature. As Fletcher and Groese (2012) state, to achieve sustainability in the apparel industry, the apparel system itself must transform. Based on the reported CSR information, the results suggest progress in some elements but progress and change in all elements must occur to achieve change in the system. However, until CSR performance can be accurately measured through CSR reporting in a systematic, measurable and comparable form, it will be difficult to gauge the progress of these apparel brands towards sustainability. 


\section{8 - Conclusion}

The fashion and apparel industry is tied to the natural world and is dependent on water, crops such as cotton and linen, and crude oil for a variety of chemicals and synthetic fibres. However the industry is only beginning to factor in the consequences of its actions on habitat loss, decreasing freshwater reserves, shrinking biodiversity, climate change, increased used of natural renewable and nonrenewable resources and growing textile waste. This research explored the reported CSR actions and initiatives of the self-declared leaders in sustainability to assess whether CSR reporting is an effective measure of their CSR performance?

The analysis of the reported CSR actions and initiatives led to the development of a database of indicators that was successful in highlighting the distribution of reported indicators among the five elements. The majority of the reported indicators were found to be in product sustainability, sustainable supply-chain management and design practice. Business innovation and consumer engagement was reported but to a much lesser extent. The results highlight that CSR reporting is not effective in providing a true reflection of an apparel brands CSR actions and initiatives and their progress towards sustainability. The comprehensive reporting by apparel brands such as Nike and H\&M versus the limited reporting by brands such as Patagonia did not provide conclusive results on CSR performance. CSR performance cannot be determined without comparability and effective reporting. Effective CSR reporting should allow for comparability. Companies voluntarily select what indicators they will report that reflect their CSR actions and initiatives. There is little research that has been done as to the effectiveness of certain indicators over others in measuring CSR actions and initiatives (Roca \& Searcy, 2012). There is also no information as to how they select, define or develop the reported indicators. Progress should be measurable and these findings reinforce the need for industry-wide guidelines, standards and/or governmental regulation concerning CSR reporting. This study also found the there no agreement as to what should be reported and how it should be done. CSR reporting is still relatively new to the apparel industry. Nike and Timberland were the first SAC apparel brands to report starting in 2000 , followed by H\&M in 2001, Puma in 2002, M\&S in 2004 and Levi's in 2007.

Reporting standards for the industry would allow for comparability. This is not only important for the consumer in being able to make better purchasing decision but comparability might help create accountability. However as long as CSR reporting is voluntary, there will be no reason for an apparel brand to fully comply with any standards or guidelines. Currently, there are no internationally accepted standards that apparel brands must adhere. There are many guidelines available but again this is left to the discretion of the individual company. To really determine whether CSR reporting is an effective measure of CSR performance it is dependent on what the desired outcome is. If the goal of the SAC apparel brands is to report on CSR performance that allows them to measure their own progress without comparison to other brands. One could conclude that CSR reporting is effective. If the desired outcome 
were to provide a clear and accurate picture to stakeholders of CSR performance, the results would suggest it is not effective. If the goal of CSR reporting is to create comparability amongst other brands, than the results again highlight the incomparability of current CSR reporting by the SAC apparel brands. One could conclude that the goal of these SAC apparel brands is to report CSR performance while maintaining incomparability. The CSR information reported was similar, it had the same distribution among the five elements, yet it appeared as if the information was purposely clouded with ambiguity and meaningless metrics. If these apparel brands report in a comparable manner, it could open them up to accountability. Accountability and comparability could potential threaten the status of self-declared leadership in sustainability. This study has shown that the means for evaluating effectiveness in CSR reporting have not been put in place.

There are plenty of opportunities that still exist for further reductions in the environmental and social impacts of the apparel industry. An apparel brand cannot achieve sustainability until the apparel system itself begins to change. Change will require further development of the collaborative actions of these brands. By committing to the SAC, it is indicative of a demonstration to building a better system that recognizes the collaborative efforts that are needed, the sharing of best practices and the development of industry wide standards and protocols.

\section{1 - Contributions}

As highlighted in the literature review, other than the Sherman (2009) study, there are no other published studies that examine the use of CSR indicators or CSR reporting within the apparel industry. The study by Sherman (2009) was limited to Nike and adidas and compared the CSR reports against the GRI with very little analysis into the reported indicators. This study helped provide insight into the CSR reporting by the SAC apparel brands. The study highlighted the type of reported CSR indicators used and their distribution among different aspects of the apparel industry. This research was primarily focused on those indicators that are unique to the apparel industry. The research developed a model that provides a clear and basic portrayal of the core elements of the apparel industry where an apparel brand may consider developing their CSR actions and initiatives. The use of this model and categorization of the reported indicators could provide a baseline on how CSR indicators are reported in the apparel industry among the SAC brands.

This is the first study to provide information as to the type of indicators reported in CSR disclosures by the apparel industry. It is also is the first to attempt a comparison among the self-declared leaders in apparel sustainability. This study highlights the diversity of indicators in CSR reporting that does not allow for comparability and the need for standards. 


\section{2 - Limitations}

One of the limitations of this thesis is that it relies solely on the current publicly available reported CSR data published by the individual apparel brands. Utilizing publicly available information is not always reflective in all the CSR actions and initiatives an apparel brand may be participating in. Certain apparel brands may have exaggerated their CSR activities while others may be more modest. This discrepancy has the ability to skew the results in an unfavorable way for certain apparel brands. The intended audience may be different for the various apparel brands thus accounting for the type and amount of publicly available information. Reported information came in many different forms from published CSR reports to continually updated blogs and certain indicators only pertain to a small proportion of the apparel brands.

There are issues in having a binary yes/no participation questions regarding the CSR indicators, as there are varying degrees of performance and participation by the apparel brands. Counting the number of indicators has its limitations in that some indicators are not as relevant or do not have the equivalent impact as other indicators. Membership to the UNGC has a completely different impact and to a much lesser extent than the elimination of the use PVCs in one's supply-chain. Therefore, while this study did provide a foundational review of current reported CSR initiatives and actions, the data and results are not fully reflective an apparel brand's commitment and performance as it relates to sustainability.

\section{3 - Foundations for Future Research}

By assessing and creating a review of multiple case studies of the current initiatives and actions by the sustainability leaders in the apparel industry, this research can highlight the achievements and areas of improvement, which can be built upon further. As there are no standard practices for environmental or social responsibility in the apparel and fashion industry, by providing a foundational review of current practices may help the industry move towards the development of standard practices, and further development of effective metrics and indicators. Social and environmental factors have been poorly considered in the apparel industry and it is difficult to gather precise and detailed information. Therefore, once effectiveness can become established and/or explored, the potential for policy, standards and regulations can be developed. There are opportunities to attach financial costs to the benefits and the environmental impacts of an apparel brand. Research may continue on to areas such as legislation, CSR development for the apparel industry and more comprehensive behavioural studies of this new phenomenon of fashion over-consumption (Siegel, 2011). To date there has not been any reviews of apparel brands CSR initiatives and actions or a cross-case review.

A common perception in the industry is that once the product has moved into the hands of the consumer, it is no longer the responsibility of the apparel brand (Joergens, 2006; Gwilt and Rissanen, 2011). However, considering the fact that the some of the largest impacts in the LCA of a garment are 
during the consumer use phase (Allwood et al., 2006; Laursen et al., 2007; Madsen et al., 2007; Fletcher, 2008), understanding and engaging of stakeholder groups such as the consumer at this phase seems logical in generating innovative solutions that satisfy both apparel brands and the consumer. By understanding where apparel brands are in reducing their environmental and social impacts will highlight areas and impacts that need to be addressed. Labour rights have been an issue since the beginning of the $20^{\text {th }}$ century and codes of conduct were introduced in the 1990s, however, in June 2012 an industrywide code of conduct guideline was published (NICE, 2012). There has, however, been a notable rise in the media attention of the CSR activities in the apparel and fashion industry along with the increasing market share of environmentally friendly apparel. These advances should help increase the pace of research, innovation and creative business strategies in developing a sustainable apparel system.

Further research could focus on evaluating the relationship between apparel brands CSR reporting of their programs and the actual implementation of their initiatives. This can include studies on effective supply-chain management and increasing transparency and traceability. Transparency and traceability increase the credibility of an apparel brand and its products. Studies may also be conducted on the effectiveness of actions and initiatives of apparel brands on consumer behaviour. It may also look at how to encourage more socially and environmentally responsible behaviours by the consumer such as disposing of clothing and or reducing impacts incurred during the use phase.

The cost of apparel will increase as we see the price of raw materials increase such as cotton and crude oil (Fletcher, 2008). It is becomingly increasingly difficult for apparel brands to keep the cost of clothing at the current value prices. The volume of clothing that is produced today and the value pricing is not sustainable and will affect the current fast fashion phenomenon. Research into new business models such as "slow fashion" can be studied and implemented and as to how consumers will react and adapt to rising clothing prices. This study has highlighted the many opportunities this industry has in becoming more sustainable. 
APPENDIX A: Database of collected CSR information

\section{CSR}

Presence of CSR report

Year of the first CSR report

Year of the current CSR report

Frequency of CSR reports

Number of pages in the current report

Number of pages dedicated to environmental issues

Number of pages dedicated to social issues

Scope of report

Use of guidelines

Use of gap analysis report

Presence and name of sustainability program

Presence of CSR team/department

Year CSR team/department was established

Presence of environmental policy

Availability of environmental policy to the public

Presence of EMS

\section{Profile}

Year company was established

Number of company brands

Type of retailer

Number of retail stores

Number of countries with retail locations

Number of employees

Presence of on line retailing

Presence of franchise stores

Annual revenue

Gross profit

\section{Employees}

Rating of employee satisfaction

Availability of long-term incentive programs to employees

Equal opportunities for employees

Presence of Code of Conduct

Availability of Code of Conduct to the public

Presence of labour rights policy

Presence of Community Engagement

Relief efforts

\section{Share listings}

DAX-30

MSCI World Textiles, Apparel \& Luxury Goods Index

Dow Jones Sustainability Index (DJSI) World (sustainability)

FTSE4 Good Europe Index (sustainability)

ASPI Index (sustainability)

London Stock Exchange 
ECPI Ethical Index Euro

ECPI Ethical Index Global

OMXGES Sustainability Nordic Index

Calvert Social Index

KLD Indexes

\section{Suppliers/Vendors/Factories}

Presence of multi-tiered Supply Chain

Number of suppliers

Number of countries with supplier locations

Number of factories

Presence of supplier standards

Presence of supplier assessment

Number of audit visits per year

Public availability of supplier list

Ownership of factories

Works with suppliers to improve compliance

Builds relationships with suppliers

Presence of education/training programs for workers

Presence of education/training programs for management

Limit the number of times subcontracting is permitted

Presence of system for tracking suppliers and subcontractors

Presence of subcontractor standards

Presence of Licensees

Presence of environmental guidelines

Presence of environmental management system

Use co-location for suppliers

Presence of supplier ranking system

Presence of worker standards

\section{Public Policy}

Works with local governments

Attempts to influence policy change

Participation in wage freedom of association issues in Cambodia

Participation in government enforcement of minimum wages in India

Ban against use of cotton from Uzbekistan

\section{Code of Conduct}

Presence of Code of Conduct

Presence of multiple Codes of Conduct

Year Code of Conduct was established

Year Code of Conduct was last revised

Presence of vendor code of conduct

Year vendor Code of Conduct was established

Year vendor Code of Conduct was last revised

Is the Code of Conduct based on standards

Developed own Code of Conduct

Uses Code of Conduct developed by others

Year sustainability initiatives began 


\section{Audits}

Presence of audit program

Presence of audit team

Are audits based on a standard?

Duration of audit

Total number of audits performed

Total number of facilities audited

Use of unannounced audits

Uses audit follow up practice

Availability of audit results to the public

Audits also performed by third parties?

How is the credibility of the audit program assessed?

How does the company deal with non-compliance?

How is compliance measured?

Presence of rating system

Violations categorized (major/minor)

Presence of key performance indicators

Action/remediation plans

Licensee audits

\section{Collaboration/multi-stakeholder initiatives/memberships}

\section{Social}

Sustainable Apparel Coalition

Fair Labor Association (FLA)

Business for Social Responsibility (BSR)

Fashion Against Aids

Water Aid

Global March Against Child Labor

Unicef

UN Global Initiative to Fight Trafficking

Self-Employed Women Association (SEWA)

Global Union Federation for Garment Sector (GUFGS)

International Labor Organization (ILO)

Social Accountability International (SAI)

Ethical Trading Initiative (ETI)

Apparel and Footwear International RSL Management (AFRIM) Working Group

International Garment and Leather Workers Association (ITGLWF)

UN Human Rights

Unicef All for Children Program

UN Global Compact (UNGC)

Garment Stakeholders Forum

American Red Cross

World Business Council for Sustainable Development (WBCSD)

World Federation of the Sporting Goods Federation (WFSCI)

Global Social Compliance Programme (GSCP)

Sustainable Compliance Initiative

Brown Shoe Collaboration

ILO Better Work

Human Resources Management System (HRMS)

Better Factory Cambodia (BFC) 
China Labor Support Network (CLSN)

Handshake

Brands Co-Operation Forum India

Garment Sector Roundtable India

World Economic Forum

DEFRA Sustainable Action Plan (SCAP)

International Federation of Agricultural Producers

Environmental

Better Cotton Initiatives (BCl)

UNGC's CEO Water Mandate

Textile Exchange

IMO

Cotton Inc.

Natural Resource Defense Council Responsible Sourcing Initiative

BSR's Apparel Mills and Sundries Working Group

Leather Working Group

Outdoor Industry Association (OIA)

European Outdoor Group (EOG)

World Wildlife Foundation (WWF)

Environmental Defense Fund (EDF)

Greenpeace Zero Discharge of Hazardous Chemicals

Pesticide Action Network UK

Solidaridad

Eco Working Group

Climate

Smartway (EPA)

Wayahead with ERRT (European Retail Round Table)

Clean Shipping Project

Ceres Business for Innovative Climate and Energy Policy (BICEP)

U.S. EPA's Climate Leader's Program

Carbon Disclosure Project

Climate Neutral Network

Supply-chain

Control Union

Supplier Ethical Data Exchange (SEDEX)

Global Apparel Strategic Alliance (GASA)

Collaborative Actions

Sustainable Clothing Action Plan (SCAP)

Worldwide Responsible Accredited Production (WRAP) Program

American Apparel and Footwear Association

Fair Factories Clearinghouse (FFC)

\section{Certifications}

OE 100

OE Blended

Control Union

IMO

ISO14001

OHSAS 18001 
LEED

Bluesign

Oeko-Tex

\section{Consumer Engagement}

Washing/drying behaviours

Clothing end-of-life disposal

\section{Environment}

Identified environmental impact in supply chain

Share best practices

Conduct LCA

Presence of data reporting

\section{Raw Materials}

Organic Cotton use

Third/independent party certification

Accredited certification body

Factories certified to relevant standard

Transaction certification

Organic linen use

Third/independent party certification

Accredited certification body

Factories certified to relevant standard

Transaction certification

Organic wool use

Third/independent party certification

Accredited certification body

Factories certified to relevant standard

Transaction certification

Organic hemp use

Third/independent party certification

Accredited certification body

Factories certified to relevant standard

Transaction certification

Recycled cotton use

Third/independent party certification

Accredited certification body

Factories certified to relevant standard

Transaction certification

Recycled polyester use

Third/independent party certification

Accredited certification body

Factories certified to relevant standard

Transaction certification 
Recycled polyamide use

Third/independent party certification

Accredited certification body

Factories certified to relevant standard

Transaction certification

Recycled wool use

Third/independent party certification

Accredited certification body

Factories certified to relevant standard

Transaction certification

Tencel $^{\mathrm{TM}}$ use

Third/independent party certification

Accredited certification body

Factories certified to relevant standard

Transaction certification

Sustainable textiles

Other sustainable textiles

Fur use

Leather use

PVC use

VOC use

Transparency/traceability/'String'

Offer $100 \%$ organic

Organic blends

Used in all clothing divisions

Specialized collections

Garments labeled accordingly

\section{Goals}

Organic cotton use

Transitional cotton

Recycled cotton

Better Cotton $(\mathrm{BCl})$ sustainable cotton

Fair-trade cotton

Recycled polyester

Tencel $^{\mathrm{TM}}$

Organic linen

Organic wool

Recycled wool

Clothing recycling

\section{Progress}

GHG emissions

Baseline data to measure targets 


\title{
Energy Efficiency \& Climate Change - Targets
}

\author{
Greenhouse gas \\ Target met \\ Offset \\ Political action \\ Sourcing \\ Use \\ Overall environmental footprint \\ Energy consumption
}

\section{Water conservation}

Waterless dyeing

Water reduction

\section{Waste}

Waste reduction

Recycling

Apparel recycling

Hanger recycling

Hanger reuse

\section{Chemicals}

Restricted substance list (RSL)

Hazardous Chemical Discharge Initiative Greenpeace Detox

Chemical tests

Environmental guideline regarding textile wet processing

Low-impact dye use

\section{Design}

Materials guidelines

Materials guidelines database

Data source for database

Frequency of updates

Index tool

Sustainability training/education

Use of LCA

Data source for LCA

Review current research

Use RSL

Availability of RSL to the public

Frequency of updates

PVC use

Design for environment approach

Colour use

Colour combination

Dye use

Material combination 
Reduce product/style ranges

Sustainable material content

Sustainable product guidelines

Eco-Index tool

Sandblasting ban for denim

Reduce textile waste/scraps

Sustainable material content

Sustainability throughout entire product range

Pattern efficiency

Use cotton/polyester blends (natural/technical nutrient blend)

Environmentally preferred rubber 


\section{References}

Abernathy, F. H., Dunlop, J. T., Hammond, J. H., \& Weil, D. (1999). A stitch in time. New York, NY: Oxford University Press.

Adams, C. A., \& Frost, G. R. (2008). Integrating sustainability reporting into management practices. Accounting Forum, 32, 288-302.

Adams, C. (2004). The ethical, social and environmental reporting-performance portrayal gap. Accounting, Auditing \& Accountability Journal, 17 (5), 731-757.

Adidas Group. (2012, April 13). Takeback programme for sports shoes is a groundbreaking initiative in Brazil. Retrieved May 19, 2012, from Adidas Group: http://www.adidas-

group.com/en/sustainability/Environment/Archive/2012_takeback_programme_brazil.aspx

Agins, T. (2000). The end of fashion: How marketing changed the clothing business forever. New York, NY: William Morrow Paperbacks.

Akgun, M. E. (2008). An epidemic of silicosis among former denim sandblasters. European Respiratory Journal, 32 (5), 1295-1303.

Akgun, M. E. (2005). Silicosis caused by sandblasting of jeans in Turkey: a report of two concomitant cases. Journal of Occupational Health, 47, 346-349.

Allwood, J. M., Laursen, S. E., Malvido de Rodríguez, C., \& Bocken, N. M. (2006). Well dressed? The present and future sustainability of clothing and textiles in the United Kingdom. Cambridge, UK: University of Cambridge Institute for Manufacturing.

American Apparel Manufacturers Association. (1996). Focus, an economic profile of the apparel industry. Arlington, VA: American Apparel Manufacturers Association.

Anaya, S. (2010, July) In ethical fashion, desirability is sustainability. Retrieved May 20,2012, from: http://www.businessoffashion.com/2010/07/in-ethical-fashion-desirability-is-sustainability.

Armstrong, C. M., \& LeHew, M. L. (2011). Sustainable apparel product development: In search of a new dominant social paradigm for the field using sustainable approaches. Fashion Practice, 3 (1), 29-62.

Bank of Canada. (2012). Inflation calculator. Retrieved May 20, 2012, from: http://www.bankofcanada.ca/rates/related/inflation-calculator/

Barthes, R. (2006). The language of fashion. Oxford, UK: Berg Publishers.

Bell, Q. (1979). On human finery. New York, NY: Shocken Books.

Benjamin, W. (2003). Selected writings, vol. IV: 1938-40. Cambridge, MA: Belknap Press of Harvard University Press.

Bennett, W. (2003). Communicating global activism. Information, Communication \& Society, 6 (2), 143168.

Besieux, M. E. (March 2012). Dirty laundry: Reloaded. Amsterdam: Greenpeace International.

Better Cotton Initiative. (2012). Better cotton initiative. Retrieved August 31, 2012 from:

http://bettercotton.org/ 
Bhaduri, G., \& Ha-Brookshire, J. E. (2011). Do transparent business practices pay? Exploration of transparency and consumer purchase intention. Clothing and Textile Research Journal, 29 (2), 135-149.

Birtwistle, G. \& Moore, C.M. (2007). Fashion clothing - where does it all end up? International Journal of Retail \& Distribution Management, 35(3), 210-216.

Brand, J., Teunessen, J., Van der Zwaag, A., \& Van den Berg, N. (2006). The power of fashion: About design and meaning. Arnhem, Netherlands: Uitgeverij Terra.

Brookshire, J.E., \& Norum, P.S. (2011). Willingness to pay for socially responsible products: Case of cotton apparel. Journal of Consumer Marketing, 28(5), 345-353.

Bisschops, I., \& Spanjers, H. (2003). Literature review on textile wastewater characterisation. Environmental Technology, 24 (11), 1399-1411.

Bondy, K., Matten, D., \& Moon, J. (2008). Multinational corporation codes of conduct: Governance tools for corporate social responsibility? Corporate Governance: An International Review, 16 (4), 294-311.

Bouten, L., Everaert, P., Van Liedekerke, L., \& De Moor, L. (2011). Corporate social responsibility reporting: A comprehensive picture? Accounting Forum, 35, 187-204.

Braungart, M. (2002). Cradel to cradle. New York, NY: North Point Press.

Breward, C. (2003). Fashion. Oxford, UK: Oxford University Press.

Breward, C. (1995). The culture of fashion. Manchester, UK: Manchester University Press.

Browne, M. A., Crump, P., Niven, S. J., Teuten, E., Tonkin, A., Galloway, T., et al. (2011, September 06). Accumulation of microplastic on shorelines worldwide: Sources and sinks. Environmental Science \& Technology, 45 (21), 9175-9179.

Business for Social Responsibility. (2012). The state of sustainable business. Retrieved November 5 , 2011 from: https://www.bsr.org/en/about/bsr-report/2010/the-state-of-sustainable-business

Butler, S. M., \& Francis, S. (1997). The effects of environmental attitudes on apparel purchasing behavior. Clothing and Textile Research Journal, 15 (2), 76-87.

Calefato, P. (2004). The clothed body. New York, NY: Berg Publishers.

Carrigan, M., \& Attalla, A. (2001). The myth of the ethical consumer - do ethics matter in purchase behaviour. Journal of Consumer Marketing, 18 (7), 560-578.

Carroll, A. (1999). Corporate social responsibility, evolution of a definitional construct. Business \& Society, 38 (3), 268-295.

Carroll, A. (1991). The pyramid of corporate social responsibility: Toward the moral management of organizational stakeholders. Business Horizons, 34 (4), 39-48.

Carter, C. R., \& Rogers, D. S. (2008). A framework of sustainable supply chain management: moving toward new theory. International Journal of Physical Distribution \& Logistics Management, 38 (5), 360 387.

Carty., V. (2001). The Internet and grassroots politcs: Nike, the athletic apparel industry and the antisweatshop campaign. Journal of Critical Postmodern Organization Science, 1 (2), 34-48. 
Centers for Disease Control. (2003, September 05). International chemical safety cards - Antimony trioxide. Retrieved July 03, 2012, from: http://www.cdc.gov/niosh/ipcsneng/neng0012.html

Chan, S. H., Wu, T. Y., Juan, J. C., \& Teh, C. Y. (2011). Recent developments of metal oxide semiconductors as photocatalysts in advanced oxidation processes (AOPs) for treatment of dye wastewater. Journal of Chemical Technological \& Biotechnology, 1130-1158.

Chen, H. L., \& Burns, L. D. (2006). Environmental analysis of textile products. Clothing and Textiles Research Journal, 24 (3), 248-261.

Claudio, L. (2007). Waste couture. Environmental Health Perspectives, 115 (9), 458-454.

Clay, J. (2004). World agriculture and the environment. Washington, DC: Island Press.

Clean Clothes Campaign. (March 2012). Deadly Denim - Sandblasting in the Bangladesh garment industry. Amsterdam, the Netherlands: Clean Clothes Campaign.

CSR Europe. (2009, September 1). Trends and best practice in online CSR/sustainability reporting. Retrieved May 17, 2012, from: http://ec.europa.eu/enterprise/policies/sustainable-business/corporatesocial-responsibility/reporting-disclosure/swedish-

presidency/files/surveys_and_reports/trends_and_best_practice_in_online_csr_and_sustainability_rep_e n.pdf

Connell, K. Y. H. (2010). Internal and external barriers to eco-conscious apparel acquisition. International Journal of Consumer Studies, 34, 279-286.

DEPA. (2003). Danish Environmental Protection Agency: Survey of chemicals in consumer products No23: Survey of chemical compounds in textile fabrics. Retrieved June11, 2012 from: http://www.mst.dk/NR/rdonlyres/B9CDE217-9E41-4F27-A8A3-921D5B50A737/0/23.pdf.

Davis, G., \& Searcy, C. (2010). A review of Canadian corporate sustainable development reports. Journal of Global Responsibility, 1 (2), 316-329.

De Tienne, K. B., \& Lewis, L. W. (2005). The pragmatic and ethical barriers to Corporate Social Responsibility disclosure: The Nike case. Journal of Business Ethics, 60, 359-376.

Deegan, C. (2002). Introduction: The legitimising effect of social and environmental disclosures -A theoretical foundation. Accountability \& Auditing Accountability Journal, 15, 282-311.

Dell, J. (2011, September 20). Pressure on Uzbekistan to end child cotton labour. Retrieved May 20, 2012 from: http://www.bbc.co.uk/news/world-asia-pacific-14973062

Dickson, M. A., \& Eckman, M. (2006). Social responsibility: The concept as defined by apparel and textile scholars. Clothing \& Textiles Research Journal, 24 (3), 178-191.

Dickson, M. A., \& Littrell, M. A. (1996). Socially responsible behaviour: values and attitudes of the alternative trading organisation consumer. Journal of Fashion Marketing and Management, 1 (1), 50 - 69.

Dickson, M. A., Loker, S., \& Eckman, M. (2009). Social responsibility in the global apparel industry. New York, NY: Fairchild Books.

Donaldson, T., \& Preston, L.E. (1995). The stakeholder theory of the corporation: Concepts, evidence and implications. The Academy of Management Review, 20(1), 65-91.

Easey, M. (Ed) (1995). Fashion marketing. Blackwell Science, Oxford. 
Eckman, M., Damhorst, M. L., \& Kadol, S. J. (1990). Toward a model of the in-store purchase decision process: Consumer use of criteria for evaluating women's apparel. Clothing and Textiles Research Journal, 8 (13), 13-22.

EcoTextile News. (2012, June/July). A blueprint for sustainable fashion. EcoTextile News, 49, 35-36.

EcoTextile News. (2012, June 24). Climate change impacts textile profits. Retrieved June 24, 2012, from: http://www.ecotextile.com/2012061311549/fashion-retail-news/climate-change-impacts-textile-profits.html

EcoTextile News. (2012, June/July). Consumer-facing eco label. EcoTextile News, 49, 4.

Ecotextile News. (2012, June 13). Climate change impacts textile profits. Retrieved June 20, 2012 from: http://www.ecotextile.com/2012061311549/fashion-retail-news/climate-change-impacts-textile-profits. html (2012). Retrieved July 5, 2012, from NIKE Inc.: http://nikeinc.com/pages/responsibility\#

Environmental Justice Foundation. (2009). Somebody knows where your cotton comes from. Retrieved June 20, 2012, from: http://www.ejfoundation.org/pdf/track_and_trace_web.pdf

Environmental Justice Foundation. (2012). The Numbers Speak for Themselves. Retrieved June 12, 2012, from: http://www.ejfoundation.org/page148.html

Elliot, K., \& Freeman, R. (2003). Can labor standards improve under globalization? Washington, DC: Institute for International Economics.

Ellram, L., \& Cooper, M. (1993). Characteristics of supply chain management and the implications for purchasing and logistics strategy. International Journal of Logistics Management, 4 (2), 1-10.

Emmelhainz, M. A., \& Adams, R. J. (1999). The apparel industry response to "sweatshop" concerns: A review and analysis of codes of conduct. The Journal of Supply Chain Management: A Global Review of Purchasing and Supply, 35 (3), 51-57.

Energy Star. (2012, April 18). Clothes washers. Retrieved March 20, 2012 from: http://www.energystar.gov/index.cfm?fuseaction=find_a_product.showProductGroup\&pgw_code=CW

Energy Star. (2012). Clothes washing. Retrieved June 12, 2012, from:

$\mathrm{http}: / /$ www.energystar.gov/index.cfm?fuseaction=find_a_product.showProductGroup\&pgw_code=CW

Environment Canada. (2001, March 01). Priority substances list assessment report: Textile mill effluents. Retrieved June 1, 2012, from: http://www.hc-sc.gc.ca/ewh-semt/pubs/contaminants/psl2Isp2/textile_effluents/index-eng.php

Environmental Justice Foundation. (2012). Cotton in Uzbekistan. Retrieved May 20, 2012, from: http://www.ejfoundation.org/page142.html

Environmental Justice Foundation. (2012). White gold: Uzbekistan, a slave nation for our cotton? London, UK: Environmental Justice Foundation.

Epstein, M. J. (2008). Making sustainability work. Sheffield, UK: Greenleaf Publishing Limited.

Epstein, M. J., \& Roy, M.J. (2003). Making the business case for sustainability; linking social and environmental actions to performance. Journal of Corporate Citizenship, 9, 79-96.

Esbenshade, J. (2004). Monitoring sweatshops: Workers, consumers, and the global apparel industry. Philadelphia: Temple University Press. 
European Commission. (2001, July 18). Promoting a European framework for Corporate Social Responsibility. Retrieved July 29, 2012, from: http://eur-

lex.europa.eu/LexUriServ/site/en/com/2001/com2001_0366en01.pdf

Fairtrade Foundation. (2010, November). The great cotton stitch-up. Retrieved November 14, 2011, from Fairtrade Foundation:

http://www.fairtrade.org.uk/includes/documents/cm_docs/2010/f/2_ft_cotton_policy_report_2010_loresv2. pdf

Fan, D., \& Lo, C. K. (2012). A tough pill to swallow? The impact of voluntary occupational health and safety management system on firms' financial performance in fashion and textiles industries. Journal of Fashion Marketing and Management, 16 (2), 128-140.

Farrer, J., \& Fraser, K. (2009). Conscience clothing: polarization of the fashion textile market. TextilesQuarterly Magazine of the Textile Institute, (1), 10-13.

Farrer, J., \& Finn, A. (2008). A solution to fashion textile unsustainability. PerAda Magazine. Retrieved April 7, 2012 from: http://www.perada-magazine.eu/pdf/1314/1314.pdf

Ferrigno, S. (2012). An insider's guide to: Cotton sustainability. London, UK: MCL Global.

Fair Labor Association. (2012). Retrieved November 16, 2011 from: http://www.fairlabor.org/

Fletcher, K. (2008). Sustainable fashion \& textiles. London, UK: Earthscan.

Fletcher, K., \& Grose, L. (2012). Fashion \& sustainability. London, UK: Lawrence King Publishing Ltd.

Freeman, E. (1984). Strategic management: A stakeholder approach. Boston, MA: Pitman.

Gam, H. J. (2011). Are fashion-conscious consumers more likely to adopt eco-friendly clothing? Journal of Fashion Marketing and Management, 15 (2), 178-193.

Gereffi, G. (1999). International trade and industrial upgrading in the apparel commodity chain. Journal of International Economics, 48 (1), 37-70.

Gereffi, G., \& Frederick, S. (April 2010). The global apparel value chain, trade and the crisis. The World Bank: Development Research Group \& Trade and Integration Team. Retrieved May 14, 2012 from:

http://www-

wds.worldbank.org/external/default/WDSContentServer/IW3P/IB/2010/04/27/000158349_2010042711184 1/Rendered/PDF/WPS5281.pdf

Glin, L., Kuiseu, J., Thiam, A., Vodouhê, D. S., Dinham, B., \& Ferrigno, S. (2010). Living with poison pesticides in West African cotton growing. London, UK: PAN UK.

Goodwill. (2009, October 21). Retrieved June 16, 2012, from: http://www.goodwill.org/pressreleases/levis-and-goodwill-partner-to-launch-a-care-tag-for-our-planet/

Gottlieb, A., Shaw, C., Smith, A., Wheatley, A., \& Forsythe, S. (2003). The toxicity of textile reactive azo dyes after hydrolysis and decolourisation. Journal of Biotechnology, 101 (1), 49-56.

Goworek, H. (2011). Social and environmental sustainability in the fashion industry: a case study of a fair trade retailer. Social Responsibility Journal. 7(1), 74-86.

Gracey, F., \& Moon, D. (2012). Valuing our clothes: The evidence base. WRAP.

Graedel, T., \& Allenby, R. (1995). Industrial Ecology. New Jersey: Prentice Hall. 
Greenpeace. (2010). Dirty laundry. Amsterdam, the Netherlands: Greenpeace International.

GRI. (2011). Sustainability reporting guidelines \& apparel and footwear sector supplement. Amsterdam, the Netherlands. Electronic Pilot Version: GRI.

Gwilt, A., \& Rissanen, T. (2011). Shaping sustainable fashion: Changing the way we make and use clothes. London, UK: Earthscan.

Hemphill, T. A. (2004). Monitoring global corporate citizenship: Industry self-regulation at a crossroads. The Journal of Corporate Citizenship, 14, 81-95.

Hethorn, J., \& Ulasewicz, C. (2008). Sustainable fashion: Why now? New York, NY: Fairchild Books.

Hillary, R. (ed.) (1995). Life cycle assessment. Cheltenham, UK: Stanley Thornes.

Hiller Connell, K. Y. (2011). Exploring consumers' perceptions of eco-conscious apparel acquisition behaviors. Social Responsibility Journal, 7 (1), 61-73.

Holton, L. (2012, June 25). Brits toss \$142 million in clothing after single wearing. Retrieved June 25, 2012, from: http://www.greenbiz.com/blog/2012/06/25/brits-toss-142-million-clothing-after-singlewearing?page $=0 \% 2 \mathrm{C} 1$

Horn, M. J., \& Gurel, L. M. (1975). The second skin: An interdisciplinary study of clothing. Boston, MA: Houghton Mifflin.

HRSDC. (2012). Canadians in context - Population size and growth. Retrieved May 20, 2012, from: http://www4.hrsdc.gc.ca/.3ndic.1t.4r@-eng.jsp?iid=35

Hubbard, G. (2009). Unsustainable reporting. Adelaide, Australia: University of Adelaide.

Hubbard, J. (2012, May 16). Water consumption and footwear. Retrieved June 20, 2012 from: http://www.wto.org/english/res_e/publications_e/wtr10_forum_e/wtr10_6july10_e.htm

Hunkeler D., \& Rebitzer G. (2003). Life cycle costing - Paving the road to sustainable development? The International Journal of Life Cycle Assessment, 8 (2), 109-111.

Hustvedt, G., \& Dickson, M. A. (2009). Consumer likelihood of purchasing organic cotton apparel: influences of attitudes and self identity. Journal of Fashion Marketing and Management, 13 (1), 49-65.

IHE Delft. (2003, March). Virtual water trade. Retrieved May 20, 2012, from:

http://www.waterfootprint.org/Reports/Report12.pdf

Institute of Public \& Environmental Affairs. (2012). Cleaning up the fashion industry. Institute of Public \& Environmental Affairs.

ISO. (2006). ISO 14040 International Standard. Environmental management life cycle assessment principles and framework. Geneva, Switzerland, International Organization for Standardization.

Israel Rosen, E. (2002). Making sweatshops: The globalization of the U.S. apparel industry. Berkeley, CA: University of California Press.

Jin, B. (2006). Performance implications of information technology implementation in an apparel supply chain. Supply Chain Management: An International Journal, 11 (4), 309-316.

Joergens, C. (2006). Ethical fashion: myth or future trend? Journal of Fashion Marketing and Management, 10 (3), 360 - 371. 
Jones, R. M. (2006). The apparel industry. Ames, IW: Blackwell Publishing.

Kaiser, S. (2008). Mixing metaphors in the fiber, textile, and apparel complex: Moving toward a more sustainable fashion system. In J. Hethorn, \& C. Ulasewicz, Sustainable fashion: Why now? (pp. 139-163). New York, NY: Fairchild Books.

Kakabadse, N. K., Rozuel, C., \& Lee-Davies, L. (2005). Corporate social responsibility and stakeholder approach: a conceptual review. International Journal of Business Governance and Ethics, 1 (4), 277-302.

Kamila, A. Y. (May/June 2003). How three green businesses survive the U.S. textile industry collapse. In Business, 25 (3), 10.

Kant, I. (1798/2006). Anthropology from a pragmatic point of view. (R. B. Louden, Ed.) Cambridge, UK: Cambridge University Press.

Kaufman, A., Tiantubtim, E., Pussayapibul, N., \& Davids, P. (2004). Implementing voluntary labour standards and codes of conduct in the Thai garment industry. The Journal of Corporate Citizenship, 13, 91-99.

Kerschner, E. M., \& Huq, N. (2011, 06). Asian affluence: The emerging 21st century middle class. Retrieved May 18, 2012, from: http://fa.smithbarney.com/public/projectfiles/35257b34-b160-45e4-980d8bca327db92b.pdf

Kilner, J. (2011, 09 18). Global clothing brands boycott Uzbek cotton. Retrieved May 20, 2012, from: http://www.telegraph.co.uk/news/worldnews/asia/uzbekistan/8771473/Global-clothing-brands-boycottUzbek-cotton.html

Kim, H. S., \& Damhorst, M. L. (1998). Environmental concern and apparel consumption. Clothing and Textiles Research Journal, 16 (3), 126-133.

Kim, H.-S., \& Damhorst, M. L. (1999). Environmental attitude and commitment in relation to ad message credibility. Journal of Fashion Marketing and Management, 3 (1), 18-30.

King, C. (1963). Fashion adoption: a rebuttal to the 'trickle down theory'. In G. Sproles, Perspectives of Fashion (pp. 31-39). Minneapolis, MN: Burgess Publishing.

Klein, N. (2000). No logo: Taking aim at the brand bullies. Toronto, ON: Knopf-Random.

Klien, J. G., Smith, N. C., \& John, A. (2004). Why we boycott: consumer motivations for boycott participation. Journal of Marketing, 68, 92-109.

KPMG International. (2010). KPMG International survey corporate responsibility survey reporting 2008. Luxembourg: KPMG International.

Langener, L. (1959). The importance of wearing clothes. New York, NY: Hastings House.

Laufer, W. S. (2003). Social accountability and corporate greenwashing. Journal of Business Ethics, 43 (3), 253-261.

Laursen, S. E., Hansen, J., Drojdahl, A., Hansen, O. C., Pommer, K., Pedersen, E., et al. (2003). Survey of chemical compounds in textile fabrics. Copenhagen, Danish Environmental Protection Agency.

Laursen, S. E., Hansen, J., Knudsen, H. H., Wenzel, H., Larsen, H. F., \& Kristensen, F. M. (2007). EDIPTEX - Environmental assessment of textiles. Danish Ministry of the Environment.

Laursen, S., \& Hansen, J. (1997). Environmental assessment of textiles. Copenhagen, Denmark: Danish Environmental Protection Agency. 
Law, K.M., Zhang, Z.M., \& Leung, C.S. (2004). Fashion change and fashion consumption: the chaotic perspective. Journal of Fashion Marketing and Management, 8(4), 362-374.

Lee, Y., \& Kincade, D. H. (2003). US apparel manufacturers' company characteristic differences based on SCM activities. Journal of Fashion Marketing and Management, 7 (1), 31 - 48.

Lim, S.-J., \& Phillips, J. (2008). Embedding CSR values: The global footwear industry's evolving governance structure. Journal of Business Ethics, 81, 143-156.

Lin, J. (2003). A new look: retail clothing sales in Canada. Retrieved May 20, 2012, from: http://www.statcan.gc.ca/pub/11-621-m/11-621-m2003006-eng.pdf

Lipovetsky, G. (1994). The empire of fashion: Dressing modern democracy. Princeton, NJ: Princeton University Press.

Ljungberg, L. Y. (2007). Materials selection and design for development of sustainable products. Materials in Engineering, 28 (2), 466-479.

Locke, R., Qin, F., \& Brause, A. (2007). Does monitoring improve labour standards? Lessons from Nike. Industrial and Labor Relations Review, 61 (1), 3-31.

Lohman, C., Fortuin, L., \& Wouters, M. (2004). Designing a performance measurement system: A case study. European Journal of Operational Research, 156 (2), 267-286.

Marks \& Spencer. (2012). Plan A. Retrieved July 16, 2012, from:

http://plana.marksandspencer.com/about/partnerships/oxfam/shwopping

Madsen, J., Hartlin, B., Perumalpillai, S., Selby, S., \& Aumônier, S. (2007). Mapping of evidence on sustainable development impacts that occur in life cycles of clothing. Report to the Department for Environment, Food and Rural Affairs, Environmental Resources Management (ERM) Ltd. Defra, London. Retrieved from: http://randd.defra.gov.uk/Document.aspx?Document=EV02028_7073_FRP.pdf.

Marian, P. (2012, 04 11). CHINA: Global brands hit by new claims of textile pollution. Retrieved May 24, 2012, from: http://www.just-style.com/news/global-brands-hit-by-new-claims-of-textile-

pollution_id114017.aspx

McDonough, W., Braungart, M., Anastas, P. T., \& Zimmerman, J. B. (2003). Applying the principles of green engineering to cradle-to-cradle design. Environmental Science \& Technology, 37 (23), 434A-451A.

McWilliams, A., \& Siegel, D. (2001). Corporate social responsibility: a theory of the firm perspective. The Academy of Management Review, 26 (1), 117-127.

Meadows, D. (2008). Thinking in systems. White River Junction, VT: Chelsea Green Publishing.

Mekonnen, M., \& Hoekstra, A. Y. $(2010,12)$. The green, blue and grey water footprint of crops and derived crop products. Retrieved June 20, 2012, from: http://www.waterfootprint.org/Reports/Report47WaterFootprintCrops-Vol1.pdf

Micklin, P. (2007). The Aral Sea disaster. Retrieved May 12, 2012, from: http://www.iml.rwthaachen.de/elearning/srw/uebungsmaterial/AralSeaDisaster.pdf

Minney, S. (2012). Naked fashion: The new sustainable fashion revolution. Oxford, UK: New Internationalist. 
Moore, B. (2011, 1101$)$. Has campaigning for an ethical fashion industry had any impact? Retrieved May 22, 2012, from: http://www.guardian.co.uk/environment/green-living-blog/2011/nov/01/campaigningethical-fashion-industry

Morgan, L. R., \& Birtwistle, G. (2009). An investigation of young fashion consumers' disposal habits. International Journal of Consumer Studies, 33 (2), 190-198.

Nakano, Y. (2007). Perception towards clothes with recycled content and environmental awareness: The development of end markets, In M. Miraftab, \& AR Horrocks, (eds), In Ecotextiles: The way forward for sustainable development in textiles, (pp. 3-14), Cambridge, UK: Woodhead Publishing Limited.

Natural Resources Canada. (2010, September 16). Retrieved June 21, 2012, from: http://oee.nrcan.gc.ca/equipment/appliance/9965

Natural Resources Canada. (2010, August 10). Retrieved May 21, 2012, from: http://oee.nrcan.gc.ca/equipment/appliance/10333

Natural Resources Canada. (2010, August 10). Buying and operating tips: Clothes dryers. Retrieved from: http://oee.nrcan.gc.ca/residential/personal/appliances/clothes-dryers-tips.cfm?attr=4

Natural Resources Canada. (2010, September 16). Buying tips: clothes washers. Retrieved November 10, 2011, from: http://oee.nrcan.gc.ca/residential/personal/appliances/clothes-washers-tips.cfm?attr=4

NICE. (2012, June 10). Retrieved Feburary 19, 2012 from: http://www.nicefashion.org/en/news/code.html

Nikereuseashoe. (2012). Nike Grind. Retrieved July 16, 2012, from:

http://www.nikereuseashoe.com/using-nike-grind

Noack, S. (2011). Cleaner production in jeans laundries in Northeast Brazil. Implementing Environmental and Resource Management, 1, 79-89.

Noor, K. B. (2008). Case study: A strategic research methodology. America Journal of Applied Science, 5 (11), 1602-1604.

Nordic Fashion Association. (2012). NICE code of conduct: For the fashion and textile industry. Copenhagen: Nordic Fashion Association \& Danish Fashion Institute.

NRDC. (2011, March 19). Smarter business: Smart design. Retrieved July 17, 2012, from: http://www.nrdc.org/business/design/denim.asp\#.UA2GpDbdrCk.

Organic Textile Association. (2011). Cotton and the environment. Retrieved June 21, 2012, from: http://www.ota.com/organic/environment/cotton_environment.html

Pariset, J. (2008, February). The linen shirt eco-profile. Retrieved May 28, 2012, from: http://www.saneco.com/IMG/pdf/linen_shirt_eco-profile.pdf

Park, H., \& Lennon, S.J. (2006). The organizational factors influencing socially responsible apparel buying/sourcing. Clothing and Textiles Research Journal, 24(3), 229-247.

Patagonia.com (2012). Environmentalism. Retrieved June 25, 2012, from: http://www.patagonia.com/ca/environmentalism

Plastina, A. (2005). Cotton consumption rebounds but cotton's market share falls. Retrieved July 03, 2012, from: http://www.cottonbangladesh.com/April2010/lCAC.htm 
Pruett, D., \& CCC. (2005). Looking for a quick fix: How weak social auditing is keeping workers in sweatshops. Amsterdam, the Netherlands: Clean Clothes Campaign.

Pui-Yan Ho, H., \& Choi, T.-M. (2012). A Five-R analysis for sustainable fashion supply chain management in Hong Kong: a case analysis. Journal of Fashion Marketing and Management, 16 (2), 161-175.

Puma. (2011, April). Annual Report 2010. Retrieved October 04, 2011, from: http://safe.puma.com/us/en/wp-content/uploads/GB-e-2010-sp.pdf

Quinn, F. J. (1997). What's the buzz? Logistics Management, 36 (2), 43-47.

Quodon, J. (2004). Effects of the introduction of an EPR management system on the economy. In Development, Economic Aspects of Extended Producer Responsibility (pp. 119-133). Danvers, MA: OECD.

ReDress Limited. (2012). Retrieved June 18, 2012, from The R Certificate: http://rcertificate.com/

Remmen, A., Astrup, A., \& Frydendal, J. (2007). Life cycle management: The business guide to sustainability. Retrieved March 25, 2012, from: http://www.unep.org/pdf/dtie/DTI0889PA.pdf

Riddselius, C. (November 2010). Fashion victims - a report on sandblasted denim. Stockholm, Sweden: Fair Trade Center.

Ridoutt, B. G., \& Pfister, S. (2010). A revised approach to water footprinting to make transparent the impacts of consumption and production on global freshwater scarcity. Global Environmental Change, 20, 113-120.

Rin, J. (2000). Development of environmental performance indicators for textile process and product. Journal of Cleaner Production, 8 (6), 473-481.

Roca, L. C., \& Searcy, C. (2012). An analysis of indicators disclosed in corporate sustainability reports. Journal of Cleaner Production, 20, 103-118.

Rock, M. (2003). Public disclosure of the sweatshop practices of american multinational garment/shoe makers/retailers: Impacts on their stock prices. Competition and Change, 7 (1), 23-38.

Reap, J., Roman, F., Duncan, S., \& Bras, B. (2008). A survey of unresolved problems in life cycle assessment. The International Journal of Life Cycle Assessment, 13(4), 290-300.

Ross, R. (2008). Clothing: A global history. Cambridge, UK: Polity Press.

Ross, R. (2004). Slaves to fashion: Poverty and abuse in the new sweatshops. Ann Arbor, MI: University of Michigan Press.

Rudell, F., \& College, I. (2006). Shopping with a social conscience: Consumer attitudes toward sweatshop labor. Clothing and Textiles Research Journal, 24 (4), 282-296.

Sartre, J.-P. (1993). Being and nothingness. New York, NY: Washington Square Press.

Searcy, C. (2009). Setting a course in corporate sustainability performance measurement. Measuring Business Excellence, 13 (3), 49 - 57.

Searcy, C. (2011). Updating corporate sustainability performance measurement systems. Measuring Business Excellence, 15 (2), 45-56. 
Shaw, D., \& Tomolillo, D. (2004). Undressing the ethical issues in fashion: A consumer perspective, In Bruce, M., Moore, C. and Birtwistle, G. (Eds.), International Retail Marketing: A Case Study Approach (pp. 141-152). Burlington, MA: Elsevier Butterworth-Heinemann.

Shaw, D., Hogg, G., Wilson, E., Shui, E., \& Hassan, L. (2006). Fashion victim: The impact of fair trade concerns on clothing choice. Journal of Strategic Marketing, 14, 427-450.

Shen, L., Worrell, E., \& Patel, M. K. (2010). Environmental impact assessment of man-made cellulose fibres. Resources, Conservation and Recycling, 55, 260-274.

Sherburne, A. (2009). Achieving sustainable textiles: A designer's perspective. In R. Blackburn, Sustainable Textiles - Life cycle and environmental impact (pp. 3-32). Boca Raton, FL: Woodhead Publishing Limited.

Sherman, R. W. (2009). The Global Reporting Initiative: What value is added? International Business \& Economics Research Journal, 8 (5), 9-22.

Siegle, L. (2012, April 07). Is H\&M the new home of ethical fashion? Retrieved April 7, 2012, from: http://www.guardian.co.uk/business/2012/apr/07/hennes-mauritz-h-and-m

Siegle, L. (2011). To die for. London, UK: Fourth Estate Ltd.

Simmel, G. (2003). The philosophy of fashion. In D. B. Clarke, M. A. Doel, \& K. M. Housiaux (Eds.), The Consumption Reader (pp. 238-245). New York, NY: Routledge.

Smith, A. (1759/2002). The theory of moral sentiments. In Haakonssen, K. (Ed.), Cambridge, UK: Cambridge University Press.

Smith, G. G., \& Barker, R. H. (1995). Life cycle analysis of a polyester garment. Resources, Conservation and Recycling, 14, 233-349.

Soles4souls. (2012). Retrieved July 17, 2012, from:

http://www.soles4souls.org/get_involved/statewidedrives.html

Soles4souls. (2012). Go green with soles4souls. Retrieved May 20, 2012, from:

http://www.soles4souls.org/about/green.html

Soth, J., Grasser, C., Salerno, R., \& Thalmann, P. (1999). The impact of cotton of fresh water resources and ecosystems. Zurich, Switzerland: WWF.

Spar, D., \& La Mure, L. (2003). The power of activism: assessing the impact of NGOs on global business. California Management Review, 45 (3), 78-101.

Sproles, G. (1981). Analysing fashion life cycles - principles and perspectives. Journal of Marketing, 45, 116-124.

Steinberger, J. K., Friot, D., Jolliet, O., \& Erkman, S. (2009). A spatially explicit life cycle inventory of the global textile chain. The International Journal of Life Cycle Assessment, 14 (5), 453-455.

Stephens Fringes, G. (2002). Fashion: From concept to consumer. Upper Saddle River, NJ: Prentice-Hall.

Stevens, C. (2004). Extended producer responsibility and innovation, In Organisation for Economic CoOperation and Development, Economic Aspects of Extended Product Responsibility (pp. 199-217).

Danvers, MA: OECD. 
Stewart, M. L. (2005). Copy and copyrighting haute couture: Democratizing fashion, 1900-1930s. French historical Studies, 103-130.

Stone, E. (2012). In Fashion. New York, NY: Fairchild Books Inc.

Strutnin, R. (2008). Managing brands through supply chain visibility. China Business Review, 35 (3), $30-$ 33.

Supply Chain Council. (2012). What is "supply chain"? Retrieved July 29, 2012, from: http://supplychain.org/node/69

Sustainable Apparel Coalition. (2012). Retrieved July 26, 2012 from:

http://www.apparelcoalition.org/index.html

Sutantoputra, A. W. (2009). Social disclosure rating system for assessing firms' CSR reports. Corporate Communication: An International Journal, 14 (1), 34-48.

Svendsen, L. (2006). Fashion: A philosophy. London, UK: Reaktion Books.

Sweeney, E. A., Chipman, J. K., \& Forsythe, S. J. (1994). Evidence for direct-acting oxidative genotoxicity by reduction products of azo dyes. Environmental Health Perspective, 102, 119-122.

Taylor, G. (2003). Spinning wheels. Journal of Fashion Marketing and Management, 7 (4), 339-345.

Thompson, D. (2002). Tools for environmental management: A practical introduction and guide. Gabriola, B.C.: New Society Publishers.

TimberlandPro. (2012). Protective apparel. Retrieved July 10, 2012, from: http://www.timberlandpro.eu/protective-apparel/polar-fleece/timberland-pro-315-recycled-polar-fleeceblack-4263315

Tiplady, R. (2006). Zara: Taking the lead in fast fashion. Business Week: Europe. Retrieved May 5, 2012 from:

http://www.businessweek.com/globalbiz/content/apr2006/gb20060404_167078.htm?chan=\%20innovation _branding+profiles

Tokatli, N. (2007). Global sourcing: Insights from the global clothing industry: The case of Zara, a fast fashion retailer. Journal of Economic Geography, 8(1), 21-38.

Treehugger. (2008, 05 19). Retrieved August 01, 2012, from: http://www.treehugger.com/sustainablefashion/esprit-ecollection-clothing-ahead-of-their-time.html

U.S. Congress, Office of Technology Assessment. $(1987,04)$. The U.S. Textile and Apparel Industry: A Revolution in Progress. Retrieved November 10, 2011, from: http://www.fas.org/ota/reports/8733.pdf

U.S. Environmental Protection Agency. (2002). RCRA in Focus: Textile Manufacturing. USEPA.

U.S. EPA. (2012, June 21). Retrieved July 10, 2012, from:

http://www.epa.gov/waste/conserve/materials/textiles.htm

United Nations Industrial Development Organization. (2010). Making private standards work for you. Vienna: UNIDO.

United Nations. (2003). International Year of Freshwater 2003. Retrieved June 24, 2012, from: http://www.un.org/events/water/factsheet.pdf 
Upton, D. (1998). Just-in-time and performance measurement systems. International Journal of Operations \& Production Management, 18 (11), 1101 - 1110.

Usagain. (2012). Retrieved June 11, 2012, from: www.usagain.com/for-planet

Van Marrewijk, M. (2002). Concepts and definitions of CSR and corporate sustainability: Between agency and communion. Journal of Business Ethics, 45 (2/3), 95-105.

Veblen, T. (1899/2009). The theory of the leisure class. New York, NY: Oxford University Press.

Veerman, K. (2004 ). Revised Stance on Producer Responsibility in Waste Policy in the Netherlands. In Organisation for Economic Co-Operation and Development, Economic Aspects of Extended Producer Responsibility (pp. 135-149). Danvers, MA: OECD.

Victor-Innovatex. (2003). Sustainable textile development at Victor Innovatex. Retrieved June 18, 2012, from: http://www.victor-innovatex.com/doc/sustainability.pdf

Von Drehle, D. (2003). Triangle: The fire that changed America. New York, NY: Atlantic Monthly Press.

Waddock, S., \& Bodwell, C. (2004). Managing Responsibility: What can be learned from the quality movement? California Management Review , 47 (1), 25-37.

Walker, S. (2006). Sustainable by design: Explorations in theory and practice. London, UK: Earthscan.

Walsh, M. (1979). The democratization of fashion: The emergence of the women's dress pattern industry, The Journal of American History, 66 (2), 299-313.

Welters, L. (2008). The fashion of sustainability. In J. Hethorn, \& C. Ulasewicz, Sustainable fashion, Why now? (pp. 3-29). New York, NY: Fairchild Books, Inc.

Wilson, K. (1979). A history of textiles. Boulder, CO.: Westview Press.

Winakor, G. (1969). The process of clothing consumption. Journal of Home Economics, 61 (8), 629-634.

Wittgenstein, L. (2004). Tractatus Logico-Philosophicus. Whitefish, MT: Kessinger Publishing.

Wolfendale, J., \& Kennett, J. (2011). Introduction: Who cares about fashion? In J. Wolfendale, \& J.

Kennett, Fashion: Philosophy for everyone (pp. 1-13). Chichester, UK: Wiley-Blackwell.

Wong, E., \& Taylor, G. (2000). An investigation of ethical sourcing practices: Levi Strauss \& Co., Journal of Fashion Marketing \& Management, 40 (1), 71-79.

Wood, C. (2009, December 14). Can china turn cotton green? Miller-McCune, 30-34.

World Commission on Environment and Development (Brundtland, G.H.), (1987). Our common future. Retrieved October 14, 2011, from:

http://www.regjeringen.no/upload/SMK/Vedlegg/Taler\%20og\%20artikler\%20av\%20tidligere\%20statsminis tre/Gro\%20Harlem\%20Brundtland/1987/Address_at_Eighth_WCED_Meeting.pdf

World Trade Organization. (2011). International trade statistics 2011 - Merchandise trade. Retrieved June 19, 2012, from: http://www.wto.org/english/res_e/statis_e/its2011_e/its11_merch_trade_product_e.pdf

World Wildlife Foundation. (2009, 08). Commodity fact sheet: Cotton. Retrieved June 19, 2012, from: http://assets.wwf.ch/downloads/factsheet_cotton.pdf

World Wildlife Foundation. (2012). Cotton farming. Retrieved June 17, 2012, from:

http://wwf.panda.org/about_our_earth/about_freshwater/freshwater_problems/thirsty_crops/cotton/ 
Wyman, D. (2005). Stretching or shrinking? The textile and clothing industries in Canada. Retrieved October 17, 2011, from: http://publications.gc.ca/collections/Collection/Statcan/11-621-M/11-621MIE2005022.pdf

Yin, R. K. (2009). Case study research: Design and methods. Thousand Oaks, CA: Sage Publications.

YouGov. (2012). Bored with your clothes? Retrieved July 17, 2012, from:

http://iis.yougov.co.uk/extranets/ygarchives/content/pdf/EcoFriendlylnsurance.pdf 